\title{
THE EFFECT OF HIPPOTHERAPY \\ ON TEN CHILDREN WITH CEREBRAL PALSY
}

\author{
A Thesis \\ Presented in Partial Fulfillment of the Requirements for \\ the Degree Master of Science in the \\ Graduate School of The Ohio State University
}

By

Renee Lynn Casady, B.S., P.T., HPCS

The Ohio State University

2002

Master's Examination Committee:

Deborah S. Nichols, Ph.D., P.T., advisor

Jane D. Case-Smith, Ed.D., OTR/L

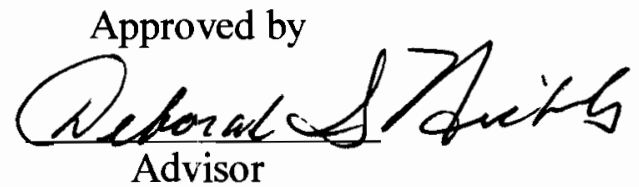

School of Allied Medical

Linda Pax-Lowes, Ph.D., P.T. PCS

Professions 


\begin{abstract}
This 30-week research study was designed to determine if change occurs in subjects before, during and after ten weeks of hippotherapy. Hippo is "horse" in greek. Hippotherapy is treatment using the movement of the horse to improve neuromusculoskeletal dysfunction. A convenience sample of ten subjects with cerebral palsy participated in this study. The subjects were between the ages of 2.5 and 7 years old and had not received hippotherapy prior to this study. The PEDI ( Pediatric Evaluation of Disability Inventory ) and GMFM (Gross Motor Function Measure ) were the outcome measures. An equal time period of ten weeks elapsed between four test dates. Following the baseline of ten weeks without treatment, each subject received hippotherapy once a week for ten weeks. Participation was excellent. One way analysis of variance with repeated measures was done with a priori $\mathrm{p}<.05$. The null was rejected for all of the PEDI subscales, four out of five GMFM subscales, the total PEDI score and the total GMFM score. Tukey's procedure for post hoc multiple comparisons determined the significant effect of hippotherapy.
\end{abstract}




\section{DEDICATION}

I dedicate this work to my husband and children, who supported me throughout this project with loving patience and sacrifice. The scope of this project was far bigger than any of us imagined.

Foremost, I dedicate this research study to the Creator of children and

horses. May the work of this project add to our knowledge about the value of the horse for children like those in the study. 


\section{ACKNOWLEDGMENTS}

I would like to thank my advisor, Dr. Deborah S. Nichols, PT for her guidance during this research study. I would also like to thank Dr. Jane Case-Smith, OTR/L and Dr. Linda Pax-Lowes, PT, for their comments throughout this project. I am very grateful for the assistance of Jill Clutter and Dr. Larry Sachs in the analysis of the data.

To all of the children and families who dedicated thirty weeks for this project, I sincerely hope that this study will shine some light on the benefit of the horse.

I would like to thank my colleagues in hippotherapy such as Barbara Heine, PT and Penny Clark, PT for lending their expertise and leading the way in making hippotherapy a viable therapy tool.

I am extremely grateful to the horses and volunteers of Discovery Riders, Inc. which played a vital part in the treatment phase of this study.

I wish to thank three sources of granted funds that assisted with the expense of this study: North American Riding for the Handicapped Association Region IV, American Hippotherapy Association, and the Rositta Schiller award from OSU.

I feel rather indebted to my friends and colleagues, Nancy Beck, OTR/L and Victoria Macklin, MS, PT who watched and scored forty GMFM videotapes. 


\section{VITA}

November 14, 1961

Born - East Stroudsburg, PA

1983

B.S. in Physical Therapy

Ithaca College, Ithaca, NY

1984

Physical Therapist,

Good Shepherd Rehab Hospital, Allentown, PA

1985

Physical Therapist,

Visiting Nurses' Association, Easton, PA

1986

Physical Therapist,

City of Faith Medical Center, Tulsa, OK

1986

Director of Physical Therapy

Three Rivers Area Hospital, Three Rivers, MI

1987 Physical Therapist

Mary Rutan Hospital, Bellefontaine, $\mathrm{OH}$

1988 Physical Therapist

Bellefontaine P.T., Bellefontaine, $\mathrm{OH}$

1993 to present Physical Therapist

Logan County Board of MR/DD, Bellefontaine, $\mathrm{OH}$

\section{FIELDS OF STUDY}

Major Field: Allied Medical Professions

Tract: Advanced Professional Tract

Focus: Pediatrics 
TABLE OF CONTENTS

\section{$\underline{\text { Page }}$}

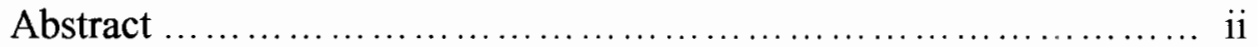

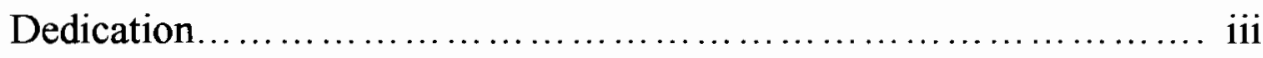

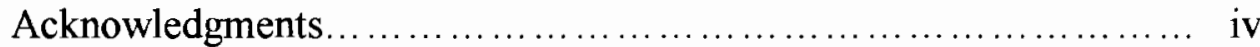

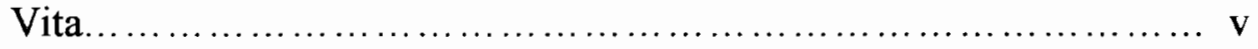

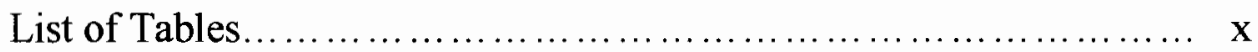

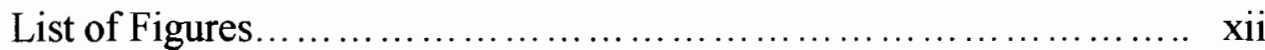

Chapters:

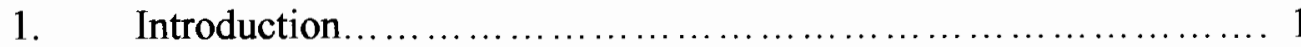

1.1 Background of the Problem........................... 1

1.2 Significance of the Problem............................. 4

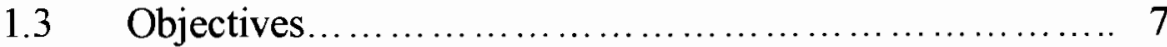

$1.4 \quad$ Research Hypothesis ..................................... 7

$1.5 \quad$ Research Approach.................................... 7

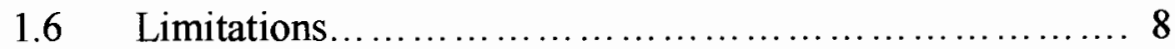

$1.7 \quad$ Definition of Terms.................................. 10

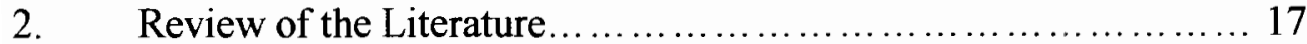

2.1 History of Horseback Riding for Special Populations........ .17 


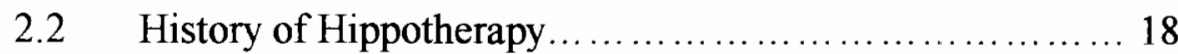

$2.3 \quad$ Hippotherapy Today ................................... 19

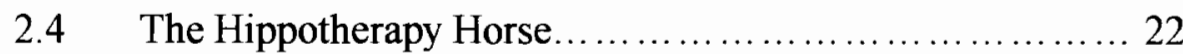

2.5 The Horse-Rider Biomechanical Relationship...............23

2.6 Therapeutic Uses of Hippotherapy ....................... 25

$2.7 \quad$ Efficacy of Hippotherapy ............................. 27

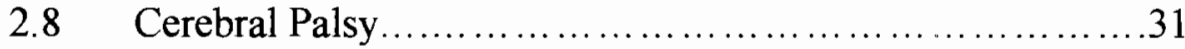

$2.9 \quad$ Instrument Reliability ................................... 34

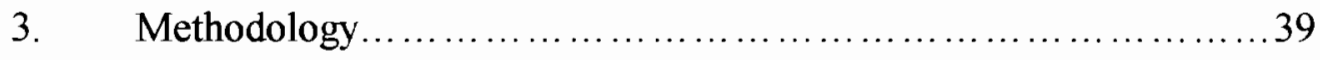

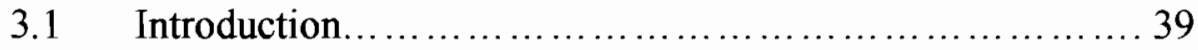

3.2 Research Design.......................................... 39

3.3 Hypothesis ............................................... 44

$3.4 \quad$ Subject Selection..................................... 44

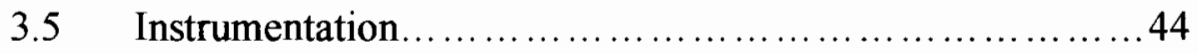

3.6 Data Collection......................................... 45

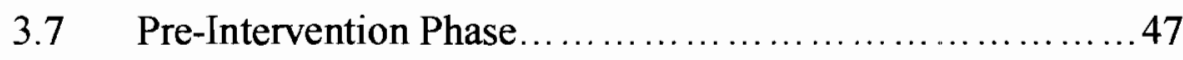

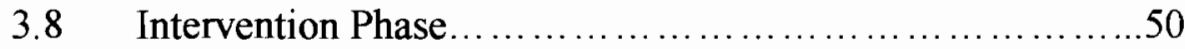

3.9 Post Intervention Phase ................................. 53

3.10 Statistical Procedures.....................................54 


\section{Page}

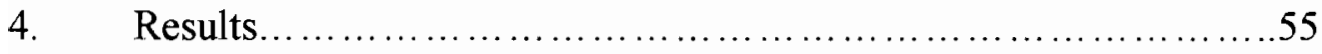

$4.1 \quad$ Introduction .............................................. 55

$4.2 \quad$ Subject Population........................................ 55

$4.3 \quad$ Statistical Analysis.....................................58

$4.4 \quad$ Individual Treatment Effects ............................62

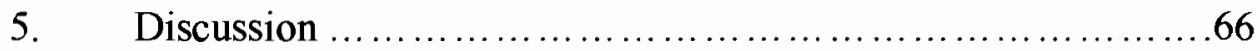

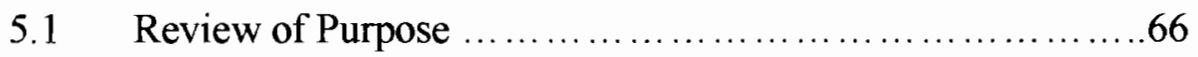

5.2 Discussion of Results .................................... 66

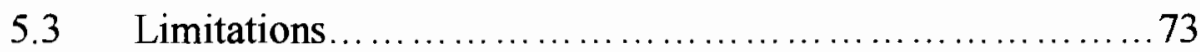

$5.4 \quad$ Implications............................................. 77

$5.5 \quad$ Recommendations for Future Research ...................81

\section{APPENDICES}

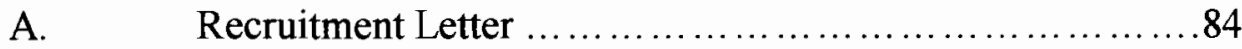
B. Letter to Participants .................................. 86
C. Informed Consent Form $\ldots \ldots \ldots \ldots \ldots \ldots \ldots \ldots \ldots \ldots \ldots \ldots$
D. Physician Prescription Form …......................92

E. Hippotherapy Participant Application / Health History .......95

F. Authorization for Emergency Medical Treatment ...........98

G. Hippotherapy Participant Release / Waiver of Liability ...... 100

H. Hippotherapy Attendance Chart ..................... 103 
$\underline{\text { Page }}$

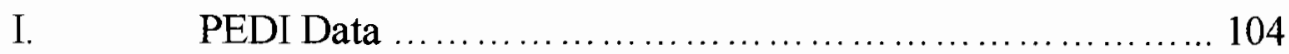

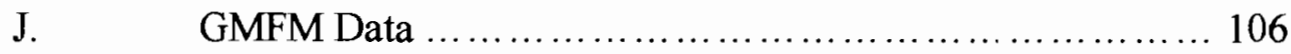

K. Change in GMFM percent score per subject ................ 109

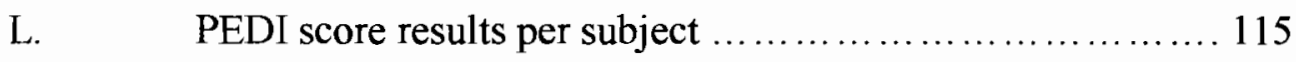

M. Post Hoc Interrater Reliability Result .................... 122

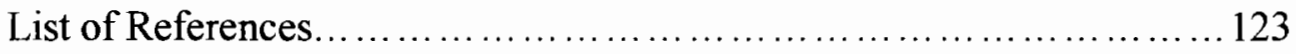




\section{LIST OF TABLES}

Table $\quad \underline{\text { Page }}$

1. Pilot Test of Interrater Reliability ...................... 43

2. Average Absolute Rater Agreement ...................... 43

3. Subject demographics ............................. 56

4. Frequency of OT/PT/SLP during treatment phase $\ldots \ldots \ldots . \ldots 57$

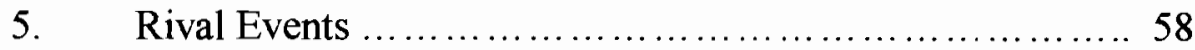

6. PEDI and GMFM correlation $\ldots \ldots \ldots \ldots \ldots \ldots \ldots \ldots \ldots \ldots \ldots$

7. ANOVA Test on PEDI ................................ 59

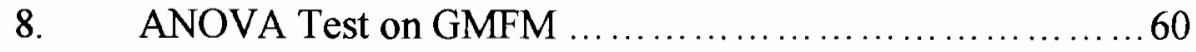

9. GMFM mean score and standard error ...................63 63

10. PEDI mean scores and standard error .....................6 64

11. Tukey's post hoc analysis ............................... 65

12. Total GMFM score change in other research studies .........68 68

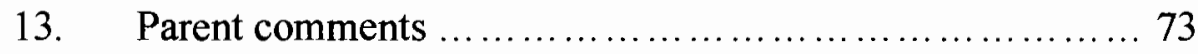

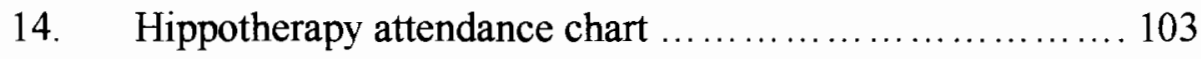

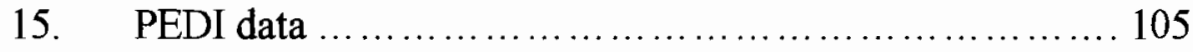


16. GMFM data for subject $\# 1, \# 2, \# 3, \# 5, \# 6 \ldots \ldots \ldots \ldots \ldots \ldots . . \ldots 107$

17. GMFM data for subject $\# 7, \# 8, \# 9, \# 10, \# 11 \ldots \ldots \ldots \ldots \ldots . . \ldots 8$

18. Post Hoc Interrater Reliability ......................... 122 


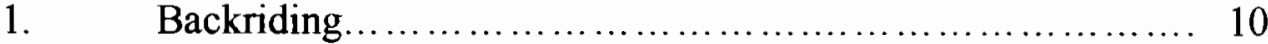

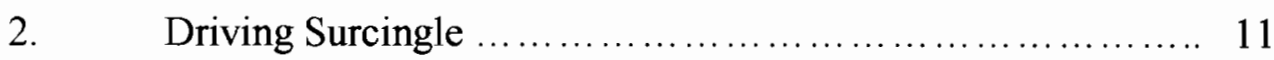

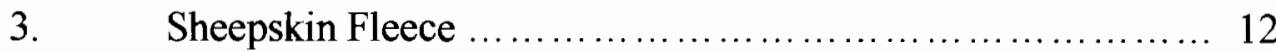

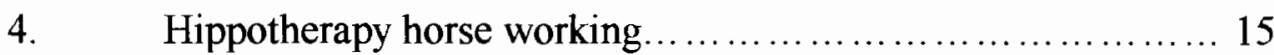

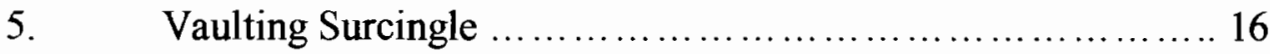

6. Pretest-Pretest-Posttest-Posttest Design ..................... 40

7. Change in GMFM percent score - Subject \#1 ............... 110

8. Change in GMFM percent score - Subject \#2 ............... 110

9. Change in GMFM percent score - Subject \#3 ................ 111

10. Change in GMFM percent score - Subject \#5 ............... 111

11. Change in GMFM percent score - Subject \#6 .............. 112

12. Change in GMFM percent score - Subject \#7 ............... 112

13. Change in GMFM percent score - Subject $\# 8 \ldots \ldots \ldots \ldots \ldots \ldots \ldots$

14. Change in GMFM percent score - Subject \#9 ............... 113

15. Change in GMFM percent score - Subject $\# 10 \ldots \ldots \ldots \ldots \ldots 114$

16. Change in GMFM percent score - Subject $\# 11 \ldots \ldots \ldots \ldots \ldots 114$ 


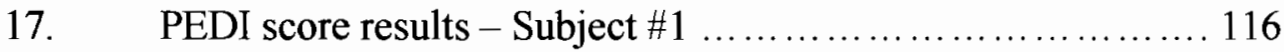

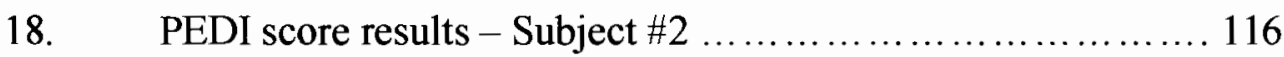

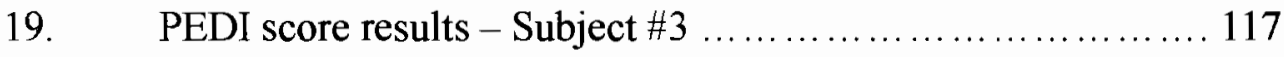

20. PEDI score results - Subject $\# 5$........................ 117

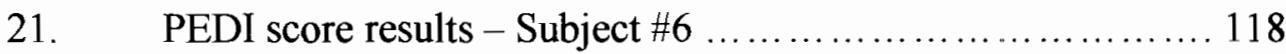

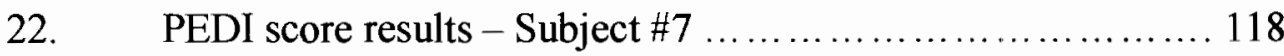

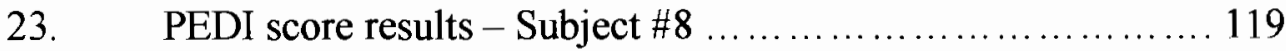

24. PEDI score results - Subject $\# 9$.......................... 119

25. PEDI score results - Subject \#10 ....................... 120

26. PEDI score results - Subject \#11 ....................... 120 


\section{CHAPTER 1}

\section{INTRODUCTION}

\subsection{Background of the Problem}

Hippotherapy has been used for increasing strength, balance, posture, and function since the 1960's in Europe. However in the United States, physical, occupational and speech therapists have only been using hippotherapy, integrated with their typical treatment programs, since the 1980's. Today, therapists who use hippotherapy are experiencing an increased demand for their services. ${ }^{1}$ The reason for this surging interest must be more than just a fascination with using a living creature instead of balls and swings. For hippotherapy to be recognized as a viable treatment option in these days of evidence-based practice, empirical research must support the value of hippotherapy.

People commonly confuse hippotherapy with therapeutic riding lessons. Therapeutic horseback riding lessons teach equestrian skills to people with physical or cognitive dysfunction, or in other words, therapeutic riding lessons teach horsemanship and riding skills to children or adults with special needs. ${ }^{2}$ Hippotherapy does not teach riding skills and is not recreational. In therapeutic riding, the rider influences or controls the horse. In hippotherapy, the horse influences the rider. ${ }^{1}$ Hippotherapy is 
used by therapists to reach traditional goals for clients with neuromotor dysfunction. Therapists use the movement of the horse to achieve short and long term goals that are determined by a patient evaluation and subsequent treatment plan.

The effects of therapeutic riding have been examined and documented more than hippotherapy. The physical and psychological value of therapeutic riding has been cited in health related and horseback riding publications. The use of the horse as a leisurely activity for people with disabilities or special needs is valid. Physical benefits of riding a horse have also been noted. Horseback riding has been effective in improving the balance of riders with vestibular problems. ${ }^{2}$ Upper and lower extremity coordination was improved in physically disabled adult riders after riding in a therapeutic riding program. ${ }^{3}$ Riding a horse has a sensory and emotional component that is difficult to measure, but gives great hope and joy to riders for whom movement is difficult or impossible. ${ }^{4}$ In one study, four children with cerebral palsy experienced improved posture, decreased incidence of falling, better head control and increased freedom of movement after five weeks of riding lessons. ${ }^{5}$ In another study, nineteen children with cerebral palsy between the ages of 4 and 12 achieved greater skill and confidence riding a horse after six months of horseback riding, but insignificant quantitative change in the outcome measures. ${ }^{6}$ All of the aforementioned reports are from therapeutic riding situations, not from hippotherapy.

Horses are a live treatment tool and require special training for therapists who want to use them. Therapists who use equine movement as a treatment tool should attend the three-day workshops developed and taught by instructors from the American 
Hippotherapy Association (AHA). The material covered in these workshops is an overview of the characteristics of the horse and applies the science of a moving horse to human neuromotor recovery. ${ }^{7}$

Horses are selected for hippotherapy based on the quality of their movement, temperament and training. The movement of the horse is the key to effective hippotherapy. Mounting a patient on just any horse and walking that horse randomly around an arena is not hippotherapy. Even when an ideal horse is found, the outcomes rely on the clinical expertise of the therapist. The movement variations of the horse should be used in a comprehensive treatment plan that is suitable for each individual client. $^{8}$

Hippotherapy is recognized by the American Physical Therapy Association, the American Occupational Therapy Association and the American Speech and Hearing Association. Using the movement of a horse is comparable to other therapy tools such as balls, equilibrium boards or swings. However the multi-dimensional variability of the horse's movement and the ability of the therapist to modify the movement make the horse a very special treatment tool. ${ }^{9}$

The American Hippotherapy Association supports and encourages therapists to use hippotherapy in patient treatment plans and to refer to the use of the horse in medically relevant treatment terms in all documents. Treatment goals should reflect gains to be obtained off of the horse. The AHA also recommends that when therapists bill for therapy services, CPT (Current Procedural Terminology) codes should be used 
that reflect the purpose for which the horse is used, e.g. therapeutic procedure/exercise, neuromuscular re-education, therapeutic activities, or cognitive habilitation or rehabilitation. ${ }^{9}$

There is a great deal of enthusiasm among proponents of hippotherapy, however hippotherapy should be critically examined just like other treatment tools on the basis of its effect on functional outcomes. Clinical research provides evidence for physical therapy treatment tools and modalities. Evidence of the benefits of hippotherapy is

limited. Medical insurance companies are questioning the effectiveness of hippotherapy. In 1999, there was an inquiry made by Blue Cross/Blue Shield to determine if hippotherapy was recognized as standard care or remained in the investigational phase. ${ }^{10}$ Aetna, Inc. does not cover the use of hippotherapy for the treatment of cerebral palsy because of insufficient scientific data in peer reviewed medical literature. ${ }^{11}$ Empirical research that measures functional outcomes from hippotherapy is pertinent and needed.

\subsection{Significance of the Problem}

The most recent definition of hippotherapy from the American Hippotherapy Association calls hippotherapy:

"a term that refers to the use of the movement of the horse as a tool by physical therapists, occupational therapists and speech-language pathologists to address impairments, functional limitations and disabilities in patients with neuromusculoskeletal dysfunction. This tool is used as part of an integrated treatment program to achieve functional outcomes." 7 
Cerebral palsy is a condition that causes neuromusculoskeletal dysfunction that can be addressed by physical therapists using hippotherapy as a treatment tool. Cerebral palsy does not refer to a single disease but rather to a group of conditions or disorders that occur due to an insult to the immature brain. ${ }^{12}$ Damage to the immature brain causes sensory and neuromotor deficits in a developing child. This damage typically occurs before the brain reaches full maturity in utero, during the birthing process or shortly after the birth of a child. ${ }^{13}$

Children with cerebral palsy have been selected as the subjects for this study because they typically have impaired movement of the trunk and extremities due to postural control problems. They demonstrate inefficient or delayed muscle recruitment when making postural adjustments while seated on a moving platform. ${ }^{14}$ The back of the hippotherapy horse can be considered a moving platform, and thus, the horse is an appropriate treatment tool for postural control problems in cerebral palsy.

An improvement in the quality of ambulation has been noted when children with cerebral palsy gain dynamic balance along with the ability to laterally shift their body weight. ${ }^{15}$ Repetitive lateral weight shifts are induced by the hippotherapy horse which would suggest that the horse can be used to improve dynamic balance.

Delayed or abnormal development of postural control has been reported to have a negative impact on the development of movement. ${ }^{16}$ An improvement in postural control should contribute to better active movement and gross motor abilities. ${ }^{17}$ Since hippotherapy may influence postural control, then hippotherapy may also contribute to 
improved movement and gross motor abilities. This research study is designed to measure the change in functional abilities before, during and after ten weeks of hippotherapy.

Two research studies have measured changes in children with $\mathrm{CP}$ after hippotherapy. McGibbon, et.al. found that eight weeks of hippotherapy decreased energy expenditure and increased scores on the running, walking and jumping dimensions of the Gross Motor Function Measure (GMFM) in five children with CP. ${ }^{18}$ Haehl, et.al. used the Pediatric Evaluation of Disability Inventory (PEDI) to measure the changes in functional performance of two subjects with CP after 12 weeks of hippotherapy. Functional improvements were noted in one of the subjects. ${ }^{19}$

As mentioned previously, hippotherapy is different from therapeutic horseback riding. There are numerous studies and reports regarding the effectiveness of therapeutic riding. However there are very few research studies in peer-reviewed literature that report the benefit of hippotherapy. Several studies show that therapeutic horseback riding produces improved balance, more precise coordination, new motor skills, decreased spasticity, and better posture. ${ }^{4,19,20,21}$ However, many of these studies are done without controls and the authors admit to internal and external threats to validity.

The neuromotor problems associated with cerebral palsy make it appropriate for this study on the efficacy of hippotherapy. Currently, there is insufficient empirical research and data that support the use of hippotherapy for clients with cerebral palsy. This particular study was designed to investigate the value of hippotherapy as a treatment tool for children with cerebral palsy. 


\subsection{Objectives}

The objectives of this research project were to: 1) measure the change in subjects with cerebral palsy for a baseline of 10 weeks before hippotherapy, then for 10 weeks during hippotherapy, and again for 10 weeks after hippotherapy, 2) determine if hippotherapy influenced the development of children with cerebral palsy.

\section{$1.4 \quad$ Research Hypotheses}

1) Hippotherapy will produce a change in functional skills as measured by the Pediatric Evaluation of Disability Inventory and the Gross Motor Function Measure.

2) There will be more functional skills gained during 10 weeks of hippotherapy as compared to the two non-treatment time periods.

\subsection{Research Approach}

All subjects received 10 weeks of hippotherapy. The frequency of hippotherapy treatment was one per week. Hippotherapy was in addition to other therapies or interventions. The Gross Motor Function Measure (GMFM) and the Pediatric Evaluation of Disability Inventory ( PEDI ) were the measurement tools used to observe the change in subjects' gross motor, social, mobility and self-help skills. Subjects were between the ages of 2.5 and 7 years old. All subjects had a medical diagnosis of cerebral palsy. A quasi-experimental time series design was used. Repeated measures taken before, during and after treatment established a trend line for development. Equal 
time intervals of ten weeks were maintained between measurements. Data analysis compared the test scores on the GMFM and PEDI before, during and after hippotherapy.

\subsection{Limitations}

The outcomes are externally valid for a limited age range of children with cerebral palsy. The researcher selected a relatively young age group because the GMFM is a measure that is known to be sensitive to changes in gross motor development in children with cerebral palsy between 12 and 79 months old. ${ }^{22}$

Children with cerebral palsy who participated in hippotherapy prior to this study were ineligible to participate. This limitation required the researcher to recruit subjects outside of Logan County, Ohio because the researcher used hippotherapy for several years in Logan County. Nearly all of the children who met the diagnostic and age requirements for this study and who resided in Logan County had already received hippotherapy in addition to their other therapies. Therefore, the researcher recruited subjects from neighboring counties, which added variability between subjects because they were from different school districts and were treated by different teams of therapists at their respective schools.

The ten-week treatment phase of this research study had to occur between the months of April and October. Treatment was rendered in an unheated, 60' $\times 120^{\prime}$ indoor riding arena with metal siding. Seasonable weather conditions and temperatures above 50 degrees Fahrenheit were necessary to conduct hippotherapy at the designated location. 
It is a distinct possibility that other therapeutic intervention may cause a change in gross motor and functional skill development. The extraneous variable of other therapies or interventions were built into the design of this research project. It was not feasible to ask subjects to refrain from other scheduled interventions done by physicians or therapists. Therefore, the researcher instructed the parents to take their children to all therapies throughout the thirty-week study. Hippotherapy has been described as an integrated treatment tool for therapists because treatment at the riding area should be complementary to treatment rendered by therapists at schools or clinics. ${ }^{1}$ The outcome of this study was externally valid for children who receive hippotherapy in addition to conventional therapy in a clinic setting.

The horse is similar to other therapy treatment tools that can be used in a variety of creative ways depending on the expertise and individuality of the therapist. Hippotherapy can appear different from one therapist to another. However the investigator will describe how the horse is used as a treatment tool so that this study has external validity and so that the treatment can be replicated by other investigators in the future. The horse is a dynamic treatment surface that can be adapted to meet the needs of the rider. Therefore, the researcher used a variety of tack and movements of the horse during each treatment session to achieve the greatest possible outcome. It is not the intent of the researcher to demonstrate that a rigid pattern of routine circumstances such as tack, horse or riding position elicits the change.

The horses used in this research project worked in hippotherapy for two years prior to this study. These horses were either led from the front by a person holding a lead rope attached to the halter ring under the horse's chin, or they were long-lined. 
Long-lining is a preferred method of directing the movement of a hippotherapy horse. ${ }^{23}$ A horse will maintain a more even tempo, keeping its' head down and back up when guided from behind through the long-lines. In the long-lining method of directing a horse, the horse wears a halter-bridle with a bit. Two, 25 foot, leather lines are clipped to each side of the bit in the horse's mouth. The lines run backwards along the sides of the horse and are held by a person walking behind the horse. This person is called a long-liner. The three horses used for hippotherapy in this study learned to work on long-lines just three months prior to the initiation of this study. The leading technique which made the horse work most effectively was used in hippotherapy. The leading techniquen was selected by the therapist in charge of the session.

\section{$1.7 \quad$ Definition Of Terms}

BACK RIDING - the therapist rides behind the patient to provide postural support and tactile cueing.

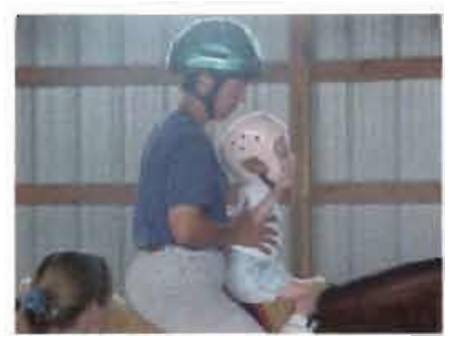

Figure 1. Picture of physical therapist backriding with a client. The client is seated in front of the therapist and posterior to the horse's withers. 
BARREL - term for the rounded, ribcage, or middle region of the horse; halfway between the nose and the tail.

BRIDLE - a leather headpiece; english or western style; used with a metal bit in the horse's mouth to give direction to the horse.

CROUP - the highest point of a horse's hindquarters.

DRIVING SURCINGLE - a handleless surcingle that has D-shaped rings typically used for directing the movement of horses from behind. The D-shaped rings are covered with fleece during hippotherapy to prevent children from putting their fingers in the rings. ( See Figure 2 )

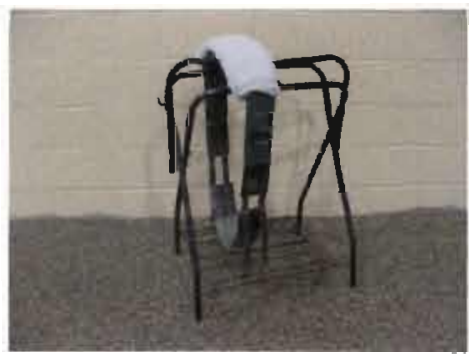

Figure 2. Driving style surcingle with white fleece over the withers region.

EQUESTRIAN - term used to refer to someone who rides a horse.

EQUINE - another word for horse. 
FLEECE - a sheepskin hide approximately 4' x 3' placed on top of the saddle pad as a soft interface between the rider and horse.

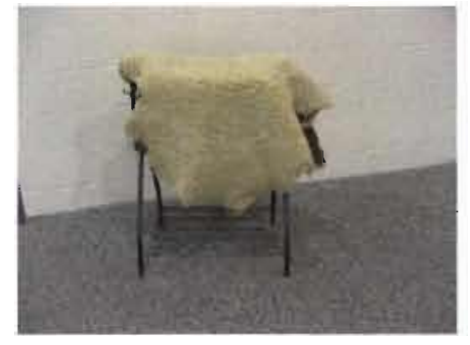

Figure 3. Authentic sheepskin fleece resting on a saddle rack.

HALTER - a nylon or leather headpiece that fits on a horse's head. Used to restrain/control the horse when it is being led, handled from the ground or tied.

HIPPOTHERAPY - a term that refers to the use of the movement of the horse as a tool by physical therapists, occupational therapists and speech-language pathologists to address impairments, functional limitations and disabilities in patients with neuromusculoskeletal dysfunction. Hippotherapy is not a modality. This treatment tool is used as part of an integrated treatment program to achieve functional outcomes for clients.

HORSE HANDLER - experienced horse person who is able to recognize signs of a horse's basic moods and behavior, and respond appropriately. Must be attentive to the 
instructions and needs of the therapist and rider during hippotherapy. Moves the horse during hippotherapy in the pace, tempo and direction that the therapist designates.

HORSE HEIGHT IN HANDS - The height of a horse is measured from the ground to the withers. Once hand is equal to four inches. Therefore a horse that is 14 hands tall is actually 56 inches tall from the ground to the top of the withers.

IMPULSION - the combination of will and energy that creates the forward movement of the horse.

LEAD ROPE - six foot length of cotton rope with a snap hook at the end which attaches to an O-shaped ring on the chin strap of the halter.

LONG LINES - two 15-20' cotton or leather lines that run along the left and right sides of a horse, attaching to each side of the bit in the horse's mouth to be used by a person walking behind the horse during hippotherapy to control the horse.

MOUNTING RAMP - a 12' wooden structure ramped at an inclination of 25 degrees ending at a 5' $\times 5^{\prime}$ level platform. Riders mount the horse from the platform as the horse stands next to the ramp. 
NARHA - the North American Riding for the Handicapped Association. A non-profit organization whose mission is to foster safe, professional, ethical and therapeutic equine activities through education, communication, standards and research for people with and without disabilities.

PADDOCK- enclosed area surrounded by fencing. Used for exercising horses or giving them freedom to walk around.

PASTERN - the shortest part of the horse's leg above the hoof and below the ankle.

REGULARITY - refers to equal step lengths of a horse.

RHYTHM - the regularity of foot fall during a horse's natural pace.

SADDLE PAD - a 2-3" thick pad approximately 36 " long. Placed directly on the horse's back to protect the horse's spine and back from any undue pressure.

SELF-CARRIAGE - the horse moves forward freely with energy-efficient movement.

SERPENTINE - moving the horse in an S-shaped pattern at a walk. The S-shapes can be juxtaposed to increase the number of left and right hand turns. 
SIDEWALKER - term for the person who walks alongside of the horse on the opposite side of the therapist. Assists the therapist with the rider's needs.

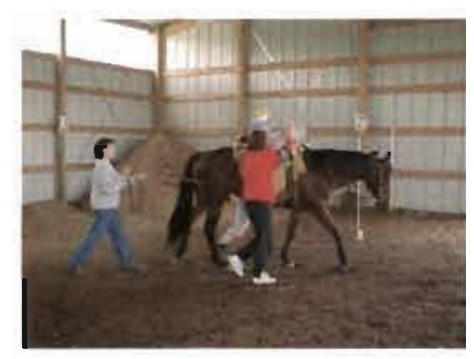

Figure 4. Horse working during hippotherapy with a therapist, sidewalker and person directing the movement of the horse through long-lines.

STRIDE LENGTH - the distance measured on the ground after a horse completely steps with all four legs.

SUPPLENESS - ability of the horse to shift their weight smoothly from one leg to another while walking.

TACK - term used for any equipment placed on the horse such as bridle, pad, or surcingle or used for the horse such as long-lines. 
VAULTING SURCINGLE - a leather strap with two handles that fits circumferentially around the girth of a horse and holds the pad in place on the horse's back. The rider puts one hand on each handle when they are seated facing the head of the horse.

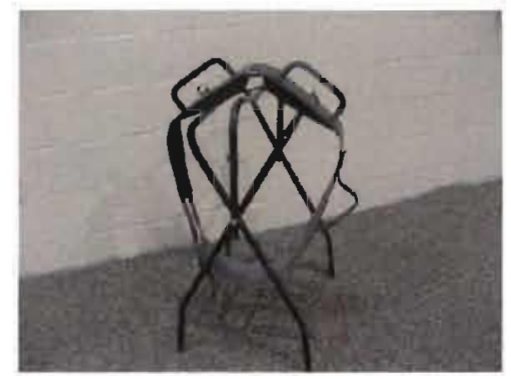

Figure 5. Brown leather vaulting surcingle with squared-off handles.

WITHERS - Prominent boney protrusion of the second to the sixth thoracic vertebrae where the neck and back join on the spine of the horse. 


\section{CHAPTER 2}

\section{REVIEW OF LITERATURE}

\subsection{History of Horseback Riding for Special Populations}

The horse has been used as a therapeutic tool for a long time. Hippocrates wrote about riding horses as exercise in 377 B.C. Huronymus Merkurialis from Italy included horseback riding in his writings, 1569 A.D. and believed that riding a horse could restore health. An English physician named Lord Thomas Sydenham supported the use of the horse for body and soul in 1670 . Clemens Joseph Tissot is recognized as the first person to suggest that there may actually be contraindications to horseback riding in his book dated $1780 .^{24}$

The development of modern day horseback riding for persons with disabilities was sparked by the Olympic victory of Liz Hartel who won the silver medal for Grand Priz Dressage at the Helsinki Olympics in 1952. Liz Hartel who walked with crutches due to polio won the event competing against able-bodied competitors. After this newsworthy event, the horse became a partner in treatment and rehabilitation of persons with disabilities. ${ }^{25}$ Great Britain led the way by establishing several therapeutic riding centers in the 1950's and 1960's. The first two therapeutic horseback riding organizations to be established in the United States of America were the National 
Foundation for Happy Horsemanship for the Handicapped, Inc. in 1967 and the North American Riding for the Handicapped Association, Inc. in 1969. Both organizations had the same goal of using horseback riding as therapy for the disabled population. ${ }^{26}$ Today, the North American Riding for the Handicapped Association (NARHA) claims over 550 riding centers as members and is responsible for setting the industry standards for education, safety and research in the United States of America. ${ }^{27}$

\section{$2.2 \quad$ History of Hippotherapy}

Equine activities are used by certified riding instructors as well as therapists to contribute to the cognitive, physical, emotional and social well being of people with disabilities. NARHA categorizes the use of the horse in four ways: therapy, education, sport and recreation/leisure. Hippotherapy, as we know it today, fits under the therapy classification by NARHA. ${ }^{27}$

Europe led the way in developing treatment uses for the horse before any other countries in the world. In the 1960's the horse was officially used and medically recognized as a component of physical therapy in Germany, Switzerland and Austria. The first riding center in the United States to use hippotherapy was Winslow Therapeutic Riding Unlimited, Inc. of Warwick, NY in 1974 under the direction of Barbara Glasow, PT. Hippotherapy made great strides in the 1980's with international contacts between therapists. In 1982 at the Fourth International Therapeutic Riding Congress, an American physical therapist named Beth Stanford presented the first medical uses of hippotherapy. In 1984, Dr. Ingrid Strauss from West Germany gave an overview of hippotherapy to NARHA members. Also in 1984, the first 3-day workshop 
covering the topic of hippotherapy was conducted by Barbara Glasow, PT. From 1988 to 1992 , hippotherapy standards, curricula and certification requirements were developed. In 1992 the American Hippotherapy Association (AHA) was formed and became the first section of NARHA in $1993 .{ }^{24}$ Today, the AHA is listed as one of three special interest sections of NARHA along with the Competition Association and the Equine Facilitated Mental Health Association. The AHA has its own board of directors and exists to promote research, education and communication among professionals utilizing the horse based on the principles of hippotherapy. ${ }^{27}$

\subsection{Hippotherapy Today}

The AHA is responsible for the current definition of hippotherapy. Hippos means horse in Greek. Hippotherapy literally means treatment with the help of a horse. By definition, hippotherapy is:

" a term that refers to the use of the movement of the horse as a tool by physical therapists, occupational therapists and speech-language pathologists to address impairments, functional limitations and disabilities in patients with neuromusculoskeletal dysfunction. This tool is used as part of an integrated treatment program to achieve functional outcomes."

Hippotherapy is treatment using the movement of the horse to elicit responses from the client or patient. The theoretical background rests on the foundation of neuromotor function and sensory processing. Medical professionals that use hippotherapy have a solid understanding of posture, movement, neuromotor function and sensory processing. This is the reason that physical therapists, occupational therapists and speech/language pathologists are the only professionals who can use hippotherapy. Hippotherapy effects can be physical, psychological, cognitive, 
behavioral, and communicative. ${ }^{24}$ However, therapists do not learn to use hippotherapy in undergraduate curriculum. Therapists attend continuing education seminars to add hippotherapy to their repertoire.

The American Hippotherapy Association offers two different three-day workshops for therapists who want to use hippotherapy. The first workshop is designed to give therapists a basic understanding of the horse. Therapists also learn how to incorporate hippotherapy into their treatment plans. For therapists who complete the first workshop, the AHA offers registration that is not a statement of proficiency but indicates only that the therapist has attended the initial level of training in hippotherapy. ${ }^{1}$ The second workshop focuses on refining a therapist's clinical judgement of selecting the right horse and treatment strategies for patients based on the therapist's' evaluation and goals. Physical and occupational therapists who practice hippotherapy for at least 3 years are eligible to take a clinical specialty exam which is offered twice a year in the United States. If therapists pass this exam, they earn the title, Hippotherapy Clinical Specialist (HPCS) ${ }^{7}$

Hippotherapy is actually an intense treatment technique because it requires more than just a therapist to perform. Hippotherapy requires a horse which has been selected for its movement quality. Not all horses have a balanced, rhythmical three-dimensional gait which is highly desired in therapy horses. Besides the horse, additional personnel required to complete a hippotherapy team include a skilled horse handler and a sidewalker. The horse handler uses either a lead rope attached to the horse's halter or long lines to move the horse along as the therapist directs. The sidewalker walks next to the rider on the opposite side from the therapist to provide stability and insure safety. 
Any activities that involve horses are generally considered high risk activities because horses can be unpredictable at times. Hippotherapy should be conducted in a safe environment with good footing and the area must be free of distractions. ${ }^{28}$ Therapists practice hippotherapy in outdoor paddocks, in indoor arenas, or at established riding centers.

Equipment on the hippotherapy horse can vary. Particular combinations of equipment are selected based on the needs of the patient and are chosen by the therapist. Occasionally, a saddle is used to seat a patient on a horse during hippotherapy. Typically, patients will sit on a combination of pads that protect the horse's back yet allow the rider to feel and respond to the motions of the horse. Pads are secured to the horse with surcingles. Surcingles can have handles such as anti-cast and vaulting surcingles. When handholds interfere with treatment goals, strap surcingles or driving surcingles are useful. ${ }^{24}$

During hippotherapy, therapists may place their patients in a variety of positions on the horse. Some of these positions are: seated facing forward, seated facing to the side, seated facing backward, prone across the barrel, prone on rump, or supine on rump. Each position facilitates a different combination of muscles. Changing a rider's visual or physical orientation influences the sensory and vestibular systems in different ways. The weight bearing surface between the horse and rider is altered to affect a rider's response to the motion. ${ }^{24}$

The horse's movement can be progressed from walking in straight lines to walking in large circles, smaller circles, serpentines, and figure of eights. Directional changes in the horse's movement elicit weight shifts or a sustained postural position in 
the hippotherapy patient. The size of the figure is graded according to the response of the rider. A horse's stride length, impulsion and speed can be varied within all of the figures. The therapist gives verbal directions to the horse handler to lead the horse according to the patient's need during each treatment session. ${ }^{24}$ For example, if a client has a problem with right lateral trunk flexion the therapist may ask the horse handler to move the horse on a sustained circle to the right. The barrel of the horse swings to the outside of the circle pattern. The typical response elicited in the rider is right lateral trunk flexion with increased weight bearing on the right hip.

\subsection{The Hippotherapy Horse}

A horse is selected for hippotherapy based on his suppleness, straightness, rhythm, symmetry, regularity and self-carriage. ${ }^{24}$ The horse must have a gentle, tolerant temperament and be in good health. The typical size of a hippotherapy horse varies from 14.2 to 15.2 hands. Many different breeds of horses can be used. The essential characteristics of a hippotherapy horse is that it be symmetrical and well-balanced when moving at a walk, move with even strides, be supple and well-muscled, and be capable of working with good impulsion and smooth movement transitions. ${ }^{28} \mathrm{~A}$ calm, relaxed attitude and the ability to grade a walking tempo and stride length are also desirable traits of a therapy horse. ${ }^{29}$ Therapists must have a working knowledge of the anatomy and gait of the horse to be able to use the horse as a modality in rehabilitation. ${ }^{24}$

The movement of the horse can be described as three-dimensional because the horse's pelvis moves in the three cardinal planes: sagittal, frontal and transverse. Anterior-posterior movement of the pelvis occurs in the sagittal plane. Lateral tilting of 
the pelvis to the left and right occurs in the frontal plane. Rotation of the pelvis occurs on the transverse plane. ${ }^{24}$ The three-dimensional movements of the horse's pelvis are lateral tilt, rotation and anterior-posterior.

\subsection{The Horse-Rider Biomechanical Relationship}

The horse and rider sit with their pelvises oriented at 90 degrees in relation to one another. A horse's movement at a walking pace is described as a four beat gait with two feet in contact with the ground at all times. The horse pushes off of the ground with a hind leg first. When this hind leg swings forward, the horse's pelvis drops down towards the ground on this swing-through side. This drop of the pelvis on the swingthrough side is rotation of the horse's pelvis. Rotation of the horse's pelvis creates lateral tilting of the rider's pelvis. The rider's trunk lengthens on the side where the horse's pelvis drops down. In addition, the forward swing of a hind leg is accompanied by lateral flexion of the horse's spine because the barrel of the horse swings to the opposite side. This lateral flexion of the horse's spine causes the rider's pelvis to rotate in the rider's transverse plane. The push off of the hind leg from the ground produces a moment of acceleration through the swing phase and produces posterior pelvic tilt in the rider on the same side as the swing phase. When the horse's hind foot strikes the ground at the end of swing phase, a deceleration moment occurs causing anterior pelvic tilt in the rider. As the horse alternately steps with each hind leg and shifts his center of gravity back and forth, lateral pelvic displacement occurs in the rider. ${ }^{24}$ 
In addition to the repetitive three-dimensional pelvic motion, there are other characteristics of a horse's movement such as cadence, velocity, stride length, and step length which are similar to human motion. ${ }^{29}$ It is precisely these attributes of a horse that are used in hippotherapy. Not all horses move the same way and therapists should assess the impact of a particular horse on the treatment goals of each individual patient. ${ }^{30}$ Hippotherapy clients may be affected differently by riding horses that have contrasting patterns of movement. A horse with a long stride and step length produced a longer stride and step length in a three out of six disabled riders as compared to when these same riders were on a horse with a shorter stride and step length. ${ }^{29}$

Riders use equilibrium reactions as they respond to the movement of the horse beneath them. ${ }^{31}$ A rider experiences up to 100 rhythmic impulses per minute on a walking horse. These impulses evoke balance and righting reactions. Therapists should position the rider with their midline oriented directly over the horse's midline. Riding astride a horse gives patients the chance to use and practice balance and equilibrium reactions that in turn may lead to improved postural alignment, body control and coordination. ${ }^{29}$ The sensations of normal movement may elicit co-contraction around joints, more stability around joints, and an ability to weight shift in children with cerebral palsy. The therapist is constantly watching the reaction of the rider during the movement of the horse and making a decision to maintain or change the rider's position. Changing a rider's position on the horse will elicit different postural responses. $^{24}$ 


\subsection{Therapeutic Uses of Hippotherapy}

Therapeutic riding instructors and therapists have used the horse to stretch muscles, strengthen muscles, reduce muscle spasms, reinforce good posture, improve gross motor control, improve fine motor control, mobilize joints, provide tactile or proprioceptive input, develop equilibrium reactions, as well as to improve head and trunk postural control. ${ }^{24}$ Therapeutic riding instructors lack the rehabilitation background of therapists so they concentrate on the recreational aspect of riding horses. When individuals participate in a therapeutic horseback riding lesson, they enjoy the freedom and fluidity of movement in an experience that is otherwise unattainable. ${ }^{32}$ Riding on a horse has been reported to have positive effects on respiratory function, circulation, neurogenic bladder and intestinal function as well as communication and behavioral skills. In addition to these physical benefits, there is an undeniable psychological effect due to the emotions that are evoked through the human-animal bond and excitement stimulated by the activity on horseback. ${ }^{33}$

Hippotherapy is used by therapists in a treatment plan designed to address impairments, functional limitations and disabilities. The primary reason for putting riders on the horse in hippotherapy is to achieve a functional outcome through the physical contact and influence of the horse. Hippotherapy uses the movement of the horse to influence movement dysfunction of clients. For example, a physical therapist can work on trunk control and isolate a weak pattern of muscle recruitment by having the horse remain on a steady walk in a circle to the right to exercise the rider's ability to sustain weight on the right hip and laterally bend to the right. By changing the direction 
of the horse as in serpentines, a therapist is actively inducing weight shifts over each side of the rider's pelvis. Riders with asymmetries will have a difficult time remaining centered while the horse maintains a steady walk on a straight line. These riders' postural control is challenged and exercised. Improvement is evidenced when the rider can maintain postural control in spite of induced weight shifts and remain centered on the walking horse. ${ }^{34}$

Approximately 100 impulses per minute are felt by a rider when they sit on a walking horse. These impulses are rhythmic and correspond to the three-dimensional movements of the horse. The rider is required to respond, adapt and balance repetitively. ${ }^{34}$ Postural reactions are challenged. Riders are actively learning to balance and stabilize against thousands of perturbations of their sitting position in one hippotherapy session. Riders must control and coordinate their posture to remain on the horse. $^{19}$

Therapists can use the movement of the horse to physically challenge their patients in a way that is similar, yet different, to other tools in a clinic. The surface of the horse underneath the rider is actually moving repetitively into and away from the rider in three planes of movement. Therapists can take advantage of this threedimensional movement and work on a patient's need for a stable base of support through feedforward postural adjustments and anticipatory muscle activation. ${ }^{12}$ Riders learn compensatory movement strategies that reduce the degree of sway created by the moving horse. They learn to make postural adjustments necessary to maintain their position on the moving horse. ${ }^{19}$ 
Hippotherapy treatment sessions vary in length from 15 to 60 minutes. The typical length of treatment is 30 minutes and depends on the tolerance and endurance of the rider. Riding a horse on a bareback pad can be more fatiguing than sitting on a saddle. Contrary to therapeutic riding lessons where 3-5 riders are on horses in the riding arena with one instructor, therapists treat one rider at a time in hippotherapy. ${ }^{21,28}$ After receiving a prescription for physical or occupational therapy, therapists conduct a thorough patient evaluation to determine if hippotherapy is indicated. Precautions and contraindications are listed in the AHA's 'Introduction to Hippotherapy: Classic Principles" manual. ${ }^{24}$ Sound clinical judgement is necessary to decide if hippotherapy is indicated on a case by case basis.

\subsection{Efficacy of Hippotherapy}

This research project was designed to quantitatively determine if gross motor and functional skills change in children with cerebral palsy before, during and after hippotherapy. Little published evidence exists to evaluate this.

V. Haehl, et.al., measured the postural sway of two subjects with cerebral palsy when they rode on a horse to determine if hippotherapy would improve postural stability and subsequently improve motor skills. The subjects received weekly hippotherapy for twelve weeks. The PEDI was the outcome measure in a pre-test, posttest design. One subject made significant progress on the mobility domain of the PEDI. 
However, the investigators could not conclude that hippotherapy caused the functional gain. The subject was receiving physical therapy in a clinic at the same time of hippotherapy. ${ }^{19}$

D. Bertoti, et.al. purposed to analyze the effect of horseback riding on posture. They used a pretest-pretest-posttest design with equal time intervals between measures and treatment after the second pretest. The eleven subjects had cerebral palsy and served as their own controls. The subjects had spastic diplegia or quadriplegia. After the second pretest, each subject received ten weeks of horseback riding. The children rode in groups of three, twice a week. The outcome measure was a postural assessment scale developed by the researcher. Data analysis was done with a Friedman test for the small sample and repeated measures. There was a significant improvement in posture $(\mathrm{df}=2, \mathrm{p}<.05)$ during the period of riding. Midline postural control with decreased anterior pelvic tilt was observed. ${ }^{35}$

J. MacKinnon, et.al. separated nineteen subjects with CP, ages 4-11, into a control group $(n=9)$ and experimental group $(n=10)$. They used three domains of the GMFM to measure sitting, standing and walking skills in a pretest-posttest design. The experimental group participated in six months of therapeutic riding lessons with a riding instructor who consulted with a physical therapist. Despite the fact that the total GMFM scores improved in most of the subjects, the researchers could not conclude that that the changes in the motor skills were from the horseback riding program since there was no attempt to stop routine therapies or activities. ${ }^{6}$ 
In a pretest-pretest-posttest design, N. McGibbon, et. al. tested gross motor function, energy expenditure and stride dimensions in five ambulatory subjects with cerebral palsy after eight weeks of bi-weekly hippotherapy. The subjects, ages 9-11, had spastic diplegia or hemiplegia. The researcher used the walking, running and jumping dimension of the GMFM in repeated measures. All five subjects had statistically significant increases $(\mathrm{p}<.05)$ in their GMFM dimension E scores during the treatment phase. The researcher was the tester and scorer of the GMFM which weakened the study's internal validity due to potential bias. ${ }^{18}$

As measured by the aforementioned studies, the goals of hippotherapy are not that a patient be able to do something better while they are on the horse. Any motor skill or active postural control achieved on the horse should influence a functional task or goal off of the horse. The stretching, facilitation, mobilization, spatial orientation, and tactile reactions that are accomplished through the movement of the horse should improve posture, balance, mobility or function after the patient gets off of the horse. ${ }^{24}$

Hippotherapy is a dynamic movement experience. The effects of hippotherapy can be explained in neural plasticity and motor learning. Neural plasticity refers to the capacity of the central nervous system to modify and reorganize as a result of practice and experience. ${ }^{36}$ Through the repetitive, rhythmical movement of the horse in hippotherapy, a child will experience and learn to anticipate movement with each step of the walking horse. They learn to produce compensatory movements that reduce the displacement of their center of gravity and keep themselves on the moving horse. 
Hippotherapy provides variability in practice conditions and encourages patients to problem solve and discover new postural strategies. ${ }^{19}$ The therapist can vary the speed and direction of the horse which will introduce variability to the task and challenge the rider to actively explore new patterns of control. Hippotherapy affects multiple systems simultaneously such as the sensory, muscular, skeletal, limbic, vestibular and ocular systems. By affecting multiple systems, hippotherapy should encourage and promote modification and reorganization of the central nervous system. ${ }^{37}$

Hippotherapy is also consistent with sensory integration theory of information processing. The central nervous system organizes information from the somatosensory, visual and vestibular systems to plan and execute movement or behavior. Sensory integration focuses on the sensory processing aspect of a motor activity. The horse is a sensory integration tool that provides a graded sensory input in the context of meaningful activity. Riders are active participants in hippotherapy. The patient is continually responding to a changing environment that encourages adaptive behaviors or movement strategies. Successful movement strategies are ones that maintain postural control on the dynamic surface. ${ }^{37,38}$

One significance of hippotherapy is the influence on postural control. Postural control is learned by active experience. The experience can be in prone, supine, sitting or standing. The development of postural control is the background of normal gross motor activities. ${ }^{36}$ The acquisition of motor skills is dependent on the development of postural control to release the arms and hands from playing a role in maintaining one's 
balance except in an emergency situation. ${ }^{39}$ Children who are unable to maintain a symmetrical posture, while reaching for a toy, will lose their balance because they shift the focus of their attention on maintaining an upright position. ${ }^{40}$

\subsection{Cerebral Palsy}

The consequences of cerebral palsy ( CP ) include motor, sensory, cognitive, intrapersonal, interpersonal, productivity, leisure and self-care problems in the individual as they grow and develop. ${ }^{41}$ The motor and sensory consequences of CP are pertinent to this study. Children with $\mathrm{CP}$ display an inability to maintain postural control of their head and trunk due to abnormal muscle co-activation and compensatory movement patterns. The damage in the central nervous system also causes the persistence of primitive reflexes. With abnormal reflex patterns and either hypotonia or hypertonia, the child with $\mathrm{CP}$ will have difficulty with automatic, voluntary movement. Abnormal voluntary movement is evidenced by the difficulties in motor planning and excess or insufficient force production. Skilled and coordinated movements are absent or impaired due to the missing foundation of righting, equilibrium, and protective reactions. ${ }^{13}$ Righting, equilibrium and protective reactions are important because they enable complex voluntary movement and postural control. These reactions contribute to the ability to balance in a sitting position and simultaneously reach, perform activities with the extremities, or shift weight without using arms for support. In children with $\mathrm{CP}$ the development of these automatic postural reactions may be delayed or absent. ${ }^{12}$ 
The diagnosis of CP is made by a physician after significant delays in motor, cognitive, or language development are observed by the parents or in clinical examinations. ${ }^{13}$ Signs of delayed, incomplete and abnormal motor development are accompanied by poor or insufficient motor control. These signs create a lack of stability on a base of support and abnormal postural adjustment when reacting to a weight shift. ${ }^{41}$

Common sensory and perceptual problems in children with $\mathrm{CP}$ include eye motility impairments, gravitational insecurity, diminished awareness of pain, hearing loss, hyper-responsiveness or hypo-responsiveness to vestibular stimulation, and tactile defensiveness. ${ }^{41}$ The sensory feedback from abnormal weight bearing and weight shifting experiences contributes adversely to the performance of tasks while maintaining functional positions. ${ }^{13}$ In the case of hemiplegic $\mathrm{CP}$, unilateral neglect may be present. There may be impaired space and form perception. Learning disabilities may be present and are usually related to perceptual problems. Dysarthric speech and delayed language development may also be present. ${ }^{41}$

The goals of treatment and therapy for children with cerebral palsy are typically to teach a variety of movement patterns and improve gross motor skills through improved postural control and balance. Other goals include improved sensory processing skills, improved perceptual skills, increased attention span and concentration, and improved hand-skill development with fine motor coordination. The long-term goal of therapy is to improve functional skills. ${ }^{41}$ 
Treatment for $\mathrm{CP}$ is most effective with an interdisciplinary approach.

Contemporary treatment strategies for $\mathrm{CP}$ emphasize the importance of early, intensive, task-specific and motivational training of movement. The motor impairments of $\mathrm{CP}$ are compounded by a lack of active movement experience and successful task-specific practice situations. Motor learning requires the use of functional activities and active participation. Treatment should be active and task-specific to carry over into daily function. ${ }^{42}$ Hippotherapy as a therapeutic treatment tool is consistent with this model of motor learning. It is active, intense, task-specific and highly motivating for the individuals in each treatment session.

Treatment for children with $\mathrm{CP}$ is also directed at increasing postural stability because postural stability is necessary for active and functional movement of the extremities. As trunk stability increases, there will be a decreased reliance on the upper extremities for postural control and stability. Postural reflex development in the form of equilibrium and righting reactions is important for balance, stability and voluntary movement. ${ }^{41}$

Vestibular, proprioceptive and kinesthetic input relays the sensations of movement to the brain. Vestibular stimulation promotes the development of equilibrium reactions. Movement against gravity is useful to facilitate active control.

Treatment should be conducted in a safe environment because persons with $\mathrm{CP}$ need to experience movement without fear. One particular treatment precaution that is pertinent to this research study is to watch for signs of sensory overload when using sensory stimulation, especially vestibular. ${ }^{41}$ Other CP treatment interventions include anti-spasticity drugs, joint splinting, corrective lenses and hearing aids. ${ }^{13}$ 
The primary pathophysiological factors in children with $\mathrm{CP}$ create impairments that may be remediated by hippotherapy. Children with $\mathrm{CP}$ are an appropriate subject population for this research study. Two quantitative outcome measures that have been used in past hippotherapy research studies to measure change in children with $\mathrm{CP}$ are the GMFM and PEDI.

\subsection{Instrument Reliability}

This study used two instruments to measure change, i.e. the Gross Motor Function Measure (GMFM) and the Pediatric Evaluation of Disability Inventory (PEDI). The GMFM was constructed to be used by therapists to determine if treatment approaches are effective as therapeutic interventions for children with cerebral palsy. The original GMFM consists of 88 test items that can be successfully completed by a five-year old child with normal gross motor abilities. The GMFM-66 with 66 test items is the most recent version of the original GMFM that has $\mathbf{8 8}$ test items. Russell, et.al. say that the GMFM-66 can provide a clearer understanding of gross motor changes for children with cerebral palsy and improves the scoring and interpretation of the data obtained with the GMFM. ${ }^{43}$ However at the time of this research proposal, validity and reliability reports for the GMFM-66 had not yet been published. Therefore, the original GMFM with 88 test items was used in this study.

The GMFM is capable of detecting changes in gross motor function including a decline or deterioration in function. One GMFM validity study used 111 children with CP who were assessed with a pretest and a posttest six months apart. Total GMFM scores were correlated with videotaped assessments $(r=.82)$, the subjective judgement 
of therapists $(r=.65)$ and parental judgement $(r=.54)$. The youngest age groups (under five years old) were more likely to show a change in gross motor function $(\mathrm{p}<.0001)$. These researchers conclude that the GMFM is a suitable outcome measure in determining the value of a therapeutic intervention for children with $\mathrm{CP} .{ }^{44}$

Bjornson, et.al. described the test-retest reliability of the GMFM to be within acceptable limits. The GMFM was given twice with one week between test dates. Two therapists participated and maintained a $>90 \%$ absolute agreement on the items. ICC for the $n=21$ sample population ( mean age $=8.2$ years $)$ ranged from .80 to 1.00 $(\mathrm{p}<.001)^{45}$

The GMFM is sensitive to changes in gross motor performance irrespective of the type of cerebral palsy. Trahan and Malouin used the GMFM with fifty children between the ages of 12 and 79 months old. A baseline measurement was followed by two posttests at four month intervals. Physical therapy, two times a week, was the active independent variable. The investigators found a significant improvement in the subjects' gross motor function $(\mathrm{p}<.05$ ) across three $\mathrm{CP}$ diagnostic categories, i.e. quadriplegia, hemiplegia, diplegia. ${ }^{22}$

Kolobe, Palisano and Stratford used videotaped sessions instead of direct observations to score their 42 subjects on the GMFM with a pretest and two posttests at three month intervals. The correlation between the GMFM change scores and the videotaped ratings was very good $(\mathrm{r}=.82)$. They advise keeping the time and location identical for subjects at each testing session as well as having at least three months between tests. If a homogenous sample of severity levels cannot be attained, then the researcher should classify each subject's level of gross motor function and control for 
the effects of severity when analyzing the data. ${ }^{46}$ McLaughlin, et.al. also found variability in functional changes measured by the GMFM depending on the type of cerebral palsy. ${ }^{47}$

The GMFM has been used as an outcome measure for different treatment interventions for subjects with CP: hyperbaric oxygen ${ }^{48}$, selective dorsal rhizotomy ${ }^{47,49}$, treadmill training ${ }^{50}$, botox injections ${ }^{51}$, conventional vs. intensive physical therapy ${ }^{44}$ and hippotherapy ${ }^{13}$. Dimension E, walking/running/jumping, of the GMFM were used by McGibbon, et.al. in their study of hippotherapy. They found a mean increase in the GMFM dimension E score after eight weeks of hippotherapy. ${ }^{18}$

In 1998, M. Ketelaar, et.al. reviewed 17 functional assessment measures commonly used in pediatric rehabilitation including the GMFM and the PEDI (the Pediatric Evaluation of Disability Inventory). Only the GMFM and the PEDI fulfilled the criteria of reliability and validity with respect to responsiveness to change. Both the PEDI and the GMFM are sensitive to changes in function over time, but the PEDI is able to detect significant changes earlier than the GMFM. For example, in a group of children with severe impairments from cerebral palsy, the PEDI detected changes in functions which the GMFM could not detect. The PEDI and GMFM are complementary because they measure different aspects of function. ${ }^{52}$ The GMFM measures gross motor ability in a standardized testing environment. Whereas the PEDI measures both gross and fine motor ability in typical daily environments. 
The PEDI was developed to assess the functional capabilities of children with disabilities aged 6 months to 7 years old. It can be used for the evaluation of older children if their functional abilities fall below that which is expected of a seven-year old child who does not have a disability. The PEDI identifies current functional performance and tracks change across time in three content domains: 1) functional skills, 2) mobility, and 3) social function. The PEDI is typically administered as a parental report/questionnaire that can be accomplished through a structured interview of the parent. ${ }^{53} \mathrm{~S}$. Harris found that a parent's perception of their child's development is reliable and that professionals can trust parental judgement. ${ }^{54}$ On the PEDI, functional performance is measured by the level of caregiver assistance needed to accomplish major functional activities such as eating or walking. ${ }^{53}$

D. Reid, et.al. critiqued the PEDI and concluded that it evaluates a limited motor reportoire by omitting higher level gross motor skills such as running or climbing. They say that the PEDI items can be mastered by a 4.5 -year old child. ${ }^{55}$ The authors of the PEDI respond to the critique by admitting that the PEDI measures function and not form. This is clinically important because the test may not be sensitive to improvements in form and may show no increases in score when, in fact, improvements in the child's abilities have taken place. They advise that clinicians should not use the PEDI as an assessment tool when the goals of treatment are improvements in the form of movement. ${ }^{56,57}$

The GMFM and PEDI are appropriate measurement tools for this research study which sets out to measure changes in function over time. Both tests are quantitative instead of qualitative in nature. The GMFM includes gross motor skills such as running 
and jumping which the PEDI does not consider. Both tests are appropriate for the diagnostic and age group requirements of the subjects in this study.

In the review of available literature, the efficacy of hippotherapy was not completely supported by studies with concrete validity or reliability. A study of the effect of hippotherapy on children with cerebral palsy is indicated. The GMFM and PEDI are reliable outcome measures to determine the efficacy of treatment interventions for children with cerebral palsy. They are appropriate measures to study the effect of hippotherapy which is rising in popularity as a treatment intervention for children with cerebral palsy. 


\section{CHAPTER 3}

\section{METHODOLOGY}

\subsection{Introduction}

This research project was designed to measure the effect of hippotherapy on the functional development of children with cerebral palsy. The researcher was also the implementer of treatment. Treatment was hippotherapy. Having used hippotherapy for over four years, the implementer is a physical therapist and board certified in the clinical specialty area of hippotherapy.

\subsection{Research Design}

A pre-test, pre-test, post-test, post-test, design was selected. Another way to describe the study design is time-series, quasi-experimental research. The experimenter was in control of X ( treatment ), but did not randomly select subjects or randomly assign $\mathrm{X}$ to subjects. The subjects acted as their own controls. See Figure 8 . There were 4 measurements of function at $\mathrm{O} 1, \mathrm{O} 2, \mathrm{O} 3$, and $\mathrm{O} 4$. The time interval between the four test dates was held constant. There were 10 weeks between each test date. 
$\mathrm{X}$ is hippotherapy treatment. Hippotherapy treatment was once a week for 30 minutes each. $\mathrm{O} 1$ to $\mathrm{O} 2$ was 10 weeks without hippotherapy. $\mathrm{O} 2$ to $\mathrm{O} 3$ was 10 weeks with hippotherapy. O3 to O4 was 10 weeks without hippotherapy.
$\mathrm{Ol}$
$\mathrm{O} 2$
$\mathrm{X}$
$\mathrm{O} 3$
O4

FIGURE 6. Pretest - Pretest - Posttest - Posttest quasi-experimental time series design used in the study.

This 30-week, time-series research design was selected to show pre-treatment, treatment, and post-treatment trends in development. With the passing of time, subjects may change due to aging and experience. In this design, maturation is not a threat to internal validity. Maturation is ruled out on the grounds that if there is a shift between $\mathrm{O} 2-\mathrm{O} 3$ which did not occur in $\mathrm{O} 1-\mathrm{O} 2$, then the shift in $\mathrm{O} 2-\mathrm{O} 3$ is due to treatment and not due to maturation.

History, however, is a weakness of the time-series design. ${ }^{58}$ Rival events occurring simultaneously with the treatment might also affect the dependent variable. The implementer recorded the rival events such as medical procedures, new equipment, or therapy that may also have caused a change in the dependent variable. Subjects who received therapy at a school or clinic were asked to continue those therapies throughout the project. Hippotherapy was provided in addition to those other therapies. 
Instrumentation could be a threat to internal validity if a change in the measurement tool causes the appearance of a change in the dependent variable. On each of the four measurement dates, the implementer administered the GMFM consistently. As stated previously, the investigator was the implementer of treatment but was not the scorer of the subjects' performance on the GMFM. The subjects were videotaped performing the items on the GMFM during each test session. The videotapes were viewed and scored by an occupational therapist and physical therapist who volunteered to help with the scoring of the subjects.

A physical therapist with 26 years of pediatric experience and an occupational therapist with 20 years of pediatric experience volunteered to be scorers for the GMFM tests. This pair of therapists were colleagues who worked together for 19 years in one school district's early intervention system. The physical therapist had formal training in the use of the GMFM in 1996 and used the GMFM in pediatric practice over the last 6 years. The occupational therapist was familiar with the GMFM but had no formal training. The researcher used the GMFM manual published by the GMFM developers to train this second scorer. The GMFM has been found to be reliable with video-recorded assessments watched by therapists with no previous experience using the instrument. Reported inter-rater reliability was .77 and $.88 .{ }^{59}$ Interrater reliability was estimated on scores obtained by the two scorers simultaneously assessing same subjects performance. As a pilot test of reliability between scorers, three children who were not participating in this study were tested with the GMFM. The researcher videotaped the testing session. The scorers viewed the tapes and scored the children. The results are recorded in Tables 1 and 2. These 
interrater reliability results are expressed as average absolute rater agreement. An ICC was not calculated because the results would not have been valid with only three subjects. Scorer A was consistently scoring children lower than scorer B ( see Table 1 ). The difference between the two scorers in this measure of interrater reliability became a point of concern ( see Table 2 ). Therefore, the researcher discussed the results with the two scorers in separate conversations. There was a discrepancy between the scorers' understanding when to rate the child a 1 or a 2 on the GMFM four-point Likert scale. Consulting the GMFM manual, the researcher explained the difference between the two scores. By clearing this misunderstanding, the actual research study could be approached confidently. To reassess the reliability between scorers, a post hoc ICC interrater reliability was done on the actual GMFM measures from the research study participants. 


\begin{tabular}{|l|c|c|}
\hline \multicolumn{1}{|c|}{ CHILD \#1 } & SCORER A & SCORER B \\
\hline Dimension A- Lying/Rolling & $20 / 51=39 \%$ & $22 / 51=43 \%$ \\
\hline Dimension B- Sitting & $30 / 60=50 \%$ & $31 / 60=52 \%$ \\
\hline Dimension C- Crawling/Kneeling & $16 / 42=38 \%$ & $20 / 42=48 \%$ \\
\hline Dimension D- Standing & $4 / 39=10 \%$ & $6 / 39=15 \%$ \\
\hline Dimension E- Walk/Run/Jump & $3 / 72=4 \%$ & $2 / 72=3 \%$ \\
\hline Total Score & $63 / 264=28 \%$ & $81 / 264=32 \%$ \\
\hline \multicolumn{1}{|c|}{ CHILD \#2 } & & \\
\hline Dimension A- Lying/Rolling & $13 / 51=25 \%$ & $11 / 51=22 \%$ \\
\hline Dimension B- Sitting & $7 / 60=12 \%$ & $8 / 60=13 \%$ \\
\hline Dimension C- Crawling/Kneeling & $0 / 42=0 \%$ & $0 / 42=0 \%$ \\
\hline Dimension D- Standing & $0 / 39=0 \%$ & $0 / 39=0 \%$ \\
\hline Dimension E- Walk/Run/Jump & $0 / 72=0 \%$ & $0 / 72=0 \%$ \\
\hline Total Score & $20 / 264=7 \%$ & $19 / 264=7 \%$ \\
\hline \multicolumn{1}{|c|}{ CHILD\#3 } & & \\
\hline Dimension A- Lying/Rolling & $47 / 51=92 \%$ & $47 / 51=92 \%$ \\
\hline Dimension B- Sitting & $56 / 60=93 \%$ & $56 / 60=93 \%$ \\
\hline Dimension C- Crawling/Kneeling & $36 / 42=86 \%$ & $36 / 42=86 \%$ \\
\hline Dimension D- Standing & $16 / 39=41 \%$ & $20 / 39=51 \%$ \\
\hline Dimension E- Walk/Run/Jump & $20 / 72=28 \%$ & $21 / 72=29 \%$ \\
\hline Total Score & $175 / 264=68 \%$ & $180 / 264=70 \%$ \\
\hline
\end{tabular}

TABLE 1. Pilot test of interrater reliability on the GMFM with three children who had CP but who were not in the study. Raw score and percent score on each dimension and total GMFM by each rater.

\begin{tabular}{|c|c|c|c|c|c|}
\hline $\begin{array}{c}\text { Dimension } \\
\mathrm{A}\end{array}$ & $\begin{array}{c}\text { Dimension } \\
\mathrm{B}\end{array}$ & $\begin{array}{c}\text { Dimension } \\
\mathrm{C}\end{array}$ & $\begin{array}{c}\text { Dimension } \\
\mathrm{D}\end{array}$ & $\begin{array}{c}\text { Dimension } \\
\mathrm{E}\end{array}$ & $\begin{array}{c}\text { Total } \\
\text { GMFM }\end{array}$ \\
\hline $92.5 \%$ & $96.0 \%$ & $92.2 \%$ & $79.4 \%$ & $89.3 \%$ & $94.6 \%$ \\
\hline
\end{tabular}

TABLE 2. The average absolute rater agreement on GMFM dimensions A through $E$ and total GMFM score. 


\subsection{Hypothesis}

Hippotherapy will produce a greater change in functional skills as measured by the Pediatric Evaluation of Disability Inventory and the Gross Motor Function Measure. There will be more functional skills gained during 10 weeks of hippotherapy as compared to the two non-treatment time periods.

The null hypothesis is that there will be no difference in functional skill acquisition during hippotherapy as compared to before and after hippotherapy.

\subsection{Subject Selection}

Subjects were required to have cerebral palsy and be between the ages of 2.5 and 7 years old between $\mathrm{O} 1$ and $\mathrm{O} 4$. A convenience sample of subjects that fit the admission criteria was used. Subjects did not have hippotherapy prior to this study. Medical clearance to participate was required. The parents were responsible for transportation to hippotherapy.

\subsection{Instrumentation}

Two instruments were used to measure change, i.e. the Gross Motor Function Measure (GMFM) and the Pediatric Evaluation of Disability Inventory (PEDI). The GMFM was designed to be used by therapists to determine if treatment approaches are effective therapeutic interventions for children with cerebral palsy. The PEDI is a norm referenced, evaluative measure of functional ability for children ages six months to 7 years old. 


\subsection{Data Collection}

The GMFM is a criterion-based observational measure. The GMFM is designed to measure performance or the best a child can or will achieve in a test situation. The GMFM consists of 88 items grouped into five dimensions: $\mathrm{A}$, lying and rolling: $\mathrm{B}$, sitting: $\mathrm{C}$, crawling and kneeling: $\mathrm{D}$, standing: $\mathrm{E}$, walking, running and jumping. Each of the 88 items is scored on a four-point Likert scale of zero to three: $0=$ does not initiate activity; $1=$ initiates activity and accomplishes $<10 \%$ of the task; $2=$ partially completes activity doing 10 to $<100 \%$ of the task; $3=$ completes activity or task independently. A zero score is given if a child is unable or unwilling to attempt the given task. ${ }^{52}$ Each dimension has an equal weight of $20 \%$. Scores for each dimension are expressed as a percentage of the max score for that dimension. A total GMFM score is obtained by adding the scores for all dimensions and then dividing by five.

Each subject was assessed a total of four times. The assessments were recorded on videotape. Aids and orthoses were permitted during assessments. The guidelines for administering the test items were followed as described in the GMFM manual. The videotaped assessments were scored by therapists familiar with the GMFM. The scorers followed the recommended guidelines for scoring the items. The mean score of the two individual scorers was used in the statistical analysis. ${ }^{60}$

There were dynamic items on the test that required movement and static items that did not require movement. Active, independent movement had to be observed in the intended direction for a subject to achieve a score higher than 0 on the dynamic items. The GMFM manual specifies the length of time that a static position must be maintained to achieve the score of 1,2 , or 3 . Subjects were encouraged to attempt as 
many items as possible to obtain the best possible total score for each dimension. If a subject was unable or unwilling to attempt a test item, a 0 was assigned for that item.

To record the GMFM, a camcorder was set up on a tripod in the room on each test date. Separate tapes were used for individual subjects on each of the four test dates. There were ten tapes from each test date and a total of forty GMFM videotapes at the end of the study. Each scorer watched and scored a box of ten tapes from one test date at a time. The scorers were given as much time as necessary to watch and score a batch of ten tapes. When one scorer finished scoring a box of tapes, the scorer gave the box of tapes back to the researcher who then passed the box on to the other scorer. Therefore, the scorers were not blind to the order of tapes due to the impracticality of waiting until the study was over to begin the process of having the scorers watch the tapes. The tapes were coded with letters and numbers to conceal the names of the subjects from the scorers. The GMFM score sheets remained in the possession of the scorers until they had watched all forty tapes. The researcher collected the GMFM score sheets and tallied the dimension scores from each scorer at the end of the study. The GMFM dimension scores from the two scorers were averaged together to become the actual raw score. The actual raw scores were converted to percent scores. The percent scores were used in the data and statistical analysis.

The subjects were also scored four times using the PEDI. The investigator administered the PEDI by interviewing the parent/caregiver on each test date. The investigator followed the administration guidelines and criteria for scoring test items as written in the PEDI Standardization and Administration Manual. ${ }^{57}$ 
The three sections of the PEDI ( functional skills, caregiver assistance and modifications ) were completed on each test date. Part I of the PEDI ( Functional Skills ) was used as a description of the child's mastery of functional skills across time. Part I is a record of the child's capability in three domains, ie. self-care, mobility and social. There are a total of 197 items in Part I: self-care ( 73 items ), mobility ( 59 items ) and social ( 65 items ). All items were checked as either capable $=1$ or unable $=0$. No items were left blank. PEDI domain scores as well as a PEDI total score were recorded for each test date.

\subsection{Pre-Intervention Phase}

The research protocol was approved by The Ohio State University Investigational Review Board. The researcher did not meet with the parents or subjects prior to the first test date. The researcher explained the study to the parents and answered questions over the phone and also at the first pretest. Communication between the researcher and parents was by mail or phone prior to first pretest. Parents signed the consent for treatment prior to the first pretest date and returned it to the researcher through the mail.

When contacted by phone, parents were asked to select a day and time during the testing week that was convenient for the first pretest. Individual, ninety-minute appointments were alloted to each subject. Testing was done at the preschool building of the Logan County Board of MR/DD in Bellefontaine, Ohio. Nine out of the eleven 
families resided outside of Logan County and traveled an average of 40 miles, one-way to the test site and to the riding arena for hippotherapy. Detailed maps with written directions were mailed to the parents before the first pretest.

Ten subjects were tested during week one. Subject number 11 started ( and finished ) the study two weeks after the other ten subjects due to a family trip. Parents were given the opportunity to ask questions about the study or hippotherapy. The researcher used photos and literature to explain treatment with hippotherapy. Maps with directions to the riding arena were provided to parents at the first test date and again at the second test date if needed.

The GMFM was performed with a camcorder set up on a tripod base to videotape the subjects' performance. The tester tried to ensure that she was not between the camcorder and the subject. Occasionally, another person was available to assist the tester by manning the camcorder.

The length of the GMFM portion of the test session varied for each subject depending on how many dimensions of the GMFM were appropriate for the individual's level of function. For example, some subjects were only tested on the lying/rolling and sitting dimensions. Other subjects were tested on all five dimensions. Consistency was maintained throughout the four test dates.

The PEDI was completed through a structured interview between the researcher and the parent/caregiver. The child was scored a 1 or 0 depending on the child's capability to perform each specific skill. The child was scored with a 1 if they had the capability of performing the item. They were given a 0 if they had not yet demonstrated capability on each particular item. No items were left blank. 
At the end of the $\mathrm{O} 1$ pretest, each subject was instructed to continue all therapies and medical interventions throughout the course of the study. In this way, the extraneous variable of other OT/PT/SLP treatment was built into the design of the study and should have remained constant throughout the 30 weeks. Hippotherapy was planned to be an additional therapeutic intervention.

Each parent was given a 2001 calendar with the 30 -weeks of the study highlighted. The parents were apprised of the importance of attending each test session as well as each hippotherapy treatment session. The researcher made many efforts to accommodate individual scheduling conflicts that arose for subjects and their families during the next 29 weeks.

Several weeks prior to the $\mathrm{O} 2$ test date, a letter was mailed to each parent asking them to select a day/time for the second pretest. All eleven parents responded and were scheduled for the second GMFM and PEDI measurement. However, subject number 4 did not show up for their appointment as scheduled. The researcher attempted to reach this parent by phone. After one week had passed, the researcher discovered by phoning a relative that the parent and subject number 4 were out of state on a trip for an undetermined length of time. They had forgotten their commitment to the test date. Through this phone conversation, the researcher determined that subject number 4 would not participate any further in the study. The family was in agreement with this determination. The ten-week baseline of development prior to treatment could not be determined for a subject who missed the second test date. 


\subsection{Intervention Phase}

A prescription for physical therapy, once a week for ten weeks was obtained from the subjects' primary physician. This prescription covered the hippotherapy treatment sessions. The researcher, a physical therapist, was the implementer of treatment. Each subject was scheduled for hippotherapy once a week for ten consecutive weeks. Five subjects were scheduled on Mondays. Five subjects were scheduled on Wednesdays. Individual hippotherapy appointments were scheduled 45 minutes apart. The actual amount of time spent on the horse in treatment was typically between 20-30 minutes. Often, the first 5 minutes of hippotherapy sessions were spent preparing the subject to mount the horse. Additional time was needed after treatment to dismount and enjoy saying goodbye to their horse. Each subject wore a safety helmet and gait belt. The implementer of treatment was a physical therapist. It was the responsibility of the physical therapist to select the appropriate horse and tack to suit the individual need of each subject and to achieve the greatest possible treatment outcome. The therapist selected one of three different horses. The emphasis of this project is that the movement of the horse causes the change in the dependent variable. A subject may have ridden one particular horse during the first treatment and another horse during the subsequent treatment sessions if a change in horse was indicated. The horse and equipment selected for each session were recorded in the treatment note.

The three horses used in this research project are owned by Discovery Riders, Incorporated. They have been used in hippotherapy treatment sessions since June 1999. Peanut is a 14.1 hand appaloosa gelding with a 32 inch back length and 25 degree pastern angle. Peanut is 15 years old and weighs 900 pounds. Beau is a 15.3 hand 
registered quarter horse mare with a 34 inch back length and 20 degree pastern angle. Beau is 18 years old and weighs 1000 pounds. Prince is a 14.1 hand quarter/morgan gelding with a 33 inch back length and 25 degree pastern angle. Prince is 15 years old and weighs 900 pounds.

Volunteers from Discovery Riders, Inc. prepared the horses before each hippotherapy session. The horse and tack were selected by the researcher to achieve the desired movement or stability outcome desired for each individual rider. Horses rarely worked two consecutive sessions. Ideally, a horse worked one hippotherapy session and then rested while another horse worked.

Typically, the horse was tacked with a thick saddle pad and a sheepskin fleece which covered his back from the withers to croup. The pad and fleece were secured to the horse just posterior to the withers by a surcingle with one, two, or no handles. If the horse was led from the front, the horse wore a halter or halter-bridle. If the horse was long-lined from behind, the horse wore a bridle or halter-bridle. The horse was determined to be ready for treatment by a skilled equestrian to ensure safety in regards to secure equipment and soundness of the horse.

Subjects mounted the horse with appropriate assistance at the mounting ramp or mounting block. The subjects were encouraged to verbally say "walk " to their horse or give some form of non-verbal cue to start their horse moving any time he was stopped during treatment. The therapist walked alongside of the horse and a sidewalker walked along on the opposite side while the handler led the horse. The horse-handler listened for the therapist's selection of direction and cadence. 
Hippotherapy treatment consisted of a variety of walking tempos and walking patterns. The therapist selected the tempo and pattern. Circles could be large or small. Serpentines had sharp turns or gentle curves. Typically, the horse maintained a steady walk on the perimeter of the treatment area in the shape of an oval. The treatment area in the riding arena was 60 feet by 80 feet.

The subjects were positioned in a variety of positions including: forward faced, rear faced, side faced, modified side sitting, prone with elbows on the horse's back, supine over the barrel, and quadruped. Periodic halts were standard for repositioning. Subjects were encouraged to achieve optimal postural alignment with symmetry of the head, trunk and lower extremities and to sit independently with no assistance from the sidewalkers. Active trunk and extremity exercises were used for stretching, strengthening, and dynamic weight shifts while maintaining postural alignment. Subjects were encouraged to bear weight through their upper extremities with their hands on the horse in the rear facing or prone positions and with their hands on the surcingle in the forward facing position. Subjects were also encouraged to independently remain in the midline so that sensory input is symmetrical. If the subject was unable to move themselves into midline orientation, the therapist and sidewalker provided physical assistance. Props such as a pillow or a ball were used for subjects to independently support themselves and maintain midline orientation.

As a subject's postural control improved, the horse's walking pattern and velocity were varied to require different compensatory strategies from the subject. Walk to halt to walk, or half halts were used to challenge quick postural adjustments of opposing muscle groups. 
During the first few weeks of hippotherapy, two subjects were too weak to sit on the horse with assistance from sidewalkers on the ground. The therapist used backriding for several hippotherapy sessions until these two subjects could remain sitting on the horse with assist from people on the ground. Backriding is when the therapist rides on the horse seated behind the patient to provide positional support. Treatment notes were written by the therapist for each hippotherapy session. Progress was noted accordingly in the written notes kept in individual file folders.

\subsection{Post-Intervention Phase}

The $\mathrm{O} 3$ posttest was held during the week following the final hippotherapy session. All ten subjects came to the first posttest. The appointment time for each test session was shortened to sixty minutes per subject. It was not taking as long to complete the GMFM and PEDI. Following this test date, the parents were asked to record the changes the saw in their child and how hippotherapy benefited their child. The parents comments were returned to the researcher in a self-acldressed stamped envelope.

The $\mathrm{O} 4$ posttest was ten weeks after the $\mathrm{O} 3$ posttest. All ten subjects came to their fourth and final test date. The GMFM assessment was recorded on videotape and the PEDI was completed again.

To examine the confounding variables, parents were asked the types and frequencies of other interventions that occurred between $\mathrm{O} 1$ and 04 . The subjects were from eight different school districts where they were serviced by therapists. 
Subject \#8 was home-schooled. The weekly frequency of OT, PT or SLP ranged from 0 to 3 times per week. Some parents reported combined OT/PT/SLP in one session. Other children had separate therapies. Subject \#1 and subject \#3 had identical therapists because they attended the same early intervention program. Subjects \#2 and \#5 went to the same preschool and had therapy with the same therapists. These were the only two pairs of subjects who had identical therapists. Hippotherapy O2-O3 occurred during the summer months of June, July and August when the children were on summer break from school. The frequency of PT/OT/SLP during O2-O3 was typically less than during O1-O2 and O3-O4.

\subsection{Statistical Procedures}

The data from the GMFM and PEDI Part I Functional Skills were entered into SPSS. Repeated measures of group means with a one way analysis of variance was done. Confidence interval was set at $\mathrm{p}<.05$ a priori. Rejecting the ANOVA null hypothesis suggested that the means differed on the four test dates, but did not state where the differences lie. A post hoc analysis with multiple comparisons was done to determine which time periods were most significant. Tukey's procedure was used to test the research hypothesis. A Tukey HSD ( honest significant difference ) value was hand calculated for each subscale and total score of the two outcome measures and compared to the change in mean score in each time period. If the difference in mean score across a time period was greater than the HSD value, then that time period was determined to be statistically significant. A post hoc ICC interrater reliability measure was calculated with the GMFM scores. 


\section{CHAPTER 4}

\section{RESLILTS}

\subsection{Introduction}

This chapter contains the results of this 30-week study. The demographics of the subject population are described. The final outcomes are presented in figures and tables. The statistical analysis of the data provide answers to the objectives and determine if the research hypothesis can be accepted.

\subsection{Subject Population}

Eleven subjects with cerebral palsy were recruited in a convenience sample. The researcher phoned therapists and physicians offices in nearby communities to inquire if they might know a family that would be interested in participating in a study on hippotherapy. Nine subjects were recruited through phoning these clinicians. In addition, two subjects who were clients of the researcher were recruited. All eleven subjects met the criteria of having a diagnosis of cerebral palsy, never having had hippotherapy and were between the ages of 2.5 and 7 years old during the course of the study. Prior to the study, one subject had ridden horses 
in therapeutic riding lessons at a stable, but did not receive hippotherapy. The fact that he had ridden in a group therapeutic riding lesson and not hippotherapy qualified him for the study. The subject demographics are presented in Table 3.

\begin{tabular}{|c|c|c|c|}
\hline Subject & Gender & $\begin{array}{c}\text { Age at } \\
\text { baseline }\end{array}$ & Type of cerebral palsy \\
\hline 1 & F & 2.25 & Spastic quadriplegia \\
\hline 2 & F & 2.33 & Right hemiparesis \\
\hline 3 & F & 2.58 & Spastic quadriplegia \\
\hline 4 & F & 2.70 & Unspecified \\
\hline 5 & $\mathrm{M}$ & 2.75 & Unspecified \\
\hline 6 & $\mathrm{M}$ & 3.83 & Spastic diplegia \\
\hline 7 & $\mathrm{~F}$ & 4.00 & Unspecified \\
\hline 8 & $\mathrm{M}$ & 4.33 & Left hemiparesis \\
\hline 9 & $\mathrm{M}$ & 5.83 & Unspecified \\
\hline 10 & $\mathrm{M}$ & 5.97 & Right hemiparesis \\
\hline 11 & $\mathrm{M}$ & 6.83 & Athetoid \\
\hline
\end{tabular}

TABLE 3. The gender, age and type of cerebral palsy of eleven recruited subjects. Subject 4 was the one subject who did not complete the study.

Attendance was excellent. The children and parents seemed to enjoy hippotherapy treatment. Nine subjects attended all ten hippotherapy sessions. One subject missed two hippotherapy sessions due to illness ( see Appendix H ). The missed treatment sessions could not be rescheduled due to conflicts in the barn schedule.

To examine the confounding variable of other therapies, parents reported the type and frequency of other interventions that took place during $\mathrm{O} 1$ and $\mathrm{O} 4$. The subjects were from eight different schools. Subject 8 was home-schooled and did not have therapy services. Because of the number of schools represented by the 
subject population, many different therapists were involved in treating the subjects throughout the study. The frequency of OT, PT or SLP also ranged greatly. One parent reported combined OT/PT/SLP in one session. Whereas, the other parents reported individual therapies. Two pairs of subjects went to the same school and had the same therapists. The ten weeks of hippotherapy took place during the summer months when children were on summer break from school and the frequency of PT, OT and SLP is typically less ( See Table 4. ). Other rival events reported by the parents are in Table 5. Rival events are confounding variables that could have caused a change in the dependent variable.

\begin{tabular}{|c|l|}
\hline SUBJECT & THERAPEUTIC INTERVENTION DURING HIPPOTHERAPY \\
\hline 1 & One PT treatment in ten weeks. \\
\hline 2 & PT once a week for ten weeks. \\
\hline 3 & Four PT treatments in ten weeks. \\
\hline 5 & PT once a week for ten weeks. \\
\hline 6 & OT and PT and SLP once a week for ten weeks. \\
\hline 7 & None \\
\hline 8 & None \\
\hline 9 & None \\
\hline 10 & PT once a week for ten weeks. \\
\hline 11 & None \\
\hline
\end{tabular}

TABLE 4. Frequency of occupational, physical and speech therapy scheduled for the subjects or attended by the subjects during $\mathrm{O} 2-\mathrm{O} 3$ treatment phase. 


\begin{tabular}{|c|l|}
\hline SUBJECT & \multicolumn{1}{c|}{ RIVAL EVENTS } \\
\hline 2 & Failure to wear the newly issued right $\mathrm{AFO}$ \\
\hline 3 & Started oral baclofen during O1-O2 \\
\hline 6 & Bilateral otitis media during O2-O3 \\
\hline 7 & Hyperbaric oxygen treatment for one week during $\mathrm{O} 3-\mathrm{O} 4$ \\
\hline 11 & Hyperbaric oxygen treatment for two weeks during $\mathrm{O} 1-\mathrm{O} 2$ and $\mathrm{O} 3-\mathrm{O} 4$ \\
\hline
\end{tabular}

TABLE 5. Rival events reported by the parent to the researcher during the study.

\subsection{Statistical Analysis}

The raw scores on the PEDI and GMFM for all ten subjects on all four test dates are listed in Appendix M and N. The PEDI raw scores and GMFM percent scores were entered into the SPSS computer program. The two outcome measures were strongly and significantly related on each test date ( see Table 6. ).

\begin{tabular}{|c|c|c|c|c|}
\hline & PEDI O1 & PEDI O2 & PEDI O3 & PEDI O4 \\
\hline GMFM O1 Pearson Correlation & .729 & & & \\
Sig. (2-tailed) & $.017^{*}$ & & & \\
$\mathrm{~N}$ & 10 & & & \\
\hline $\begin{array}{c}\text { GMFM O2 Pearson Correlation } \\
\text { Sig. (2-tailed ) }\end{array}$ & & .799 & & \\
$\mathrm{~N}$ & & $.006^{* *}$ & & \\
\hline GMFM O3 Pearson Correlation & & & .836 & \\
Sig. (2-tailed ) & & & $.003^{* *}$ & \\
$\mathrm{~N}$ & & & 10 & \\
\hline GMFM O4 Pearson Correlation & & & & $\begin{array}{c}.812 \\
\text { Sig. (2-tailed ) }\end{array}$ \\
$\mathrm{N}$ & & & & $.004^{* *}$ \\
& & & & \\
\hline
\end{tabular}

TABLE 6. PEDI and GMFM correlation on four test dates. ${ }^{* *} \mathrm{p}<.01 \quad * \mathrm{p}<.05$ 
The post hoc interrater reliability analysis was done with GMFM raw scores from each dimension and total score given by each scorer on each test date. The single measure interclass correlation was very good from .990 to .999 ( ICC ).

A one-way analysis of variance ( ANOVA ) with repeated measures was calculated for both the PEDI and GMFM. See ANOVA Tables 7. and 8. ANOVA tested the difference between means, a priori $\mathrm{p}<.05$. The null hypothesis was rejected for all of the subscales except the GMFM Lying/Rolling $(\mathrm{p}>.05)$.

Source of Variation

df Ssq Ms F

$\begin{array}{llllll}\text { PEDI self-care } & 1.222 & 296.300 & 242.430 & 13.03 & .003^{*} \\ \text { PEDI mobility } & 1.675 & 170.600 & 101.939 & 10.67 & .002^{*} \\ & & & & & \\ \text { PEDI social } & 1.415 & 228.675 & 161.591 & 15.82 & .001^{*} \\ \text { PEDI total } & 1.454 & 2038.875 & 1402.011 & 22.37 & .000^{*}\end{array}$

TABLE 7. PEDI Part I - Functional Skills ANOVA results.

Test of within-subjects effects with Greenhouse-Geisser measure. ${ }^{*} \mathrm{p}<.05$ 
Source of Variation

GMFM lying/rolling

GMFM sitting

GMFM crawling/kneeling

GMFM standing

GMFM walk/run/jump

GMFM total df

$1.26 \quad 368.500 \quad 291.780$

3.47

.082

$\begin{array}{lllll}1.34 & 872.075 & 648.754 & 10.99 & .004^{*}\end{array}$

$1.75 \quad 1469.000$

838.892

18.21

$.000 *$

$\begin{array}{lllll}1.36 & 631.475 & 465.114 & 12.05 & .003 *\end{array}$

$\begin{array}{lll}1.07 & 641.475 & 601.408\end{array}$

6.69

$.027^{*}$

$1.26 \quad 846.675 \quad 670.900$

32.62

$.000^{*}$

TABLE 8. GMFM ANOVA results. Test of within-subjects effects with Greenhouse-Geisser measure. ${ }^{*} p<.05$

The rejection of the null hypothesis suggests that the population means differ ( see Tables 9 and 10 ) but does not tell where the differences lie. To identify the significance of specific time periods and test the research hypothesis, a post hoc analysis of multiple comparisons was done with Tukey's test for honest significant difference. A Tukey's HSD value was calculated for each PEDI and GMFM subscale. If the difference between the mean scores was greater than Tukey's HSD, then there was statistical significance in the time period analyzed ( see Table 11 ). 
Hippotherapy occurred during O2- O3. To accept the research hypothesis, there should be statistically significant change in the mean scores between $\mathrm{O} 2$ and $\mathrm{O} 3$ ( treatment phase ) and no significance between $\mathrm{O} 1$ and $\mathrm{O} 2$ (pre-treatment phase ) and no significance between $\mathrm{O} 3$ and $\mathrm{O} 4$ ( post-treatment phase ). Table 11 depicts the periods of statistical significance by showing Tukey's HSD followed by the change in mean score across each time period. There was no statistically significant change in either the PEDI or GMFM between $\mathrm{O} 1$ and $\mathrm{O} 2$ or between $\mathrm{O} 3$ and $\mathrm{O} 4$, ie. the pre-treatment and post-treatment phases.

The PEDI social and PEDI total score change was significant between $\mathrm{O} 2$ and $\mathrm{O} 3$ ( hippotherapy treatment phase ), thus supporting the research hypothesis. There was also significant change in the GMFM crawling/kneeling dimension and GMFM total score between $\mathrm{O} 2$ and $\mathrm{O} 3$, which also supports the research hypothesis. In summary, the research hypothesis was supported by both outcome measures in the analysis of mean scores. The change in the mean score on the PEDI and GMFM total measure was statistically significant during the hippotherapy treatment phase. The mean score change in one subscale of each outcome measure was also statistically significant during hippotherapy, ie. GMFM crawling/kneeling and PEDI social. 


\subsection{Individual Treatment Effects}

Seven out of ten subjects had greater change in GMFM total percent score during hippotherapy compared to before and after hippotherapy. ( See Figures in Appendix Q ). Subjects $1,3,7,8,9,10$ and 11 had more change in their total GMFM percent score in the treatment phase. Whereas, subjects 2, 5, and 6 had less or the same amount of change in their total GMFM percent score during the treatment phase as compared to the pre-treatment and post-treatment phases.

Further analysis of each individual subject's performance on the GMFM shows varying amounts of change and different functional effects during the treatment phase of hippotherapy. See Appendix I and $O$ for scores and figures showing the change across time for each individual subject. The benefit of hippotherapy varied for each individual subject. 


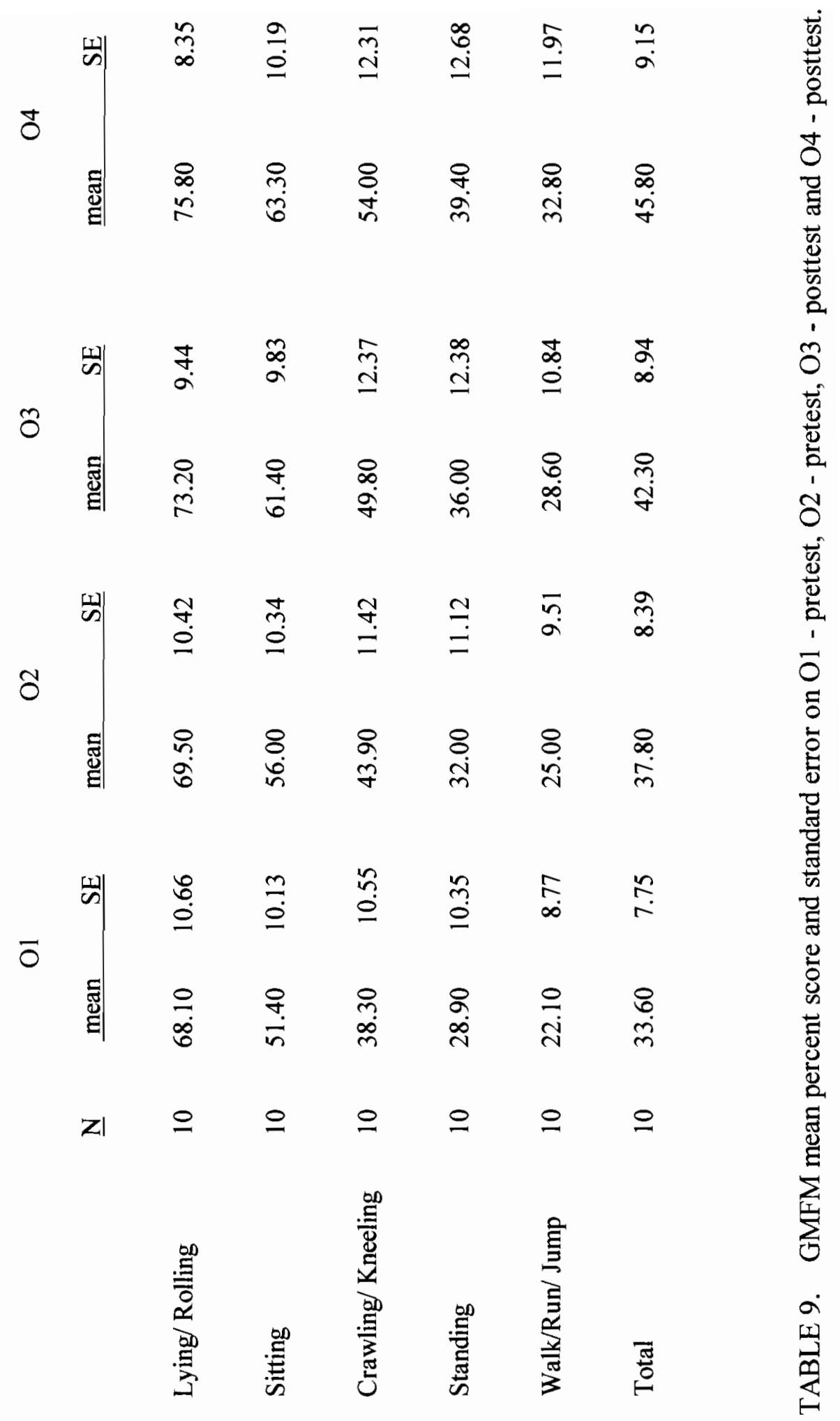




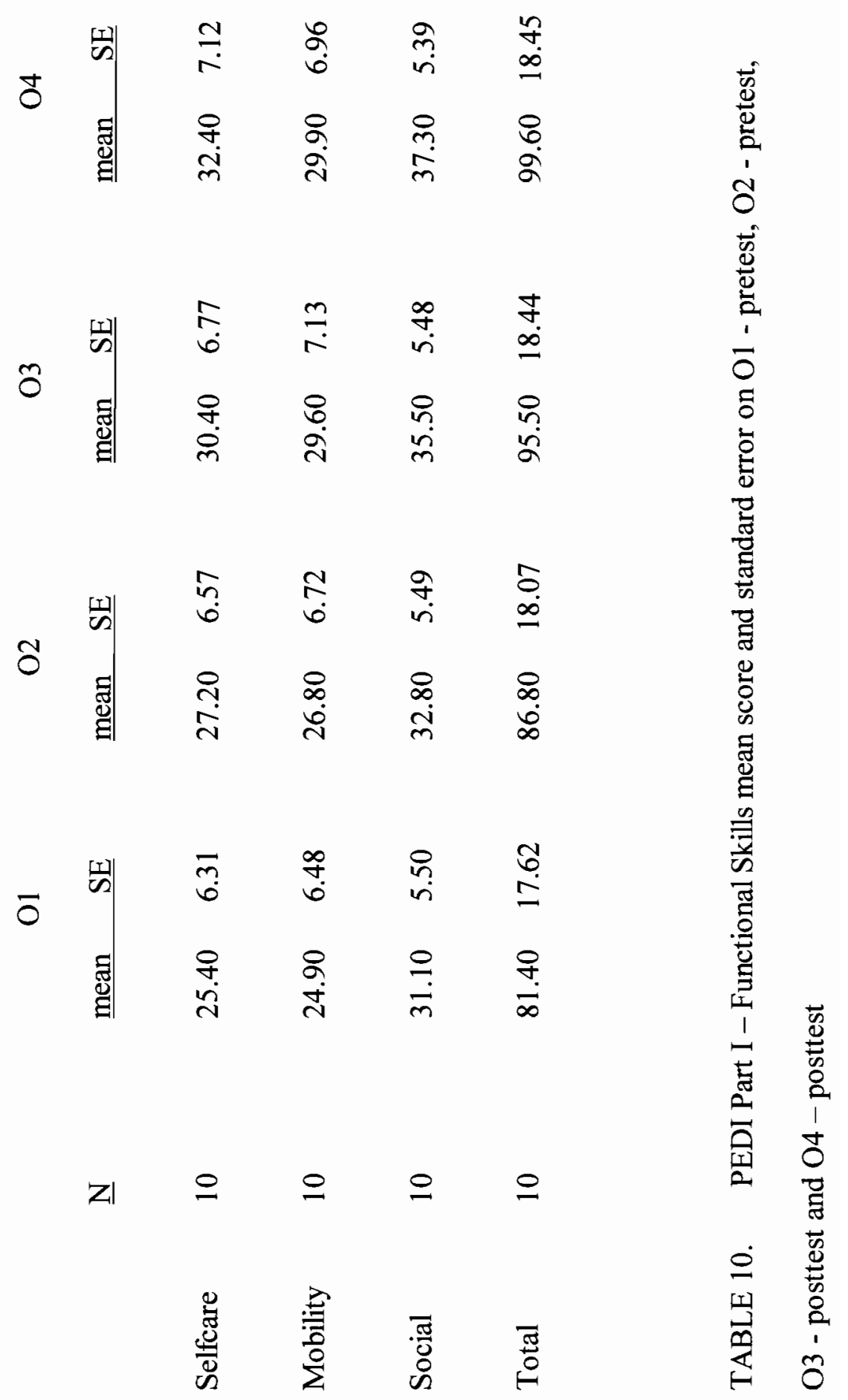




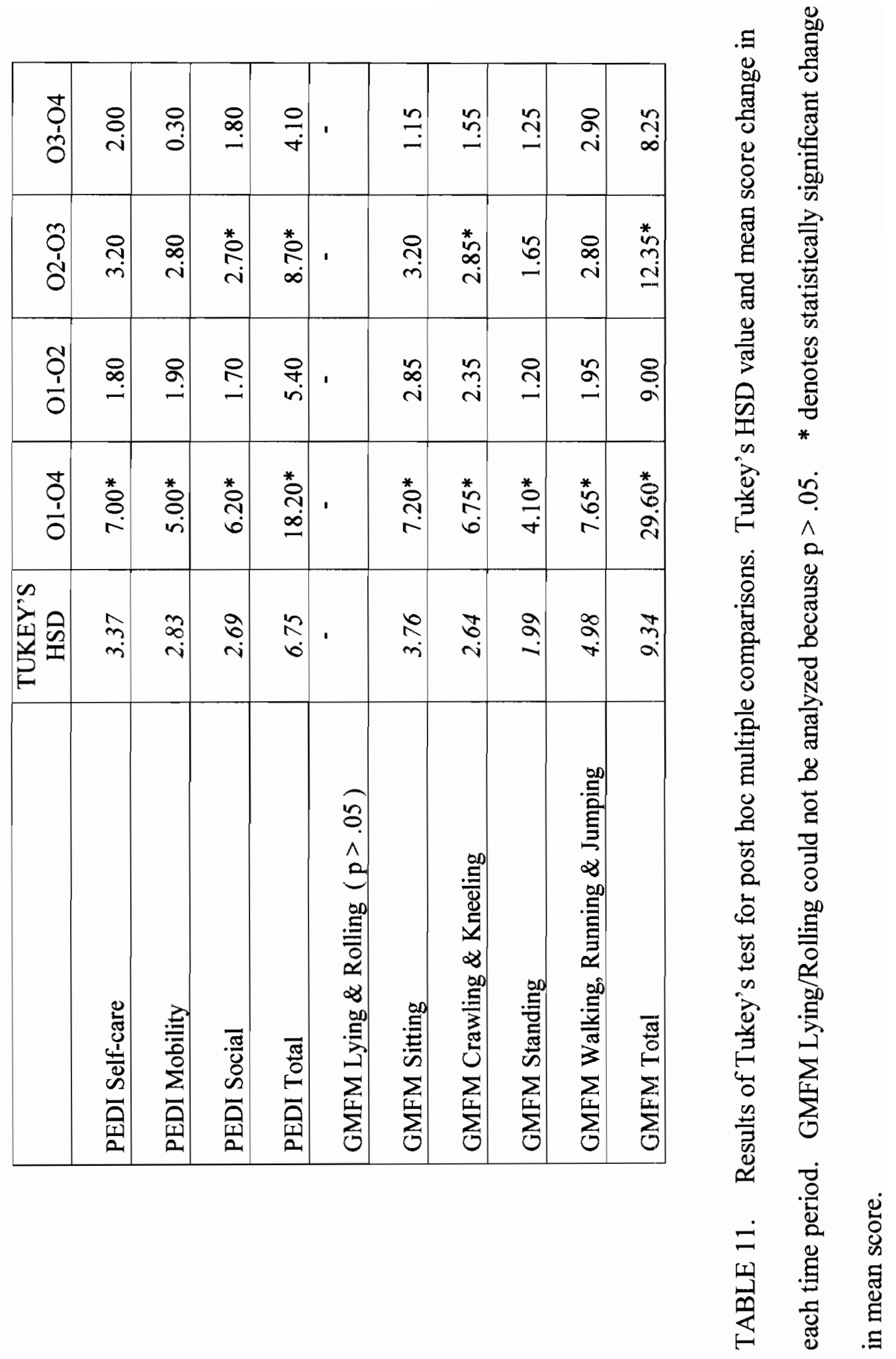




\section{CHAPTER 5}

\section{DISCUSSION}

\subsection{Review of Purpose}

The purpose of this study was to evaluate the effect of hippotherapy on children with cerebral palsy. Two outcome measures were selected as the dependent variable. The PEDI and GMFM were used to measure change in gross motor and functional status of the subjects before, during and after hippotherapy. Repeated measures were taken every ten weeks for thirty weeks. Hippotherapy was implemented during the middle ten weeks. Extraneous variables were built into the study. The primary objective was to determine if hippotherapy had an effect on children with cerebral palsy. The secondary objective was to determine what areas of function are affected by hippotherapy.

\subsection{Discussion of Results}

There was statistically significant treatment effect detected by both the PEDI and GMFM. There was greater change in the total GMFM scores in 7 out of 10 subjects during the ten weeks of hippotherapy as compared to before and after hippotherapy [ Appendix $\mathrm{J}$ and $\mathrm{K}$ ]. The group mean change across time was significant for both 
the total PEDI and total GMFM outcome measures during the hippotherapy phase. Hippotherapy did have an effect on the functional development of children with cerebral palsy.

The post hoc analysis was statistically significant for PEDI social, PEDI total, GMFM crawling/kneeling and GMFM total. Four other subscales were very close to statistical significance ( see Table 11 ). The PEDI self-care, PEDI mobility, GMFM sitting and GMFM standing dimensions missed the mark of statistical significance by a very small margin in the statistical analysis with Tukey's procedure.

Repeated measures is a stronger design than single pre-test/post-test research designs to evaluate treatment effects for children with $\mathrm{CP} .{ }^{61}$ Simple pretest/posttest designs do not provide adequate information regarding patterns of motor development. Repeated measures were used by Trahan $\&$ Malouin ${ }^{22}$ and E. Bower, et.al. ${ }^{62}$ in their studies using the GMFM.

The GMFM was specifically developed to detect changes in motor performance of children with CP. Researchers such as J. Jelsma, et.al ${ }^{61}$; T. Yang, et.al ${ }^{51} ;$ K. Bjornson, et.al ${ }^{63}$; C. Richards, et.al ${ }^{50}$; J. Collet, et.al ${ }^{48}$; E. Nordmark, et.al ${ }^{49}$; J. Trahan, et.al ${ }^{62} ;$ P.Steinbok, et.al ${ }^{64}$; and I. Hodgkinson, et.al. ${ }^{65}$ have used the GMFM to track change in subjects with $\mathrm{CP}$ after different therapeutic interventions. The ten-week time period selected in this study was a reasonable length of time to anticipate change using the GMFM in repeated measures. The GMFM has detected change in children with $\mathrm{CP}$ in six weeks, ${ }^{51,66}$ eight weeks, ${ }^{48}$ and sixteen weeks. ${ }^{22,50}$ 
The amount of change in the GMFM total percent score measured in children with CP in published studies is described in Table 12. When the GMFM results of this study are compared to other studies that also used the GMFM as an outcome measure, the change in GMFM total percent score after ten weeks of hippotherapy is comparable. There was between $1.0 \%$ and $10.0 \%$ change in the total GMFM percent score during the ten weeks of hippotherapy ( see Appendix K ). There was between $2.0 \%$ and $17.0 \%$ change in the total GMFM percent score during clinical trials of other types of intervention for children with CP ( see Table 12 ).

\begin{tabular}{|c|c|c|c|}
\hline Intervention & Authors & $\begin{array}{l}\text { Total GMFM } \\
\text { score change }\end{array}$ & Time \\
\hline Treadmill Training & C.Richards, et.al. ${ }^{50}$ & $5.0-14 \%$ & 4 months \\
\hline BoTox Injection & T. Yang, et.al. ${ }^{51}$ & $2.3-5.1 \%$ & 3 months \\
\hline PT vs. SPR & P. Steinbok, et.al. ${ }^{64}$ & $5.1-11.3 \%$ & 9 months \\
\hline SPR & E. Nordmark, et.al. ${ }^{59}$ & $2.0-17.0 \%$ & 12 months \\
\hline Hyberbaric Oxygen & J.P. Collet, et.al. ${ }^{48}$ & $2.9-3.0 \%$ & 2 months \\
\hline PT & E. Bower, et.al. ${ }^{62}$ & $3.1-5.9 \%$ & 6 months \\
\hline GMFM validity & K. Bjornson, et.al. ${ }^{63}$ & $2.6-4.6 \%$ & 12 months \\
\hline PT & J. Trahan, et.al. ${ }^{22}$ & $4.2-6.2 \%$ & 8 months \\
\hline
\end{tabular}

TABLE 12. Total GMFM percent score change in clinical trials that used the GMFM as an outcome measure. SPR = selective posterior rhizotomy. $\mathrm{PT}=$ Physical Therapy . 
The GMFM is a quantitative, criterion-based outcome measure that has been used in clinical trials to evaluate the effectiveness of treatment interventions for children with $\mathrm{CP}^{44,60}$ Similar to these clinical trials, children with varying degrees of hemiplegia, diplegia and quadriplegia participated in this hippotherapy research study.

The change detected by the GMFM measures part of the real change in subjects over time. Change may be qualitative or quantitative. A weakness of the GMFM is not being able to detect qualitative changes that children with $\mathrm{CP}$ demonstrate. ${ }^{67,68}$ Hodgkinson, et.al.'s population demonstrated qualitative improvements such as range of motion and ease of movement which are not accounted for by the GMFM. ${ }^{65}$

The technique of videotaping subjects while they perform the GMFM test items has been used in other studies. ${ }^{66,68}$ The tapes are typically viewed at a later date by scorers. Scorers have expressed a preference for observing performance directly instead of watching videotapes. ${ }^{68}$ However, the videotaping technique gives each scorer the same reference angle as well as the chance to review the subject's performance by replaying the tape. The ability to rewind and observe a portion of the test a second time improves measurement reliability between scorers. ${ }^{66}$ Yet scorers may still have different perceptions of how to quantify motor performance while watching subjects on videotapes. This was evident in the pilot test of interrater reliability ( Table 1 and 2 ). To solve the potential internal validity problem of the weak 
interrater reliability in the pilot test, the researcher discussed the interpretation of the zero to 3 Likert-scale of the GMFM. This perceptual difference was corrected as evidenced by the excellent post hoc ICC $=.990$ to .998 in the actual study.

A well-known fact in research design is that human subjects are not alike. Each subject inevitably differs from one another. The differences between subjects in this study were controlled by using each subject as his/her own control. Even though the subject population $(\mathrm{n}=10)$ was small and the differences between the subjects was great in terms of age and type of CP ( Table 3. ), the within-subjects ANOVA resulted in a statistically significant treatment effect. Differences between subjects were taken into account in the ANOVA. The ANOVA procedure removed variance from differences between subjects and increased the power and significance.

Specific intervention effects varied for each subject. The graphs in Appendix $\mathrm{O}$ illustrate the change in each subject on the five GMFM dimensions. One objective of this study was to determine what specific areas of function were most affected by hippotherapy. The areas of function most affected by hippotherapy were intended to be detected by significant change in the subscales of the PEDI and GMFM. In the post hoc analysis of the subscales, statistically significant change in the mean scores was evident in the PEDI social subscale and the GMFM crawling and kneeling dimension ( see Table 11). The change in the mean scores for the other PEDI subscales and GMFM dimensions were not statistically significant during the hippotherapy treatment period. Therefore, there were two specific areas of function influenced by hippotherapy in this study. 
The functional level of the subjects may explain the finding that hippotherapy had its greatest effect in the realm of social function and the gross motor area of crawling and kneeling skills. The group of ten subjects ranged in age from 2.25 to 6.83 years old ( Table 3 ). The social function subscale of the PEDI tests the capabilities of children in communication, social interaction and household tasks. The experience of coming to a barn and riding a horse for therapy gave each subject a valuable opportunity to use receptive and expressive communication skills as well as interact with people and a horse. While riding the horse and taking in the sensory component of balancing on a moving animal, the children were often listening or talking with the walkers. Subject \#9, who was non-verbal, used a pre-programmed communication device before and during riding. The device was used at opportune moments so subject \#9 could give the command for the horse to walk. This was done at each halt to walk transition. There were typically $10-15$ halt to walk transitions each session for him to experience the cause and effect of using his communication device to ask the horse to walk. Another example of social interaction during hippotherapy was singing in rhythm with the moving horse. Most of the children also learned to follow simple one-step commands such as moving fiom sitting forwardfaced to sitting side-faced on the horse while at a halt or walk. Other opportunities to listen and follow commands were during halts at activities such as reaching for and tossing colored bean bag frogs into a target on a barrel positioned within a reasonable distance from the rider. The subjects commonly asked the leader to halt the horse at a favorite activity. The hippotherapy treatment session was a valuable time for communication and social interaction skills to develop. 
The crawling/kneeling dimension on the GMFM was an appropriate skill area for nine out of ten subjects ( see Appendix J ). The floor mobility skills in the crawling/kneeling section of the GMFM were tested and scored for these nine subjects. Change was significant on this dimension because it was an appropriate functional goal for most of the subjects at the time of the study.

The qualitative or functional significance of hippotherapy which may have been missed by the outcome measures was subjectively reported by parents. At the end of the thirty weeks, the parents reported changes that they saw and attributed to the hippotherapy treatments. The parents were asked how hippotherapy benefited their child. See Table 12. for the anecdotal comments by the parents. 


\begin{tabular}{|c|c|}
\hline Subject & Parent Comment \\
\hline 1 & $\begin{array}{l}\text { More vocal, tolerating more movement and therapy, using arms more } \\
\text { frequently, bearing weight on her legs with splints. }\end{array}$ \\
\hline 2 & $\begin{array}{l}\text { Can walk steadily on different surfaces without swaying or falling, right } \\
\text { side not as tight, able to climb stairs with a handrail for the first time, not as } \\
\text { fearful, walks faster with more confidence and less awkward. }\end{array}$ \\
\hline 3 & $\begin{array}{l}\text { More balance, strength and control seen in army crawling, sitting with less } \\
\text { assistance, turning to reach toys and able to eat with a spoon. }\end{array}$ \\
\hline 5 & $\begin{array}{l}\text { More trunk control, able to pull himself up on knees and all fours, } \\
\text { increased attention span, happier, able to calm himself down easier when } \\
\text { upset. }\end{array}$ \\
\hline 6 & $\begin{array}{l}\text { Had an ear infection during hippotherapy but learned to walk in parallel } \\
\text { bars afterward. }\end{array}$ \\
\hline 7 & Stronger head control when sitting and lifting it off floor. \\
\hline 8 & $\begin{array}{l}\text { Sitting "Indian-style" without discomfort and independently without being } \\
\text { told. Able to stop-start-steer tricycle. Embraced new experiences without } \\
\text { anxiety. }\end{array}$ \\
\hline 9 & $\begin{array}{l}\text { Standing up straighter. Gained balance and body awareness. Using } \\
\text { communication signing more frequently and appropriately. Vocalizing } \\
\text { more. }\end{array}$ \\
\hline 10 & $\begin{array}{l}\text { Better balance while riding tricycle, standing/pushing his scooter, walking, } \\
\text { running and jumping. }\end{array}$ \\
\hline 11 & Increased upper body balance. Better head control. \\
\hline
\end{tabular}

TABLE 12. Parents comments at the end of the study. Parents were asked what changes they attribute to hippotherapy.

\subsection{Limitations}

Even though the researcher intended to keep the extraneous variable of other therapies consistent throughout the study, therapies were actually inconsistent from $\mathrm{O} 1$ to $\mathrm{O} 4$. The extraneous variable of other therapies was not held constant as planned. Hippotherapy occurred during the summer months when school 
therapy services are typically less frequent. Four of the subjects ( subject \#7, \#8, \#9 and \#11 ) did not attend any therapies other than hippotherapy during the summer months. In this regard, hippotherapy was a viable treatment tool even when the other therapy frequency waned for these four subjects. All four of these subjects had greater change in the GMFM total score during the hippotherapy intervention phase as compared to before or after hippotherapy. [ Appendix K ]

Six of the subjects ( subject \#1, \#2,\#3,\#5,\#6 and \#10) received conventional therapy during the hippotherapy intervention phase; although, the frequencies of conventional therapy was not the same. Three of these six subjects had less change in total GMFM score during hippotherapy compared to before and after hippotherapy. For subject \#2, \#5 and \#6, hippotherapy plus conventional therapy was less effective than for subject \#1, \#3, and \#10 who also had hippotherapy plus conventional therapy.

The subjects attended different schools and were treated by different therapists. The treatment approaches of those therapists most likely differed as well. The researcher did not contact these therapists during the study. Inquiry would have been beneficial to determine the amount and type of therapy before, during and after hippotherapy. Instead, the researcher relied on a parental report of how much physical, occupational or speech therapy their child received during the study. Relying on the report of the parents may not have been as accurate as contacting the therapists. Therapists would have had an exact attendance record for the extraneous variable of other therapies. Additionally, asking the therapists what changes they saw in the children after hippotherapy may have been valuable information. Subjective 
report from the therapist may have correlated with the outcome measures. Therapists judgement of change ( $r=.65$ ) correlated better with the GMFM than the parents' judgement of change $(\mathrm{r}=.54)$ in a GMFM reliability study. ${ }^{43}$

The implementer of hippotherapy in this study was not the primary therapist working with all ten of the subjects in therapy off of the horse. She was the primary therapist for only two of the ten subjects. Using the horse as a treatment intervention for functional outcomes was based on what the implementer saw as weaknesses and potential goal areas during the GMFM on $\mathrm{O} 1$ and $\mathrm{O} 2$.

Subjects \#1 and \#3 were clients of the therapist conducting the hippotherapy. Therefore, these two subjects were treated by the same physical therapist during all thirty weeks in the study. Subjects \#1 and \#3 received physical therapy at the early intervention program where the therapist worked. It was easier to determine the needs of subject \#1 and \#3 during hippotherapy because the therapist was familiar with these clients in a clinic setting. In other words, treatment options using the movement of the horse were obvious for these two particular subjects. The therapist also followed through with these two subjects during the post-intervention phase. Hippotherapy is best used as a treatment tool to complement conventional clinical therapy techniques. Compared to the other subjects, subject \#3 had some of the most significant changes on the GMFM. [ See Appendix J and K ]

Subject and parent participation were excellent throughout the study. Families made hippotherapy a priority on their summer schedule. See Appendix H for the hippotherapy attendance record. Subject \#1, who missed two hippotherapy 
sessions, also had a history of poor attendance at early intervention therapy appointments ( see Table 2 ). However, no correlation could be made between hippotherapy attendance and functional outcome.

The scorers of the GMFM did not have the same training or experience using the GMFM. This was a potential source of measurement error. The decision to use the mean score of the two scorers was an attempt to reduce this threat to internal validity. However there was less concern with the high post hoc $\mathrm{ICC}=.990$ to .998 interrater reliability.

The GMFM scorers were not blind to the order of test date. The scorers watched the tapes from test date $\mathrm{O} 1$ followed by $\mathrm{O} 2$, followed by $\mathrm{O} 3$ and then $\mathrm{O} 4$. The scorers were given as much time as necessary to finish a box of tapes from one particular test date before returning the tapes to the researcher. Typical turnover time for one scorer to watch and score a box of ten tapes was ten weeks. The scorers retained the subjects' score sheets until the final box of tapes from $\mathrm{O} 4$ was scored. Retaining the score sheets may have biased the scorers if they looked at their score from the previous test date.

The anecdotal comments from the parents may have been biased by the phrasing of the question posed by the researcher. By using the words change and benefit, the parent may have been influenced to report their answer in the positive direction. In this way, the researcher may have inadvertently biased the parent by how the question was asked. 
The researcher was also the implementer of the PEDI questionnaire on each test date. The researcher gave parents the opportunity to see their responses to the PEDI items on the previous test date. This may have biased their response. Although some parents did give responses in both directions. In other words, an occasional parent did score their child in a negative direction if they believed the child had actually regressed on that particular skill or item.

\subsection{Implications}

Hippotherapy is meaningful and functionally relevant for children with cerebral palsy. The horse is a useful therapy tool for therapists. Hippotherapy creates functional change in a relatively short period of time. McGibbon and Haehl recorded functional change after eight and twelve weeks of hippotherapy respectively. ${ }^{18,19}$ Whereas this study showed functional change after ten weeks of hippotherapy.

The treatment approach used during hippotherapy to achieve functional change can be explained in the disablement model of therapeutic intervention. Pathology may create physical impairment. Physical impairments may lead to functional limitations. Functional limitations can potentially cause a lifelong disability. ${ }^{69}$

Hippotherapy was used to remediate impairments related to the functional limitation of subjects. The researcher identified impairments by assessing the participants during their first test date. The primary areas of impairment recognizable in the subjects were balance, coordination, dynamic postural control, motor planning and endurance. The therapist used the horse's movement during hippotherapy to 
improve balance, coordination, dynamic postural control, motor planning and endurance. The positive change in movement skills or gross motor function measured by the GMFM may have been due to hippotherapy's effect on impairments due to cerebral palsy. The subsequent improvement in function may have had a positive effect on the level of disability, since the PEDI detected a treatment effect on the level of disability. This study would have been strengthened by using an impairment level outcome measure as well as the GMFM and PEDI which measured hippotherapy's effect on gross motor function and disability level.

The horse is a dynamic treatment surface. A moving surface is effective in creating motor responses during therapy. ${ }^{70}$ Postural reactions can be taught on tilt boards rocked from side to side. ${ }^{71}$ The movement generated by the horse or tilt board takes the form of perturbations or unexpected interruptions of equilibrium. These two mechanical forms of input apply external stimulus to achieve motor responses. The external stimuli is added to a host of sensory information from golgi tendon organs, cutaneous and joint receptors. ${ }^{70}$ A motor response can be altered by changing the intensity, duration or location of an external stimulus. In hippotherapy, therapist's can grade the intensity, duration and location of the external stimulus by changing the gait pattern of the horse. Horses can lengthen or shorten their stride length which changes the amplitude or intensity of movement felt by the rider. Horses can also vary their cadence which alters the duration or frequency of perturbations felt by the rider. 
Postural and movement strategies are learned and practiced through repetition. ${ }^{70}$ Due to postural control problems common to $\mathrm{CP}$, the sitting position is very unstable. Brogren, et.al. studied the automatic postural adjustments in children with $\mathrm{CP}$ while sitting on a moving platform. Dysfunctional motor recruitment and impaired co-activation were the findings of the study just mentioned. ${ }^{14}$ When a perturbation occurs that challenges a person's equilibrium, a voluntary movement takes place which opposes the direction of the perturbation. Postural muscles are usually recruited first and precede activation of focal muscles. ${ }^{70}$ This postural recruitment pattern is usually anticipatory. The postural command is scaled to put out an appropriate amount of effort considering the support surface and the amount of perturbation induced. ${ }^{72}$ Postural control must be both appropriate and efficient. Effective postural strategies must be useful against a variety of external stimuli and environmental conditions. ${ }^{73}$ With the horse, a therapist can systematically vary the characteristics of the perturbations. The postural adjustments made by the riders in hippotherapy occur as a response to unexpected, external perturbations and also as a result of expected, self-generated movements. These are feedback and feedforward movement strategies. Anticipation is learned through experience. ${ }^{74}$ Anticipatory postural adjustments are generated by the central nervous system and are used to counteract any expected perturbing forces. Repetition and practice make postural adjustment more appropriate and efficient. ${ }^{75}$ The three-dimensional, rhythmic movement of the horse at a steady walk is a repetitive external perturbation, which gives a rider 100 impulses per minute to practice anticipatory postural control. 
At the onset of hippotherapy, the subjects displayed poor midline control. Subjects could not maintain their position centered and balanced on the horse. This was seen in both the sitting forward-faced and sitting rear-faced positions on the horse. During the first few treatments, the horse had to be halted countless times to re-align the sagittal plane of the subject with the sagittal plane of the horse. Subjects who could follow a one-step command were asked to sit in the middle of their horse. Physical assistance from the therapist and sidewalker was given if a rider was unable to self-correct. Through these observations, it was noticed that all of the subjects who originally could not maintain sagittal alignment or centered balance facing forward or backward on the horse, later demonstrated the ability to maintain this position. Although it was through observational data, this treatment effect of improved postural control on the dynamic surface was irrespective of age or type of cerebral palsy. The subjects learned new motor strategies through practice and repetition. Their feedforward or anticipatory control became more efficient and appropriate.

Postural control is an impairment commonly seen in cerebral palsy. ${ }^{14}$ When postural control improves, motor skills improve ${ }^{15,17}$ even in severe $\mathrm{CP}^{71}$ The subjects' postural control improved which may have correlated with the change in function. An outcome measure that showed change in postural control would have been beneficial, but neither the PEDI nor the GMFM address this specifically.

Hippotherapy has the potential to be a valuable tool for therapists in light of recent recommendations that therapists use treatment strategies that enhance a child's motivation to progress. Engaging a child more deeply in an activity will most likely enhance the outcome of therapy. ${ }^{76}$ Therapists have been advised to provide young 
clients with environmental conditions that encourage self-initiated activity with natural restraints. ${ }^{77}$ The horse in hippotherapy is an excellent motivator. Children are active participants engaged in repetitive movement that is functional and therapeutic.

In the dynamic systems theory of motor development, skills emerge from the interaction of a variety of subsystems in task-specific contexts. Postural control, functional activity and active participation are key elements for motor development in this heterarchical view. ${ }^{77}$ Hippotherapy encompasses all of these elements. The primary task in hippotherapy is simply to remain seated on a moving horse. Other tasks can be creatively added by the treating therapist. Hippotherapy clients are actively engaged in movement or stability selections to maintain postural control. The moving horse can be a new task demand that requires therapy clients to find solutions or adapt to a change in direction or tempo during hippotherapy treatment.

\subsection{Recommendations for Future Research}

If treatment with the movement of the horse influences function by primarily altering the physical impairments of a client, then research that uses an impairment level outcome measure is needed. An outcome measure for sitting balance, postural control or motor planning may determine more precise benefits of hippotherapy.

A weakness of this study was the difference between subjects. Future studies in hippotherapy should use a more homogeneous subject population. If subjects are more alike in the area of diagnosis or age, then the specific functional skill areas affected by hippotherapy may be better detected by the GMFM or other outcome 
measures. ${ }^{49}$ If a homogenous sample cannot be obtained, researchers should classify each subject's level of gross motor function. The effects of severity could be accounted for by using the Gross Motor Function Classification System ( GMFCS ). The GMFCS is an objective classification of children with CP. The GMFCS is divided into five levels of motor ability and would be a good way to classify subjects with CP in future research. ${ }^{78}$

Hippotherapy is becoming a recognizable treatment tool for physical therapists, occupational therapists and speech/language pathologists who are familiar with the unique value of a horse. However, in these days of evidence-based practice, more empirical research is needed to provide further credible evidence for the value of hippotherapy. From the results of this researcher's thirty week study, hippotherapy appears to be a viable treatment tool and a means of achieving functional outcomes in children with cerebral palsy. Treatment interventions for cerebral palsy typically focus on maximizing a child's potential. Whether the focus of therapy is to improve motor skills, self-care or leisure activities, most therapies have one or two emphases, ie. 1) quality of movement and 2) functional ability. Hippotherapy has the potential to be a therapy that incorporates both goals for the quality of movement and functional ability. 
APPENDIX A

Recruitment Letter 
FROM: Renee Casady, PT

TO: Parent

RE: 30-week research project on hippotherapy

HELLO

I am currently recruiting subjects to participate in a 30 research study. Subjects must be between $21 / 2$ and 7 years old. Subjects must also have the diagnosis of cerebral palsy. The study is designed to measure development before, during and after hippotherapy.

\section{What is hippotherapy, you may be asking?}

Hippotherapy is therapy using a horse. As a physical therapist, I use horses as a tool to reach the typical goals of therapy. I work for the Logan County Board of MR/DD's preschool and early intervention services. I use the horse in addition to the typical balls, swings, balance boards and exercise techniques. I use 3 wonderful horses that have different qualities of movement to create an effective therapy session in an indoor riding arena.

\section{If we are interested in participating, what do we have to do?}

If you have any questions, please phone me. I'll be happy to answer any questions. I need parental permission and a physician prescription ( I'll send papers to the doctor of your choice).

\section{When will this start?}

I hope to begin the first week of April. And it will continue for 30 weeks.

The first 10 weeks begin with a measurement of each child's level of development using a videotaped test called the GMFM and a questionnaire called the PEDI. During the first 10 weeks each child in the study just goes to all of his/her usual activities, therapies, doctor's visits, etc. Then at the end of the first 10 weeks, I will measure each child's development again with the GMFM and the PEDI. Then we begin the second 10 weeks. During the second 10 weeks each child will come to hippotherapy once a week in addition to other activities/therapies. There is no cost for hippotherapy. The cost of hippotherapy will be covered by grants. Then after 10 weeks of hippotherapy, I will measure the child's development again with the GMFM and the PEDI. The final 10 weeks of the study is another period of no hippotherapy and ends with a fourth measurement of development using the GMFM and the PEDI. Basically, the study looks like this:

$$
10 \text { weeks no hippotherapy }+\mathbf{1 0} \text { weeks hippotherapy }+10 \text { weeks no hippotherapy }
$$

If you are interested but have questions, please call me. Thank you.

Sincerely,

Renee Casady, physical therapist.

Phone: 937- $\quad$ (W) or 937- 


\section{APPENDIX B}

Letter to Participants 
Dear Families,

Thank you for volunteering to participate in this 30-week hippotherapy research project. Please do not hesitate to call me to ask questions. I understand that you may have some questions about many parts of this project.

Let me again describe why I am doing this project.

It was $31 / 2$ years ago when I began using hippotherapy as a part of the school-year therapy program for the preschoolers at Logan County Board of MR/DD. Since then I have become convinced of the value of the horse for children with special needs. Now, as a graduate student at The Ohio State University I have the opportunity to conduct a research project to collect measurable data regarding the effect of the horse. There are countless doctors, therapists, insurance companies, horse-people and parents like you just waiting for reports about the benefits of the horse for children with special needs.

Over the phone, you have told me that you are willing to participate. Thank you.

\section{Would you please fill out the forms in this envelope and return them to me by Friday, March 23rd.}

$\square$ The Ohio State University consent form

$\square$ Discovery Riders, Inc. liability release form

$\square$ Discovery Riders, Inc. participant's application and health history

$\square$ Discovery Riders, Inc. authorization for emergency medical treatment

$\square$ The name, address and phone number of your child's doctor who will sign a prescription for physical therapy

Remember, you may contact me at any time with questions.

Sincerely,

Renee Casady, P.T.

Physical Therapist

(W) 937 -

(H ) $937-$ 
APPENDIX C

Informed Consent Form 

$01 \mathrm{H0049}$

\section{CONSENT TO INVESTIGATIONAL TREATMENT OR PROCEDURE}

I, , hereby authorize or direct

associates or assistants of his/her choosing, to perform the following treatment or procedure ( describe in general terms ),

I agree to volunteer my child as a participant in a research study. I understand the purpose of the research study is to see if hippotherapy has any effect on the functional development of children with cerebral palsy. I am willing to have the researcher ask our physician if my child can participatelin this research study. I will permit my child to be tested before hippotherapy treatment starts. I am willing to have this testing done to determine the abilities of my child before treatment starts. I understand that the one test ( called the Pediatric Evaluation of Disability Inventory ) is a questionnaire which I will fill out to the best of my ability. I understand that the other test ( called the Gross Motor Function Measure ) is done by: 1) an assistant to the investigator videotaping my child, 2) a professional watching my child's performance on the videotape, 3) a qualified person gives a score for the performance on the test. I agree to transport my child to the test sites on the dates requested by the researcher. I agree to cooperate with a total of four test dates. The second test date will be ten weeks after the first test date. The third test date will be ten weeks after the second test date. The fourth test date will be ten weeks after the third test date. I understand that the treatment of hippotherapy will be between the second and third test dates. I agree to transport my child to the barn for hippotherapy once a week for ten weeks. I will do my best to help my child enjoy and look forward to treatment each week. I understand that the whole research project will take 30 weeks. I agree that my child will continue all other therapies at school or elsewhere during these 30 weeks so that hippotherapy is in addition to these other therapies

upon

(myself or name of subject)

The experimental ( research ) portion of the treatment or procedure is:

Hippotherapy, which is a therapist using the movement of a horse. This treatment means that my child will be placed on a horse for up to 30 minutes during each of ten treatment sessions.

This is done as part of an investigation entitled:

The Effect of Hippotherapy on Children with Cerebral Palsy.

\section{Purpose of the procedure or treatment:}

The horse in hippotherapy will be used as a way to improve the problems associated with cerebral palsy such as poor balance, weakness and tight muscles. The purpose of this research study is to see if the moving horse makes changes in my child's balance, weakness, tight muscles or functional skills.

\section{Possible appropriate alternative procedure or treatment ( not to participate in the study is always and option ):}

I can choose not to allow my child to be a subject in this study. If I do choose to allow my child to participate, I know that I may quit at any time. 


\section{Discomforts and risks reasonably to be expected:}

The risk associated with riding on a horse include injuries from falling off of the horse. I understand this risk will be minimal in hippotherapy due to the special training of the staff, the expertise of the horse handler, the ability to control any unwanted movement of the horse and the number of people surrounding the rider. My child may feel afraid or uneasy at first, but it is possible to overcome these feelings. It is possible that muscles will be stretched from sitting and bouncing on the horse during treatment. These muscles may feel sore for a short time, but this should go away in 24 hours. I understand that my child may feel tired after hippotherapy because it is a type of endurance exercise to stay on a moving horse for up to 30 minutes. The wearing of a helmet is required during hippotherapy and sometimes the helmet feels uncomfortable to wear because the sensation of a strap under the chin can rub then skin and feel itchy or snug.

\section{Possible benefits for the subjects/society:}

As a participant in this study, the treatment of hippotherapy may cause my child to do these things better than he/she did before treatment: rolling over, sitting up, crawling, standing, walking, climbing, interact with others, express themselves, protect themself from harm with upper body reactions, play with objects, need less assistance in a task. The results of this study will give therapists evidence of the effectiveness of hippotherapy. Using the horse as a treatment tool is still a novel idea to physicians and medical insurance companies. The outcome of this research may help persons who doubt hippotherapy's usefulness to see that the horse is a valuable treatment option for children with cerebral palsy.

\section{Anticipated duration of subject's participation ( including number of visits ):}

The length of this study is 30 weeks. The 30 weeks begins on the first test date. The 30 weeks ends on the fourth test date. I will volunteer my child's participation for the entire 30 weeks. I will bring my child to all four tests at the site determined by the researcher and on the right date and time. I will bring my child to all ten hippotherapy treatments at the barn. I understand that each treatment session may take up to 45 minutes with 30 of those minutes on the horse.

I hereby acknowledge that

has provided information about the procedure described above, about my rights as a subject, and he/she answered all questions to my satisfaction. I understand that I may contact him/her at Phone No. should I have additional questions. He/She has explained the risks described above and I understand them; he/she has also offered to explain all possible risks or complications.

I understand that, where appropriate, the U.S. Food and Drug Administration may inspect records pertaining to this study. I understand further that records obtained during my participation in this study that may contain my name or other personal identifiers may be made available to the sponsor of this study. Beyond this, I understand that my participation will remain confidential. 
I understand that I am free to withdraw my consent and participation in this project at any time after notifying the project director without prejudicing future care. No guarantee has been given to me concerning this treatment or procedure.

$I$ understand in signing this form that, beyond giving consent, I am not waiving any legal rights that I might otherwise have, and I am not releasing the investigator, the sponsor, the institution, or its agents from any legal liability for damages that they might otherwise have.

In the event of injury resulting from participation in this study, I also understand that immediate medical treatment is available at University Hospitals of The Ohio State University and that the costs of such treatment will be at my expense; financial compensation beyond that required by law is not available. Questions about this should be directed to the Office of Research Risks at 292-5958.

I have read and fully understand the consent form. I sign it freely and voluntarily. A copy has been given to me.

Date:_ Time:_ PM $\quad$ PM

Signed

(Subject)

Witness (es)

( Person Authorized to Consent for Subject if Required)

I certify that I have personally completed all blanks in this form and explained them to the subject or his/her representative before requesting the subject or his/her representative to sign it.

Date:

Signed

(Signature of Project Director or his/her Authorized Representative) 


\section{APPENDIX D}

Physician Prescription Form 
Dear Dr.

A request for Physical or Occupational Therapy services which includes the use of hippotherapy has been received for your patient

from

This is an initial request for service

This is a request for continuation of service

Hippotherapy literally means treatment with the help of the horse. The term hippotherapy refers to the use of the movement of the horse as a tool by physical therapists, occupational therapists, and speech-language pathologists to address impairments, functional limitations, and disabilities in patients with neuromusculoskeletal dysfunction. This tool is used as part of a patient's existing treatment program to achieve functional outcomes.

Therapists treat patients in 30 minute individual treatment sessions. These sessions do not use the horse for recreational horseback riding. Hippotherapy takes place in a highly structured environment with trained volunteers to lead and assist the therapist.

Typical benefits from hippotherapy include:

- development of head and trunk control

- development of equilibrium reactions

- postural training

- mobilization of joints

- improved body symmetry

- improved body awareness

- sensorimotor integration

- proximal stability

- improved vestibular reactions

- motor planning

- increased endurance and strength

- timing, rhythm, coordination and spatial orientation

If you agree that the above named client may benefit from hippotherapy please fill out, sign and return the enclosed prescription form. If you have any questions please do not hesitate to call. 937- and ask for Renee Casady, physical therapist. Thank you.

Sincerely, 
Physician Prescription For Hippotherapy

PATIENT'S NAME:

ADDRESS:

HOME PHONE:

DATE OF BIRTH:

PARENT/GUARDIAN:

DIAGNOSIS:

KNOWN PRECAUTIONS:

FOR PATIENTS WITH DOWN SYNDROME, ATLANTODENS INTERVAL XRAY DATE: RESULT: + OR-

PHYSICAL THERAPY OR OCCUPATIONAL THERAPY ( circle one)

IS PRESCRIBED TO ADDRESS PHYSICAL IMPAIRMENTS, FUNCTIONAL LIMITATIONS OR DISABILITY RELATED TO THIS PATIENT'S NEUROMUSCULOSKELETAL DYSFUNCTION.

FREQUENCY: per week

DURATION: weeks

PHYSICIAN SIGNATURE:

DATE:

PHYSICIAN PRINTED NAME:

ADDRESS:

PHONE: 


\section{APPENDIX E}

Hippotherapy Participant Application and

Health History Form 
Discovery Riders, Inc.

Hippotherapy Participant's Application and Health History

GENERAL INFORMATION

Participant: Age: Height: Weight: M F

Address:

Phone: Employer/School:

Parent/Legal Guardian:

Address (if different from above):

Phone:

Referral Source:

Contact Numbers:

How did you hear about the program?

\section{HEALTH HISTORY}

Please indicate current or past problems in the following areas:

\begin{tabular}{|l|l|l|l|}
\hline & \multicolumn{1}{|c|}{ Y } & N & Comments \\
\hline Vision & & & \\
\hline Hearing & & & \\
\hline Sensation & & & \\
\hline Communication & & & \\
\hline Heart & & & \\
\hline Breathing & & & \\
\hline Digestion & & & \\
\hline Elimination & & & \\
\hline Circulation & & & \\
\hline Emotional & & & \\
\hline Behavioral & & & \\
\hline Pain & & & \\
\hline Bone/Joint & & & \\
\hline Muscular & & & \\
\hline Thinking/Cognitive & & & \\
\hline Allergies & & & \\
\hline
\end{tabular}


What medications are you currently taking, including over-the-counter medications?

Describe your abilities/difficulties in the following areas (include assistance required or equipment needed):

FUNCTION (i.e. Mobility skills such as transfers, walking, wheelchair use, driving/bus riding)

SOCIAL (i.e. Work/school including grade completed, leisure interests, relationships-family structure, support systems, companion anirnals, fears/concerns, etc)

GOALS (i.e. Why are you applying for participation? What would you like to accomplish?)

\section{PHOTO RELEASE}

I $\square$ DO

I $\square$ DO NOT

Consent to and authorize the use and reproduction by Discovery Riders, Inc. of any and all photographs and any other audio/visual materials taken of me for promotional material, educational activities, exhibitions or for any other use for the benefit of the program.

Signature:

Date:

Client, Parent or Legal Guardian 


\section{APPENDIX F}

Authorization for Emergency Medical Treatment 


\section{AUTHORIZATION for EMERGENCY MEDICAL TREATMENT FORM}

$\square$ Participant $\quad \square$ Staff $\quad \square$ Volunteer

Name:

DOB:

Phone:

Address:

Physician's Name: Medical Facility:

Health Insurance Company: Policy \#:

Allergies to medications:

Current medications:

In the event of an emergency, contact:

Name:

Relation:

Phone:

In the event emergency medical aid/treatment is required due to illness or injury during the process of receiving services, or while being on the property of the agency, I authorize

Discovery Riders, Inc. to: 1 . Secure and retain medical treatment and transportation if needed.

2. Release client records upon request to the authorized individual or agency involved in the medical emergency treatment.

\section{Consent Plan}

The authorization includes $\mathrm{x}$-ray, surgery, hospitalization, medication and any treatment procedure deemed "life saving" by the physician. This provision will only be invoked if the person(s) above is unable to be reached.

Date: Consent Signature:

$$
\text { Client, Parent or Legal Guardian }
$$

\section{Non-Consent Plan}

I do not give my consent for emergency medical treatment/aid in the case of illness or injury during the process of receiving services or while being on the property of the agency. In the event emergency treatment/aid is required, I wish the following procedures to take place:

Date: Consent Signature:

Client, Parent or Legal Guardian 


\section{APPENDIX G}

Hippotherapy Participant Release and Waiver of Liability Form 
DISCOVERY RIDERS, INC.

\section{PARTICIPANT'S RELEASE AND WAIVER OF LIABILITY ASSUMPTION OF RISK AND INDEMNITY AGREEMENT}

By signing this agreement you are giving up certain legal rights including the right to recover damages in case of injury, death or property damages. Read this agreement carefully before signing it. Your signature indicates your understanding of and agreement to its terms.

This is an agreement between the Undersigned ( and minor in my charge ) and Discovery Riders, Inc., P.O. Box 710, Bellefontaine, Ohio 43311.

$\mathrm{I}$, ( hereinafter the "undersigned") on behalf of myself, my personal representatives, heirs, next-of-kin, spouse and assigns HEREBY:

1. Acknowledge that horseback riding is a dangerous activity and involves risks that may cause serious injury and in some cases death, because of the unpredictable nature and irrational behavior of horses, regardless of their training and past performance.

2. Feel that the possible benefits to myself/my son/my daughter/my ward are greater than the risk assumed.

3. Knowing these facts and in consideration of your acceptance of this form, I voluntarily assume the risk and danger of injury or death inherent in horseback riding activities. I hereby release, discharge and promise not to sue the Discovery Riders, Inc., doing business under their own name or any other name and/or any of their, officers, employees, volunteers, agents, sponsors and sanctioning organizations ( hereinafter the "releases"), for any loss, liability, damage, or cost whatsoever arising out of or related to any loss, damage, or injury (including death ) to my person or property.

4. Release the Releases from any claim that such Releases are or may be unknowingly negligent in connection with the horseback riding experience or ability including but not limited to training or selecting horses, maintenance, care, fit or adjustment of equipment or gear on a horse or person, instruction on riding skills or supervising any riding activities. 
5. Indemnify and save and hold harmless the Discovery Riders, Inc. and their employees and agents from and against any loss, liability, damage or cost they may incur arising out of or in any way connected with any event, my use of a horse and any equipment or gear provided therewith or any acts or omissions of employees or agents.

6. Agree to abide by and follow any instructions given or rules established by the Discovery Riders, Inc. or any of their employees, agents or volunteers with regard to my participation in any event, use of a horse or any equipment or gear provided therewith.

7. The Undersigned expressly agrees that the foregoing release and waiver of liability, assumption of risk and indemnity agreement is governed by the State of Ohio and is intended to be a broad and inclusive document as is permitted by Ohio law and that in the event any portion of this agreement is determined to be invalid, illegal, or unenforceable, the validity, legality and enforceability of the balance of the agreement shall not be affected or impaired in any way and shall continue in full legal force and effect.

8. Acknowledge that this document is a contract and agree that if a lawsuit is filed against the Discovery Riders, Inc. or their agents, employees, judges or manager for any injury or damage in breach of this contract, the Undersigned will be responsible for their own cost in defending such an action.

\section{HAVE READ THIS DOCUMENT, I UNDERSTAND IT IS A PROMISE NOT TO SUE AND A RELEASE AND INDEMNITY FOR ALL CLAIMS.}

SIGNATURE DATE ( Signature should be completed in the presence of Discovery Riders Inc. staff) MINOR IN MY CHARGE 
APPENDIX H

Hippotherapy Attendance Chart 

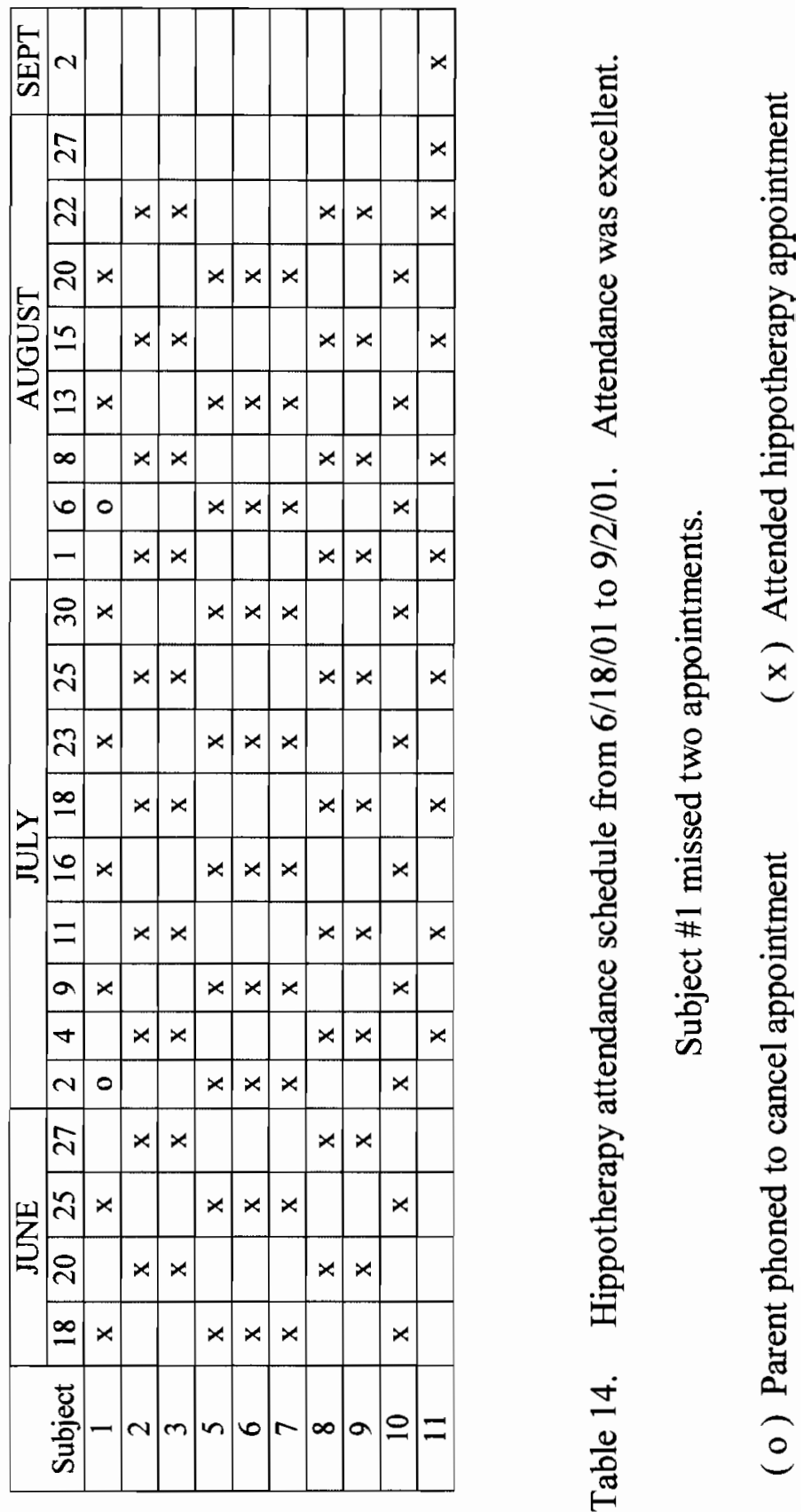
APPENDIX I

PEDI Data 


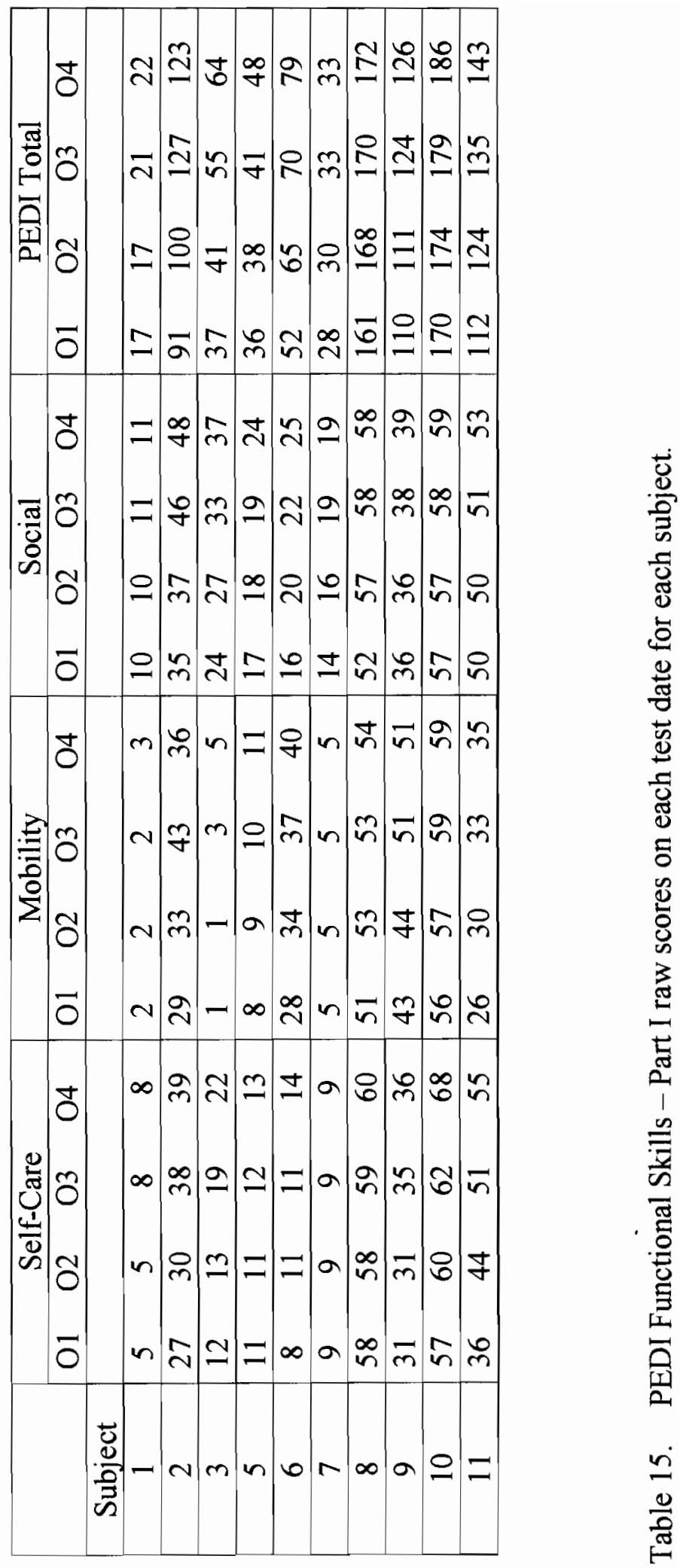




\section{APPENDIX J}

Gross Motor Function Measure Data 


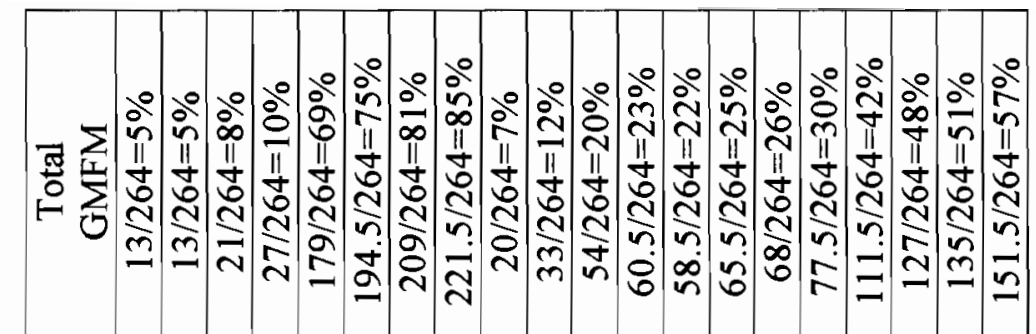

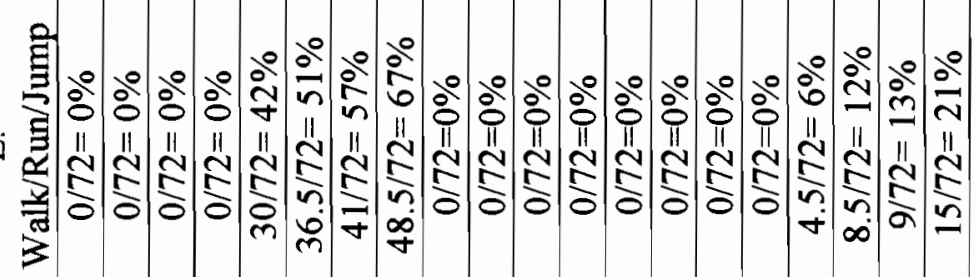

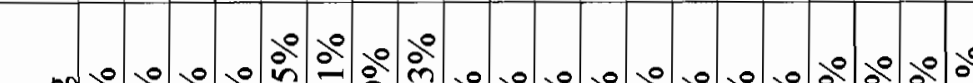

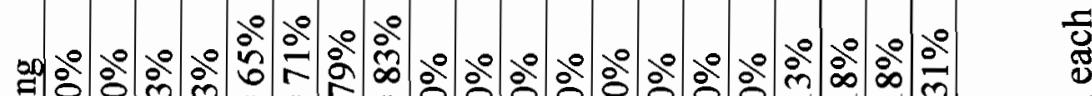

• : ت⿹弓冫

๘)

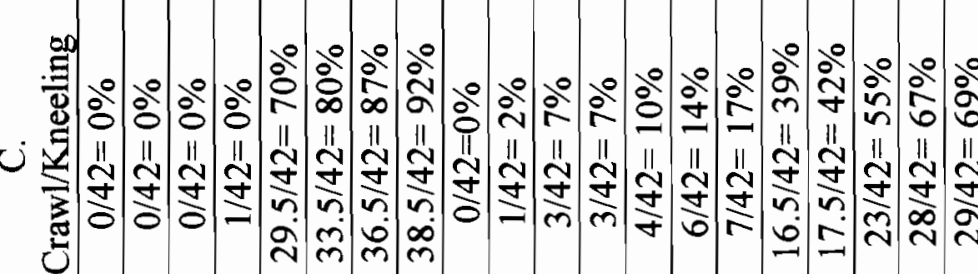

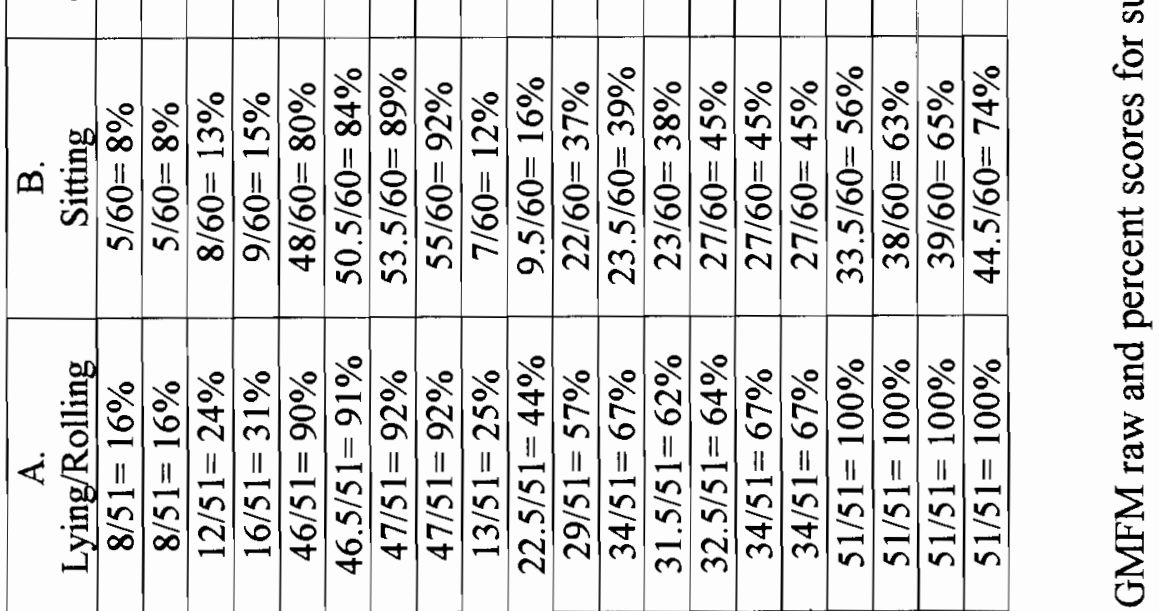

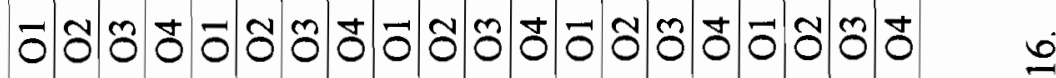

\begin{tabular}{|c|c|c|c|c|}
\hline $\begin{array}{c}\text { I \# } \\
\text { poəlqns }\end{array}$ & $\begin{array}{c}\text { 乙\# } \\
\text { loə!qns }\end{array}$ & $\begin{array}{c}\varepsilon \# \\
\text { wolqns }\end{array}$ & $\begin{array}{c}\text { S\# } \\
\text { เoəโqnS }\end{array}$ & $\begin{array}{c}9 \text { \# } \\
\text { 10วlqns }\end{array}$ \\
\hline
\end{tabular}




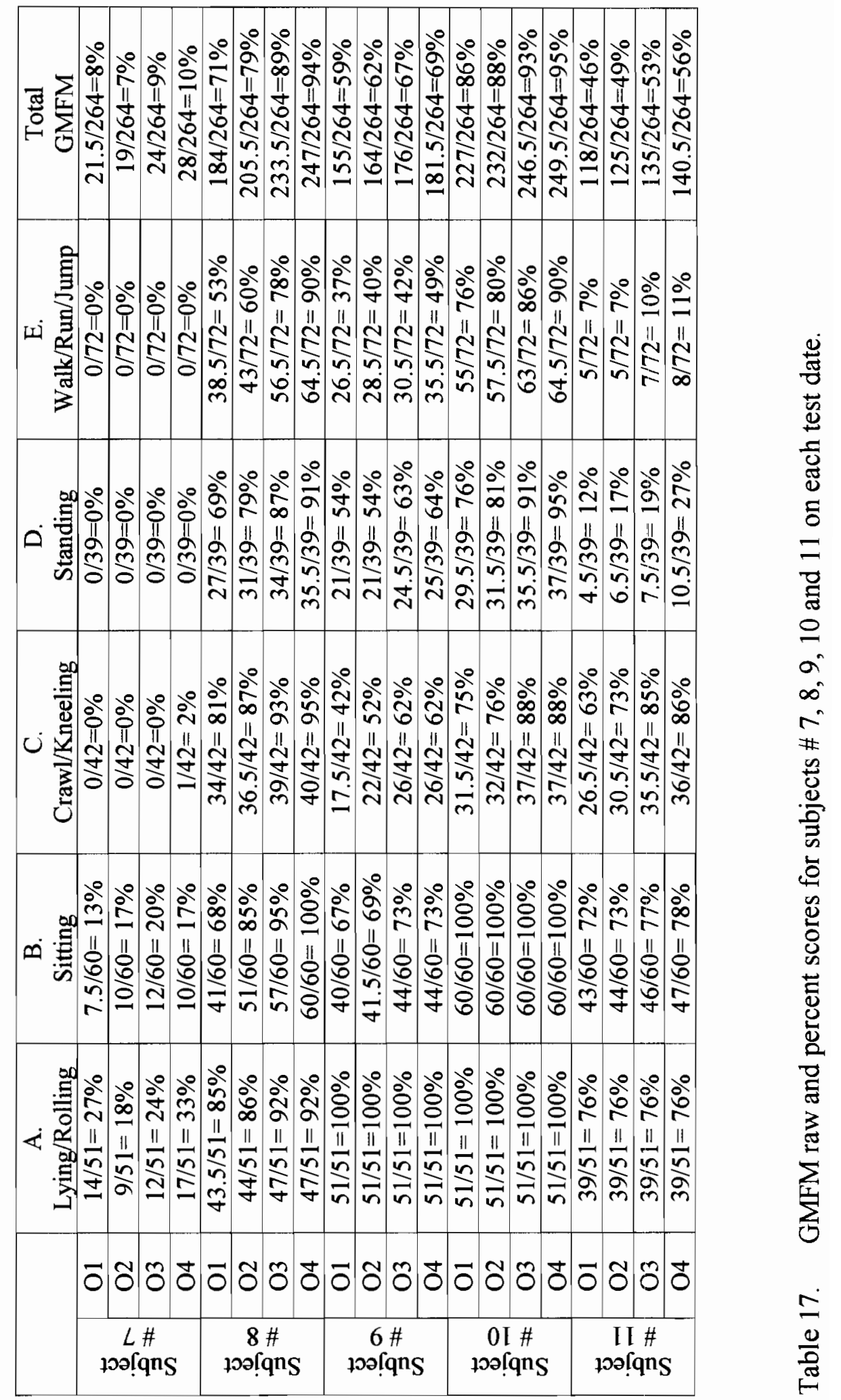




\section{APPENDIX K}

Change in GMFM Percent Score

Per Subject 


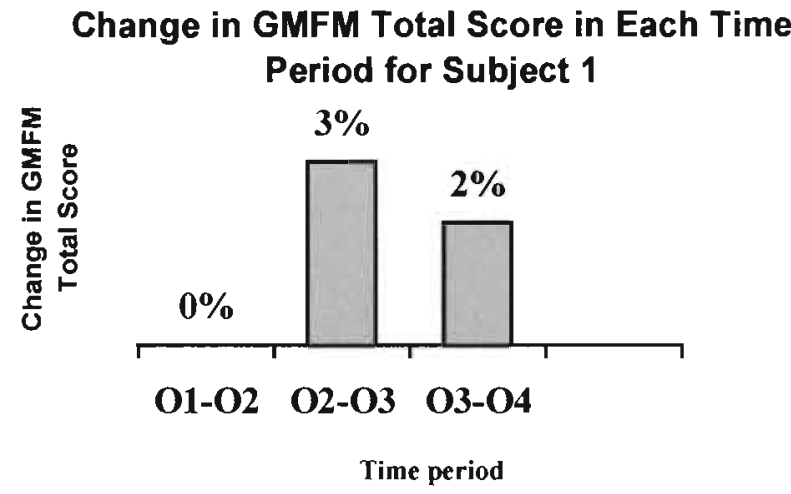

Figure 7. Change in GMFM total percent score for Subject \#1.

\section{Change in GMFM Total Score in Each}

Time Period for Subject 2

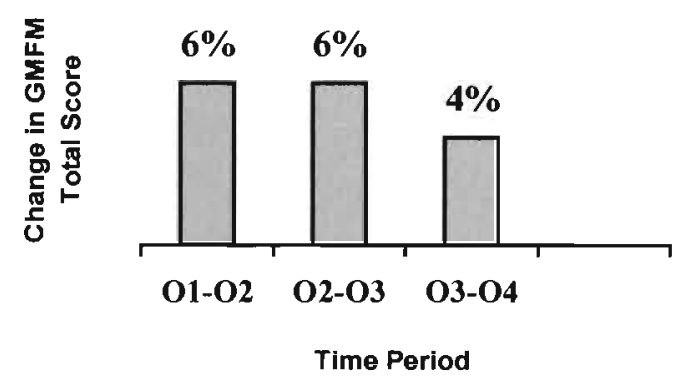

Figure 8. Change in GMFM total percent score for Subject \#2. 


\section{Change in GMFM Total Score in Each Time}

Period for Subject 3

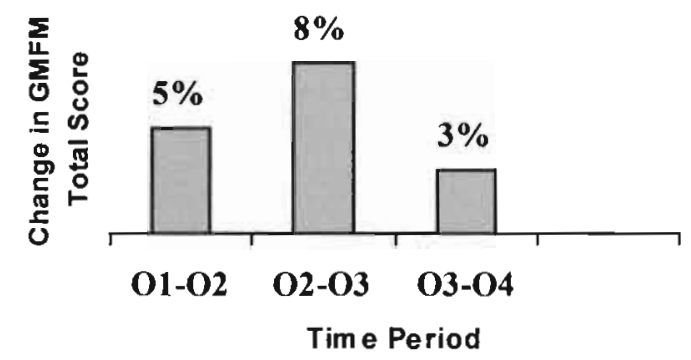

Figure 9. Change in GMFM total percent score for Subject \#3.

Change in GMFM Total Score in Each

Time Period for Subject 5

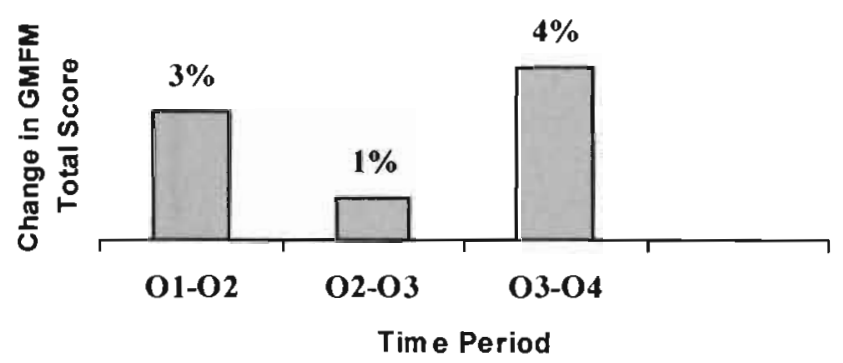

Figure 10. Change in GMFM total percent score for Subject \#5. 


\section{Change in GMFM Total Score in Each Time Period for Subject 6}

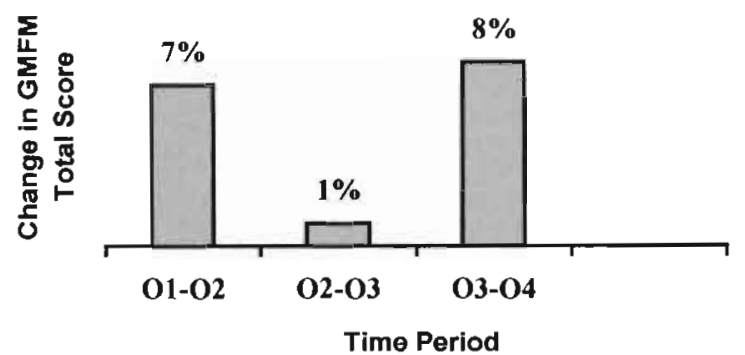

Figure 11. Change in GMFM total percent score for Subject \#6.

Change in GMFM Total Score in Each Time

Period for Subject 7

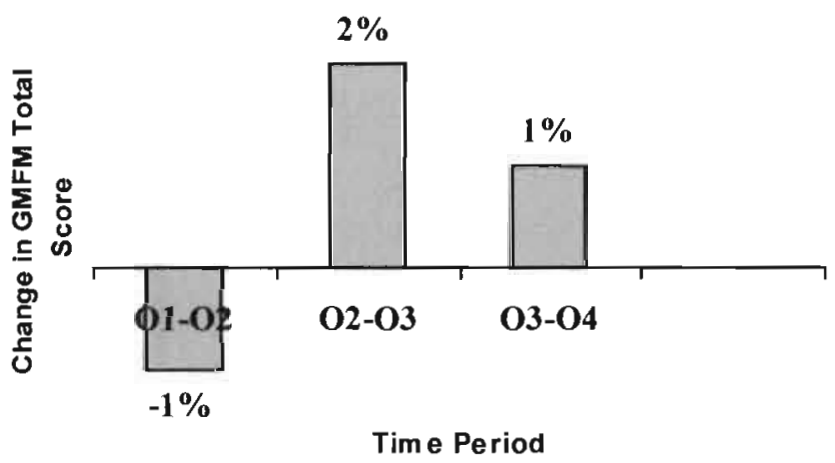

Figure. 12. Change in GMFM total percent score for Subject \#7. 
Change in GMFM Total Score in Each Time Period for Subject 8

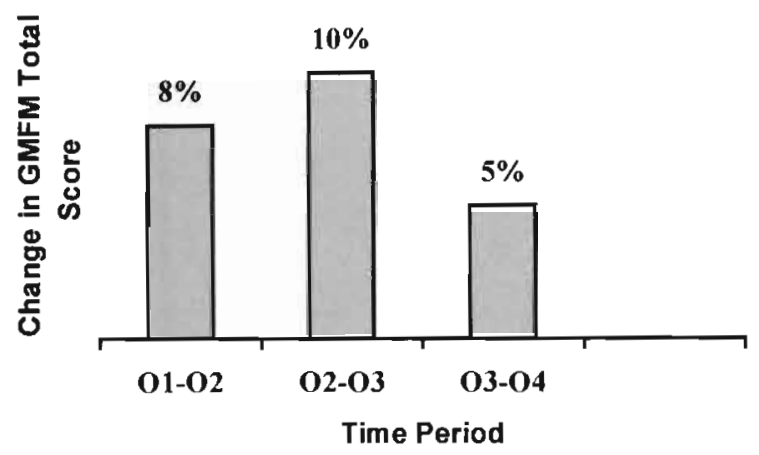

Figure 13. Change in GMFM percent score for Subject \#8.

Change in GMFM Total Score in Each Time Period for Subject 9

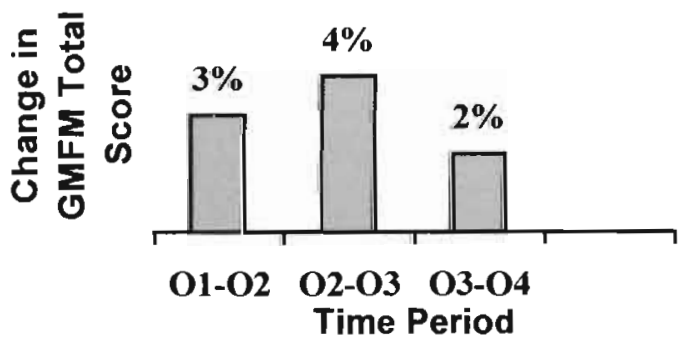

Figure 14. Change in GMFM percent score for Subject \#9. 


\section{Change in GMFM Total Score in Each Time \\ Period for Subject 10}

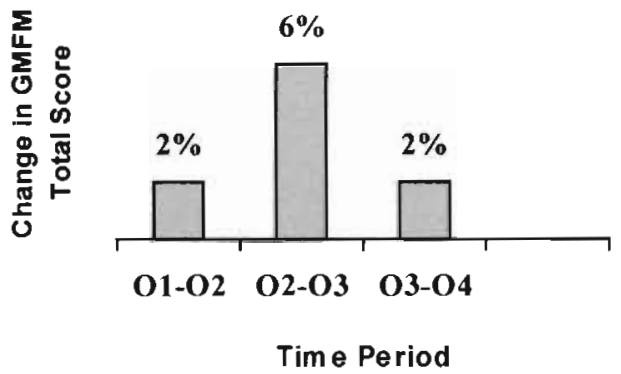

Figure 10. Change in GMFM total percent score for Subject \#10.

Change in GMFM Total Score in Each Time

Period for Subject 11

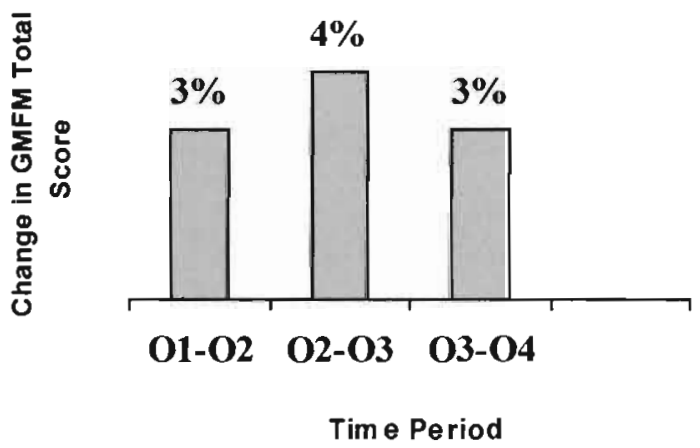

Figure 11. Change in GMFM total percent score for Subject \#11. 
APPENDIX L

PEDI Individual Score Results 


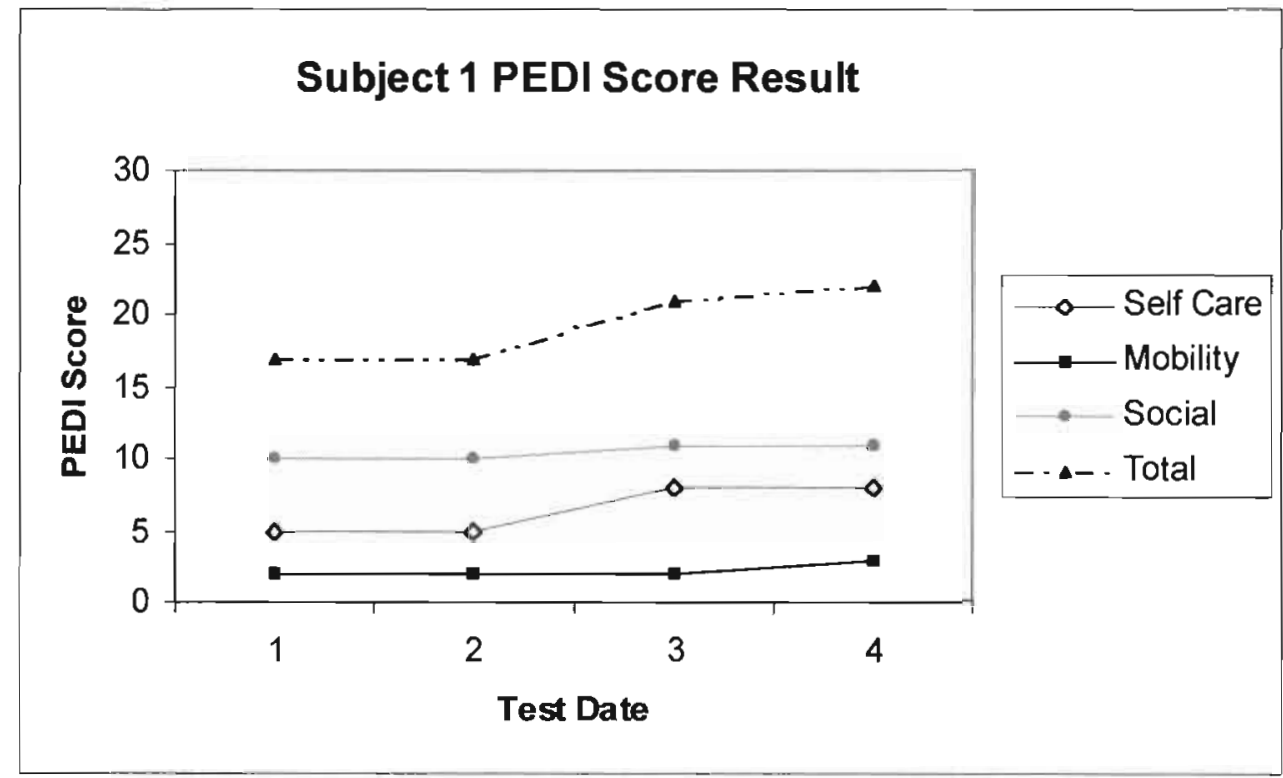

Figure 17. PEDI score results for subject \#1.

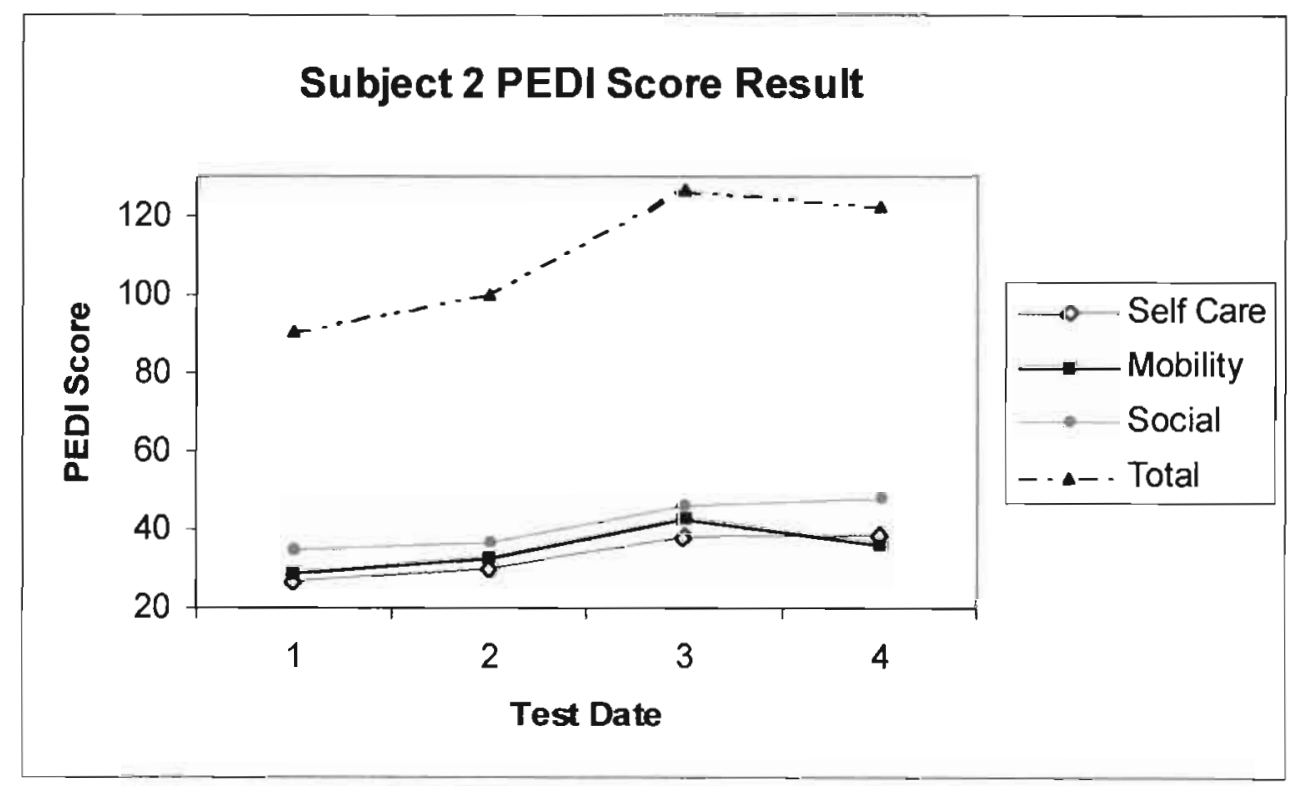

Figure 18. PEDI score results for subject $\# 2$. 


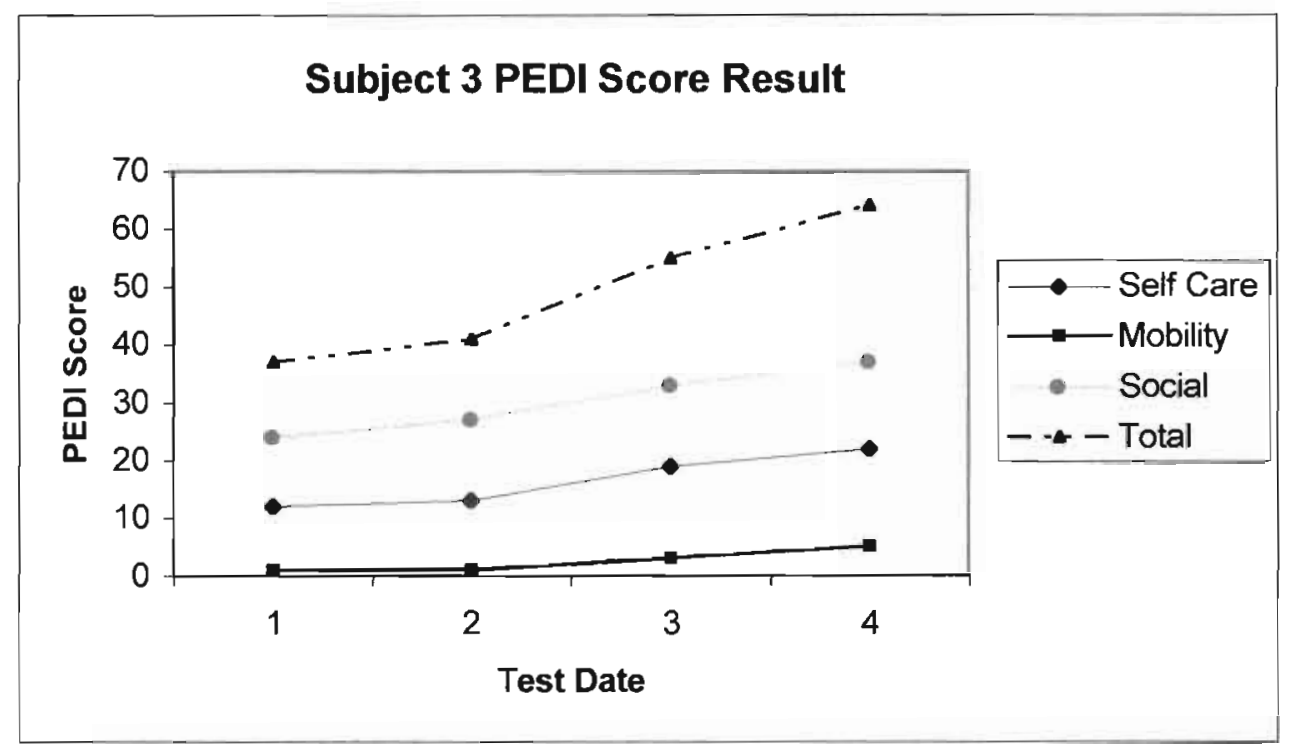

Figure 19. PEDI score results for subject \#3.

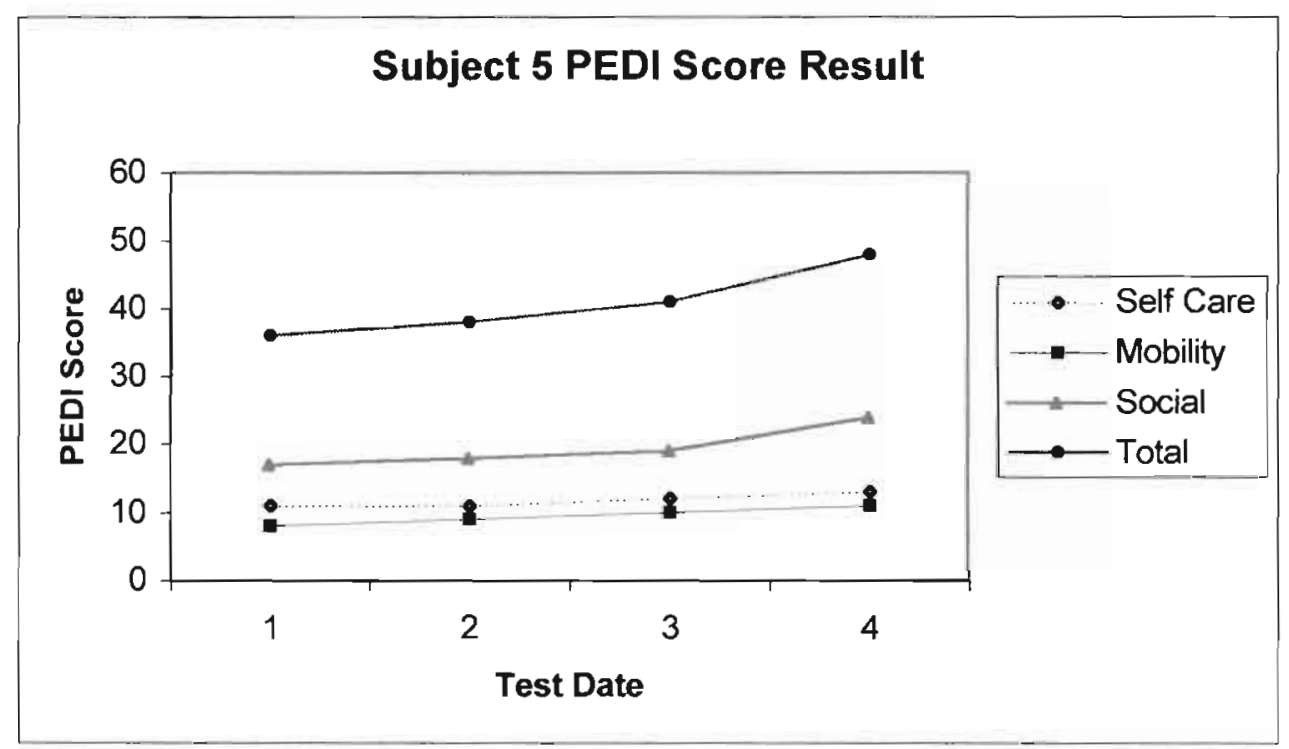

Figure 20. PEDI score results for subject \#5. 


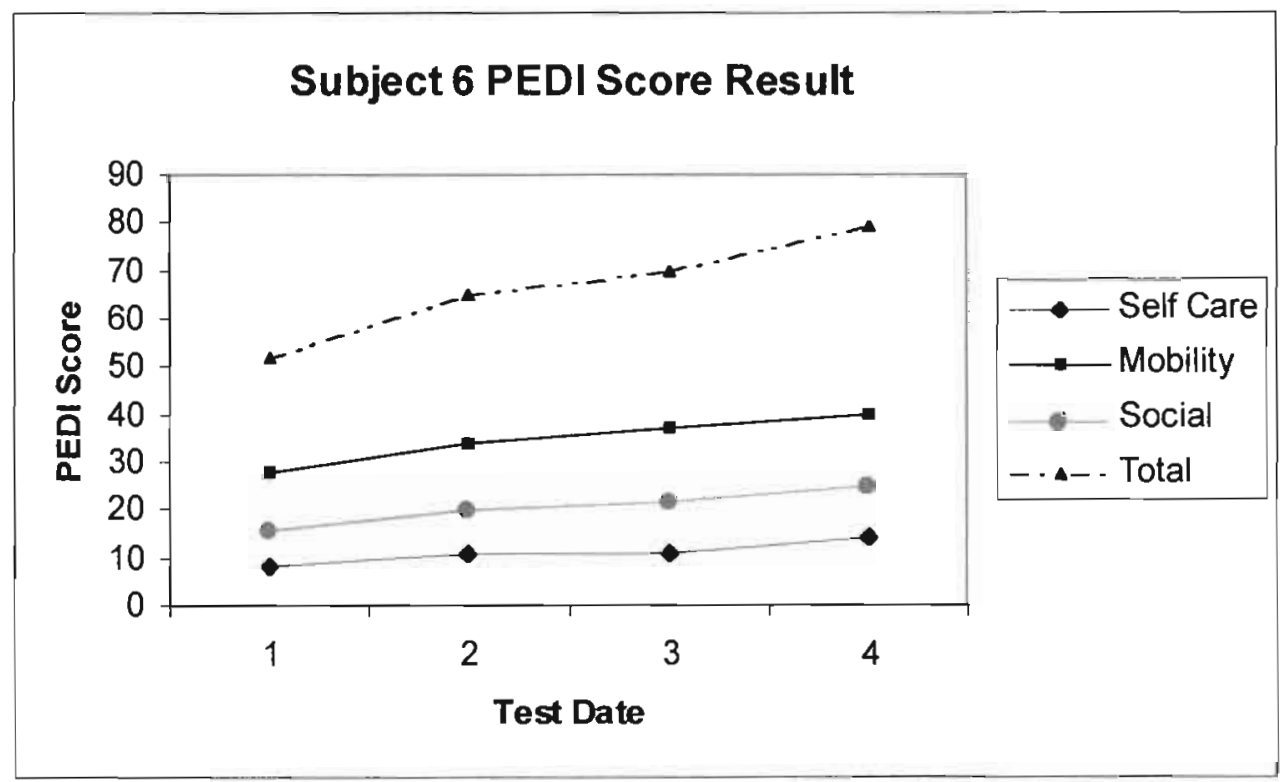

Figure 21. PEDI score results for subject $\# 6$.

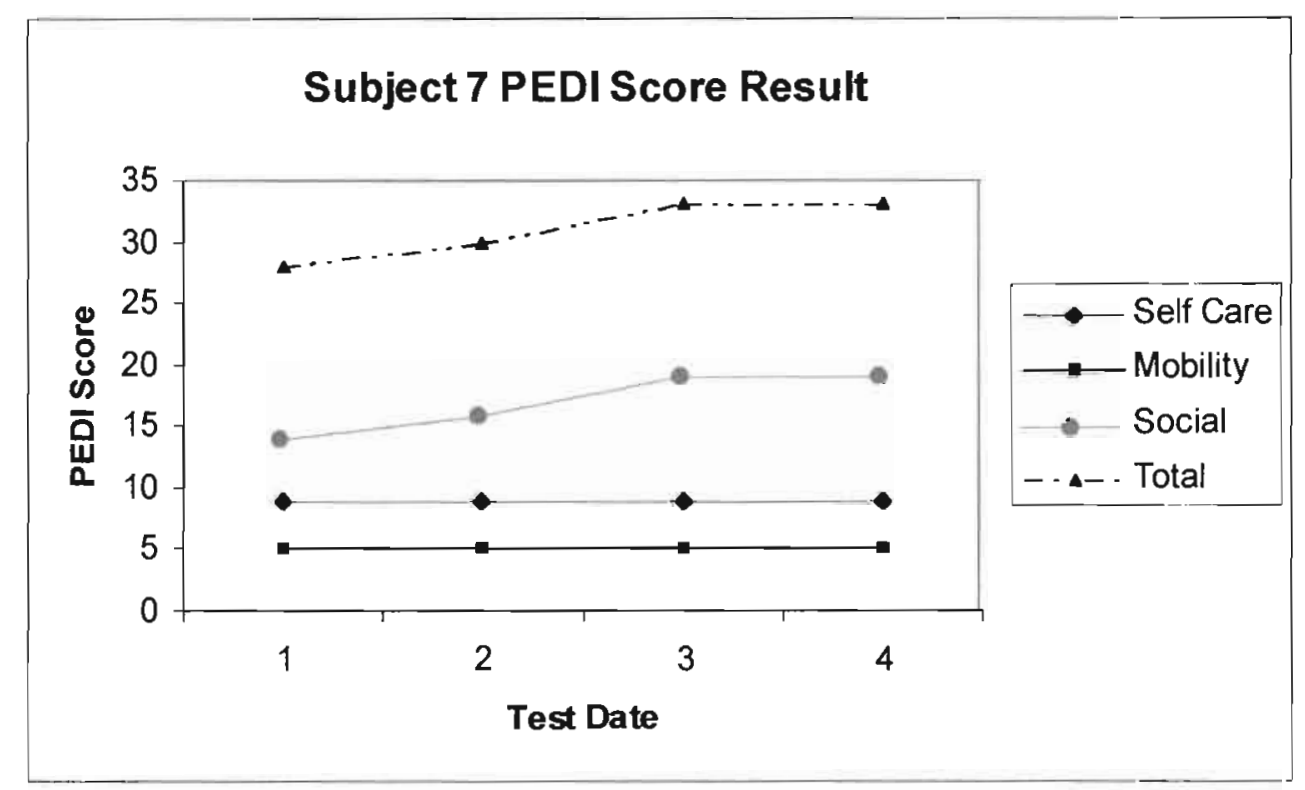

Figure 22. PEDI score results for subject \#7. 


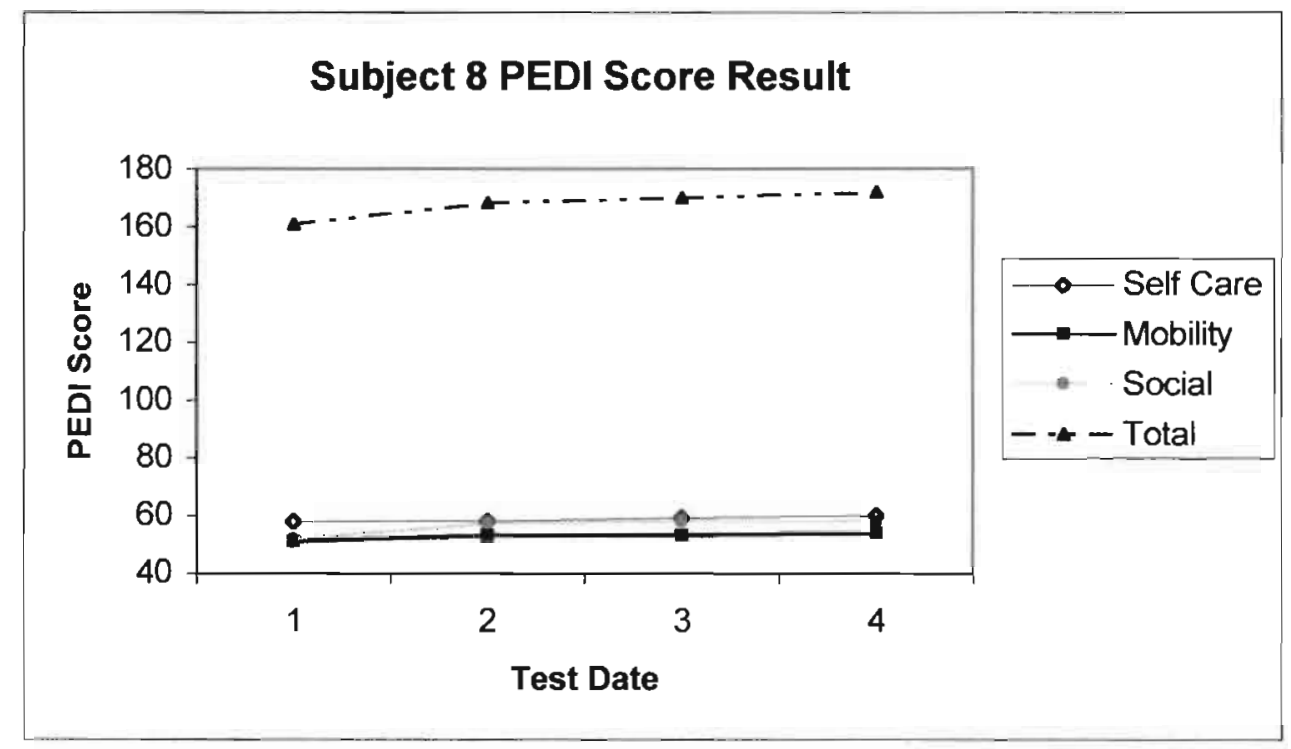

Figure 23. PEDI score results for subject $\# 8$.

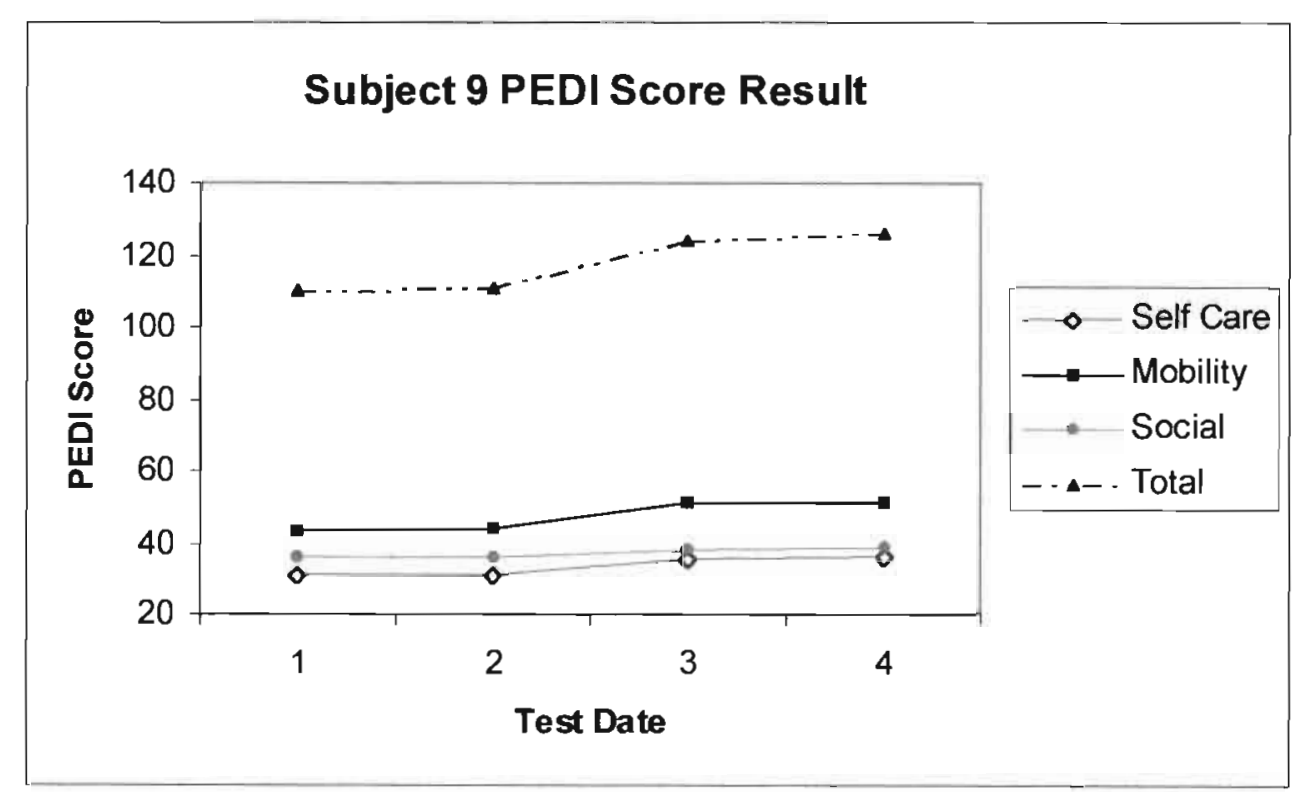

Figure 24. PEDI score results for subject \#9. 


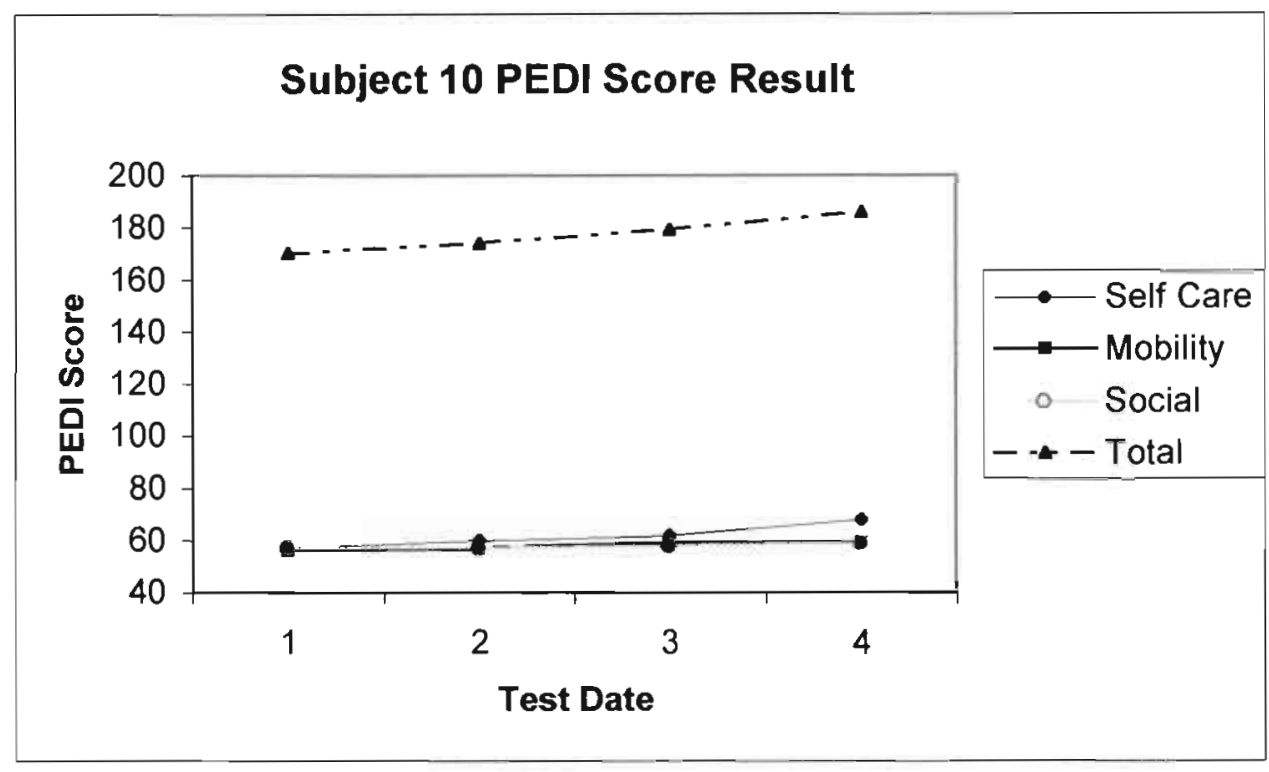

Figure 25. PEDI score results for subject $\# 10$.

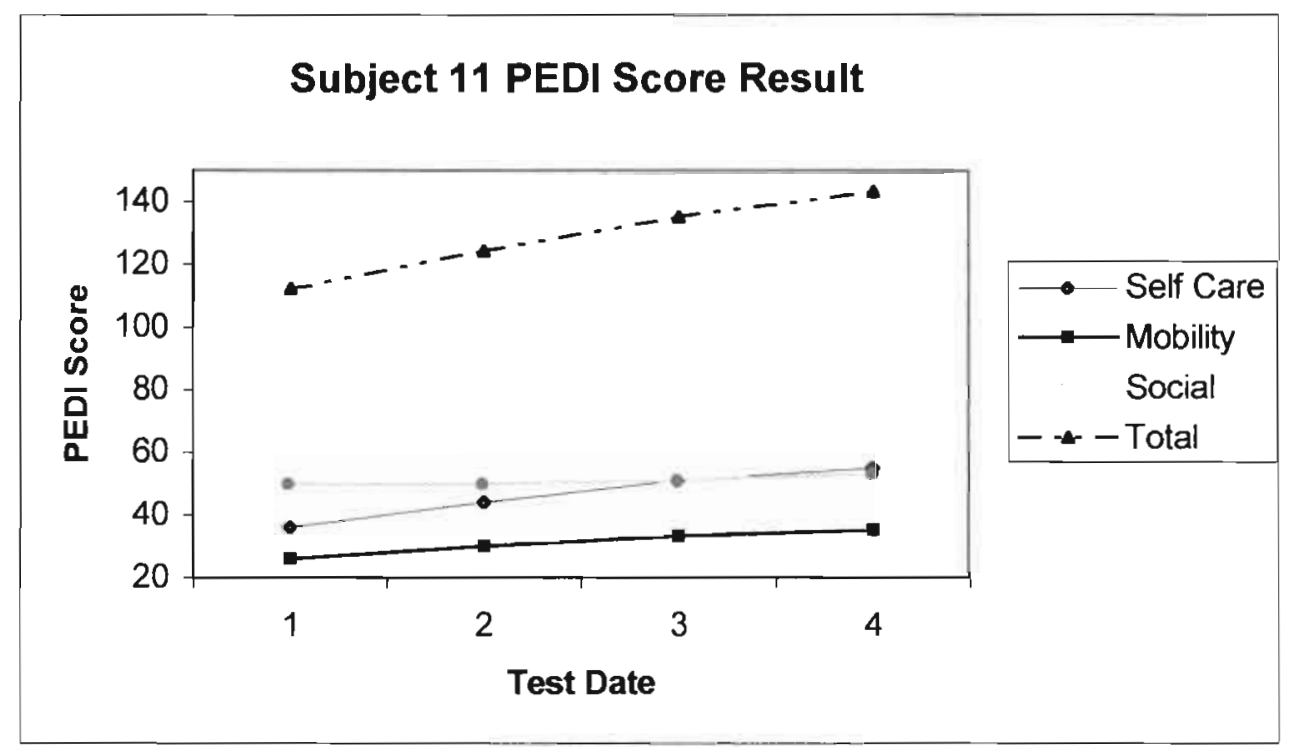

Figure 26. PEDI score results for subject \#11. 


\section{APPENDIX M}

Post Hoc Interrater Reliabilty Analysis Results 


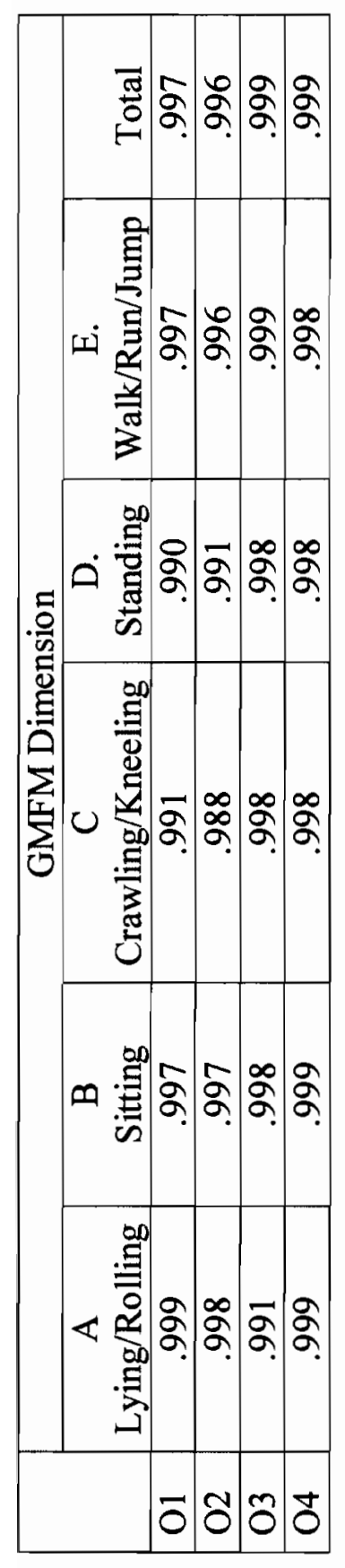

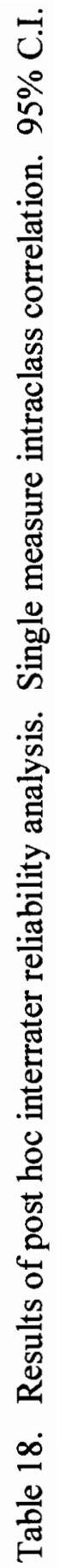




\section{LIST OF REFERENCES}

1 Heine B, Benjamin J. Introduction to hippotherapy. Advance For Physical Therapists and PT Assistants 2000; 11(13):11-13.

2 Biery MJ, Kauffman N. The effects of therapeutic horseback riding on balance. Adapted Physical Activity Quarterly 1989; 6:221-229.

3 Brock BJ. Effect of therapeutic horseback riding on physically disabled adults. Therapeutic Recreation Journal 1988; 22(3)34-43.

4 Saywell SY. Riding and ataxia. Physiotherapy 1975; 61(11):334-335.

5 Wingate L. Feasibility of horseback riding as a therapeutic and integrative program for handicapped children. Physical Therapy 1982; 62(2):184-186.

6 MacKinnon JR, Noh S, Lariviere J, MacPhail A, Allan DE, Laliberte D. A study of therapeutic effects of horseback riding for children with cerebral palsy. Physical and Occupational Therapy in Pediatrics 1995; 15(1):17-34.

7 AHA 2000 - Definition of hippotherapy. AHA News 2000; 9(2):4-5.

8 McCloskey, S. The effects of hippotherapy on gait in children with neuromuscular disorders. AHA News 2000; 9(2):10-14.

9 Glasow, B. The reimbursement puzzle - how hippotherapy can fit. AHA News 2000; 9(2):6-9.

10 Hugel C. Insurance company reviews hippotherapy. AHA News 2000; 9(2):9.

11 Aetna U.S. Healthcare's coverage policy bulletin, Retrieved March 6, 2002 from http://www.aetna.com/cpb/data/CPBA0151.html.

12 Batshaw ML, Perret YM. 1986. Children With Handicaps A Medical Primer. Baltimore: Brooks. 
13 Case-Smith J, Allen AS, Pratt PN, eds. 1996. Occupational Therapy for Children. St. Louis: Mosby.

14 Brogren E, Hadders-Algra M, Forssberg H. Postural control in children with spastic diplegia: muscle activity during perturbations in sitting. Developmental Medicine and Child Neurology 1996; 38:379-388.

15 Liao HF, Jeng SF, Lai JS, Cheng CK, Hu MH. The relation between standing balance and walking function in children with spastic diplegic cerebral palsy. Developmental Medicine and Child Neurology 1997; 39:106112.

16 Shumway-Cook A, Woollacott M. Theoretical issues in assessing postural control in Physical Therapy Assessment in Early Infancy. Ed. Wilhelm IJ. New York, Churchill Livingstone, 1993.

17 Wescot SL, Lowes LP, Richardson PK. Evaluation of postural stability in children: current theories and assessment tools. Physical Therapy 1997; 77(6):629-645.

18 McGibbon NH, Andrade C, Widener G, Cintas HL. Effect of an equinemovement therapy program on gait, energy expenditure and motor function in children with spastic cerebral palsy: a pilot study. Developmental Medicine and Child Neurology 1998; 40(11):754-762.

19 Haehl V, Giuliani C, Lewis C. Influence of hippotherapy on the kinematics and functional performance of two children with cerebral palsy. Pediatric Physical Therapy 1999; 11:89-101.

20 Haskin MR, Erdman WJ, Bream J, MacAvoy CG. Therapeutic horseback riding for the handicapped. Archives of Physical Medicine and Rehabilitation 1974; 55:473-474.

21 Haskin M, Bream JA, Erdman WJ. Special report: the Pennsylvania horseback riding program for cerebral palsy. American Journal of Physical Medicine 1982; 61(3):141-144.

22 Trahan J, Malouin F. Changes in the gross motor function measure in children with different types of cerebral palsy: and eight month follow-up study. Pediatric Physical Therapy 1999; 11(1):12-17. 
23 Hogan, A. The importance of long lining the therapy horse. AHA News $2000 ; 9(2): 22$.

24 Introduction to Hippotherapy Classic Principles Student Manual. American Hippotherapy Association, Denver Colorado, 1993. Revised 1996.

25 DePauw KP. Horseback riding for individuals with disabilities: programs, philosophy, and research. Adapted Physical Activity Quarterly 1986; 3:217226.

26 Trotter MJ. Horseback riding for handicapped children. Physical Therapy 1970; 50(2):235-236.

27 NARHA Guide. The North American Riding for the Handicapped Association, Inc. P. O. Box 33150, Denver, Colorado 80233.

28 Copeland-Fitzpatrick J. Hippotherapy and therapeutic riding: an international review. Proceedings of the Ninth International Therapeutic Riding Congress 1997. NARHA, Denver, Colorado.

29 Aisenbrey J. Pfaltzgraff P, Dismuke-Blakely R, Candelaria T. The effect of different gaited horses on the hippotherapy client's gait. Proceedings of the Ninth International Therapeutic Riding Congress 1997. NARHA, Denver, Colorado.

30 Gohmert-Dionne H. Equine modalities: conformation as it effects quality of movement and soundness. Proceedings of the Ninth International Therapeutic Riding Congress 1997. NARHA, Denver, Colorado.

31 MacPhail HEA, Edwards J, Golding J, Miller K, Mosier C, Zwiers T. Trunk postural reactions in children with and without cerebral palsy during therapeutic horseback riding. Pediatric Physical Therapy 1998; 10:143-147.

32 Lang R. Horseback riding helps handicapped children. The Physician and Sportsmedicine 1986; 14(5):221-224.

33 Griffith JC. Chronicle of therapeutic horseback riding in the United States. Clinical Kinesiology 1992; 46(1)2-7.

34 Intermediate Hippotherapy: Clinical Problem Solving Workshop Notes (2000). American Hippotherapy Association. Denver, CO.

35 Bertoti DB. Effect of therapeutic horseback riding on posture in children with cerebral palsy. Physical Therapy 1988; 68(10):1505-1511. 
36 Shumway-Cook A, Woollacott M. (1995). Motor Control Theroy and Practical Applications. Baltimore, Md: Williams and Wilkins.

37 McGibbon N, Morin C. Motor Control Theories. AHA Intermediate Hippotherapy Workshop Notes 1999.

38 McGibbon N, Morin C. Using equine movement in NDT and SI. AHA Intermediate Hippotherapy Workshop Notes 1999.

39 Bobath K. A Neurophsiological Basis for the Treatment of Cerebral Palsy. Philadelphia, Lippincott, 1980.

40 Green EM, Mulcahy CM, Pountney TE. An investigation into the development of early postural control. Developmental Medicine and Child Neurology $1995 ; 37: 437-447$.

41 Reed KL. 1991. Quick Reference to Occupational Therapy. Gaithersburg: Aspen.

42 Fetters L. Cerebral palsy: contemporary treatment concepts in: Lister M., ed. Contemporary Management of Motor Control Problems. Proceedings of the II Step Conference. Alexandria: Foundation for Physical Therapy 1991: 219224.

43 Russell DJ, Avery LM, Rosenbaum PL, Raina PS, Walter SD, Palisano RJ. Improved scaling of the GMFM for children with CP: evidence of reliability and validity. Physical Therapy 2000; 80(9):873-85.

44 Russell DJ, Rosenbaum PL, Cadman DT, Gowland C, Hardy S, Jarvis S. The gross motor function measure: a means to evaluate the effects of physical therapy. Developmental Medicine and Child Neurology 1989; 31:341-351.

45 Bjornson KF, Graubert CS, McLaughlin JF, Kerfeld CI, Clark EM. Testretest reliability of the gross motor function measure in children with cerebral palsy. Physical and Occupational Therapy in Pediatrics 1998; 18(2): 51-61.

46 Kolobe THA, Palisano RJ, Stratford PW. Comparison of two outcomes measures for infants with cerebral palsy and infants with motor delays. Physical Therapy 1998; 78(10):1062-72. 
47 McLaughlin JF, Bjornson KF, Ashley SJ, Hays RM, Hoffinger SA, Armantrout EA, Roberts TS. Their role of selective dorsal rhizotomy in cerebral palsy: critical evaluation of a prospective clinical series. Developmental Medicine and Child Neurology 1994; 36:755-769.

48 Collet JP, Vanasse M, Marois P, Amar M, Goldberg J, et.al. Hyperbaric oxygen for children with cerebral palsy: a randomized multicenter trial. Lancet 2001; 357:582-586.

49 Nordmark E, Jarnlo GB, Hagglund G. Comparison of the GMFM and PEDI in assessing motor function in children undergoing selective dorsal rhizotomy. Developmental Medicine and ChildNeurology 2000; 42(4):245-52.

50 Richards CL, Malouin F, Dumas F, Marcoux S, Lepage C, Meier C. Early and intensive treadmill locomotor training for young children with cerebral palsy: a feasibility study. Pediatric Physical Therapy 1997; 9:158-165.

51 Yang TF, Chan RC, Chuang TY, Liu TJ, Chiu JW. Treatment of cerebral palsy with botox: evaluation with GMFM. J Formos Med Assoc 1999; 98:832-836.

52 Ketelaar M, Vermeer A, Helders PJ. Clinics in Rehabilitation 1998; 12(5): $369-80$.

53 Feldman AB, Haley SM, Coryell J. Concurrent and construct validity of the Pediatric Evaluation of Disability Inventory. Physical Therapy 1990; 70(10):602-10.

$54 \quad$ Harris S. Parents and caregivers perceptions of their children's development. Developmental Medicine and Child Neurology 1994; 36:918-923.

55 Reid DT, Boschen K, Wright V. Critique of the pediatric evaluation of disability inventory ( PEDI ). Physical and Occupational Therapy in Pediatrics 1993; 13:57-87.

56 Haley SM, Coster WJ. Response to Reid DT's, et.al. critique of the PEDI. Physical and Occupational Therapy in Pediatrics 1994; 13(4):89-93.

57 Haley SM, Coster WJ, Ludlow LH, Haltiwanger JT, Andrellos PJ. 1992. Pediatric Evaluation of Disability Inventory: Development, Standardization and Administration Manual. Boston, MA: New England Medical Center. 
58 Campbell DT, Stanley JC. 1963. Experimental and Quasi-Experimental Designs for Research. Houghton Mifflen; Boston.

59 Nordmark E, Haggland G, Jarnlo GB. Reliability of the GMFM in CP. Scand J Rehabil Med 1997; 29(1):25-28.

60 Gross Motor Function Measure Manual. Russell D, Rosenbaum P, Gowland C, Hardy S, Lane M, et al. Second edition, September 1993. Gross Motor Measures Group, Ontario, Canada, L8N3Z5.

61 Jelsma J, Iliff P, Kelly L. Patterns of development exhibited by infants with CP. Pediatr Phys Ther 1999; 11:2-11

62 Bower E, Michell D, Burnett M, Campbell MJ, McLellan DL. Randomized controlled trial of physiotherapy in 56 children with cerebral palsy followed for 18 months. Dev Med Child Neuro 2001; 43: 4-15.

63 Bjornson KF, Graubert CS, Buford VL, McLaughlin J. Validity of the GMFM. Pediatr Phys Ther 1998; 10:43-47.

64 Steinbok P, Reiner AM, Beauchamp R, Armstrong RW, Cochrane DD. A randomized clinical trial to compare selective posterior rhizotomy plus physiotherapy with physiotherapy alone in children with spastic diplegic cerebral palsy. Dev Med Child Neuro 1997; 39: 178-184.

65 Hodgkinson I, Berard C, Jindrich ML, Sindow M, Mertens P, Berard J. Selective dorsal rhizotomy in children with cerebral palsy. Stereotact Funct Neurosurg 1997; 69: 259-267.

66 Ruck-Gibis J; Platkin H, Hanley J, Wood-Dauphinee S. Reliability of the GMFM for children with osteogenesis imperfecta. Pediatr Phys Ther 2001; 13:10-17.

67 Boyce WF, Gowland C, Hardy S, Rosenbaum PL, Lane M, Plews N, Goldsmith C, Russell DJ. Development of a quality of movement measure for children with CP. Physical Therapy 1991; 71(11):820-832.

68 Gowland C, Boyee WF, Wright V, Russell DJ, Goldsmith CH, Rosenbaum PL. Reliability of the gross motor performance measure. Physical Therapy 1995; 75(7)597-602.

69 Nagi SZ. An epidemioloty of disability among adults in the United States. Milbank Memorial Fund Quarterly 1976; 54: 439-467. 
70 Brown D. The bewildering relationship between sensory input and motor ouput. Neurology Report 1994; 18(1):19-21.

71 Noonan MJ. Teaching postural reactions to students with severe cerebral palsy: an evaluation of theory and technique. JASH 1984; 9(2):111-122.

72 Bozec SL, Lesne J, Bouisset S. A sequence of postural muscle excitations precedes and accompanies isometric ramp efforts performed while sitting in human subjects. Neuroscience Letters 2001; 303:72-76.

73 Horak KB. Clinical measurement of postural control in adults. Physical Therapy 1987; 67(12):1881-1884.

74 Witney AG, Vetter $P$, Wolpert DM. The influence of previous experience on predictive motor control. Neuroreport 2001; 12(4):649-653.

75 Bruin AS, Latash ML. The role of motor action in anticipatory postural adjustments studied with self-induced and externally triggered perturbations. Exp Brain Res 1995; 106(2):291-300.

76 Bartlett DJ, Palisano FJ. Physical Therapists perceptions of factors influencing the acquisition of motor abilities of children with cerebral palsy: implications for clinical reasoning. Physical Therapy 2002; 82 (3): 237-248.

77 Ketelaar M, Vermeer A, Hart H, VanPetegam-VanBeek E, Helders P. Effects of a functional therapy program on motor abilities of children with cerebral palsy. Physical Therapy 2001; 81 (9): 1538-1545.

78 Wood E, Rosenbaum P. The Gross Motor Function Classification System for cerebral palsy: a study of reliability and stability over time. Devel Med Child Neurol 2000; 42:292-296. 